Portland State University

PDXScholar

$11-4-1994$

\title{
Two Dimensional Finite Element Modeling of Swift Delta Soil Nail Wall by "ABAQUS"
}

Richard James Barrows

Portland State University

Follow this and additional works at: https://pdxscholar.library.pdx.edu/open_access_etds

Part of the Civil Engineering Commons

Let us know how access to this document benefits you.

\section{Recommended Citation}

Barrows, Richard James, "Two Dimensional Finite Element Modeling of Swift Delta Soil Nail Wall by "ABAQUS"'" (1994). Dissertations and Theses. Paper 4741.

https://doi.org/10.15760/etd.6625

This Thesis is brought to you for free and open access. It has been accepted for inclusion in Dissertations and Theses by an authorized administrator of PDXScholar. Please contact us if we can make this document more accessible: pdxscholar@pdx.edu. 


\section{THESIS APPROVAL}

The abstract and thesis of Richard James Barrows for the Master of Science in Civil Engineering were presented November 4, 1994, and accepted by the thesis committee and the department.

COMMITTEE APPROVALS:
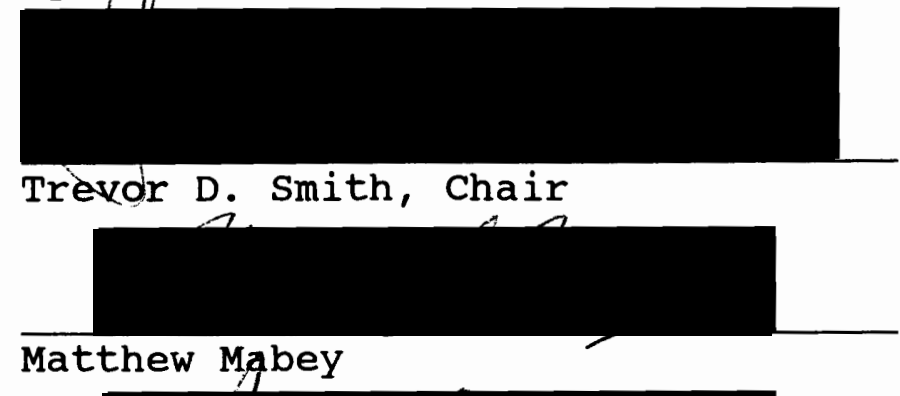

DEPARTMENT APPROVAL:

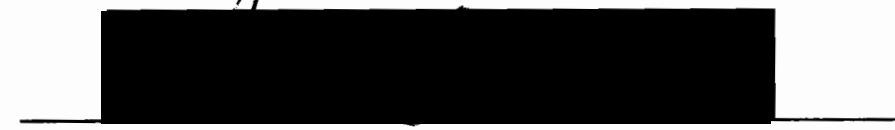

Scott Burns

Graduate offiee Representative

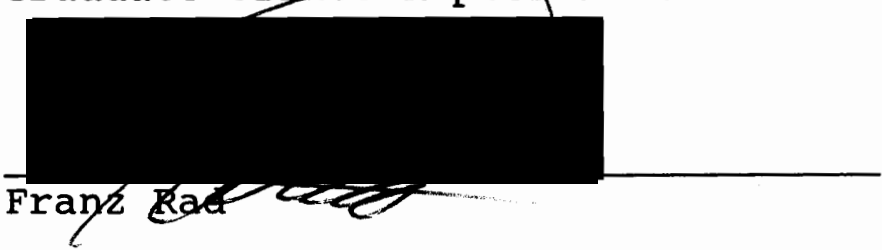

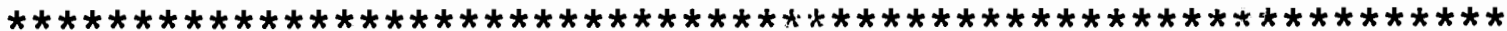

ACCEPTED FOR PORTLAND STATE UNIVERSITY BY THE LIBRARY

by

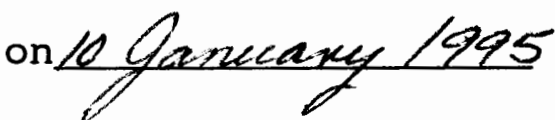




\section{ABSTRACT}

An abstract of the thesis of Richard James Barrows for the Master of Science in Civil Engineering presented November 4, 1994 .

Title: Two Dimensional Finite Element Modeling of Swift Delta Soil Nail Wall By "ABAQUS"

Soil nail walls are a form of mechanical earth stabilization for cut situations. They consist of the introduction of passive inclusions (nails) into soil cut lifts. These nailed lifts are then tied together with a structural facing (usually shotcrete). The wall lifts are constructed incrementally from the top of cut down. Soil nail walls are being recognized as having potential for large cost savings over other alternatives.

The increasing need to provide high capacity roadways in restricted rights of way under structures such as bridges will require increasing use of techniques such as combined soil nail and piling walls. The Swift Delta Soil Nail wall required installing nails between some of the existing pipe piling on the oregon Slough Bridge. This raised questions of whether the piling would undergo internal stress changes due to the nail wall construction. Thus, it was considered 
necessary to understand the soil nail wall structure interaction in relation to the existing pile supported abutment.

The purpose of this study was to investigate the swift Delta Wall using finite element (FE) modeling techniques. Valuable data were available from the instrumentation of the Swift Delta Wall. These data were compared with the results of the FE modeling. This study attempts to answer the following two questions:

1. Is there potential for the introduction of new bending stresses to the existing piling?

2. Is the soil nail wall system influenced by the presence of the piling?

A general purpose FE code called ABAQUS was used to perform both linear and non-linear analyses. The analyses showed that the piling definitely underwent some stress changes. In addition they also indicated that piling influence resulted in lower nail stresses. Comparison of measured data to predicted behavior showed good agreement in wall face deflection but inconsistent agreement in nail stresses. This demonstrated the difficulty of modeling a soil nail due to the many variables resulting from nail installation. 


\title{
TWO DIMENSIONAL FINITE ELEMENT MODELING OF SWIFT DELTA SOIL NAIL WALL BY "ABAQUS"
}

\author{
by
}

Richard James Barrows

A thesis submitted in partial fulfillment of the requirements for the degree of

\section{MASTER OF SCIENCE in CIVIL ENGINEERING}

Portland State University
1994 


\section{THESIS APPROVAL}

The abstract and thesis of Richard James Barrows for the Master of Science in Civil Engineering were presented November 4 , 1994, and accepted by the thesis committee and the department.

COMMITTEE APPROVALS:

$$
\text { Trevor D. Smith, Chair }
$$

Matthew Mabey

Scott Burns

Graduate Office Representative

DEPARTMENT APPROVAL:

Franz Rad

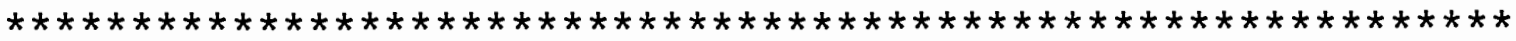

ACCEPTED FOR PORTLAND STATE UNIVERSITY BY THE LIBRARY

by

on 


\section{TABLE OF CONTENTS}

LIST OF TABLES. • • • • • • • • • • • • • • • • • • • • V v

FIGURES • • • • • • • • • • • • • • • • • • • • • • • • vi v

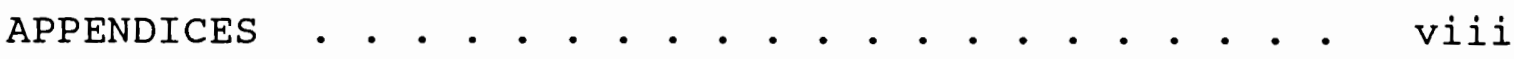

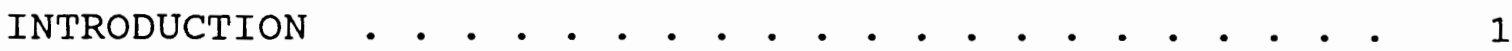

SWIFT BOULEVARD DELTA PARK INTERCHANGE SOIL NAIL WALL • 4 Project Scope . . . . . . . . . . . . . . . 4 Construction . . . . . . . . . . . . . . 6

Construction Problem Areas . . . . . . . . . . 7

INSTRUMENTATION • • • • • • • • • • • • • • • • • 12

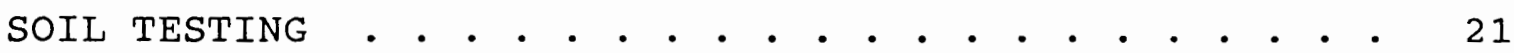

Laboratory Soils Testing At Swift Delta . . . . . 21

Insitu Testing At Swift Delta . . . . . . . . . 24

TWO DIMENSIONAL FINITE ELEMENT MODELING • • • • • • • . 29

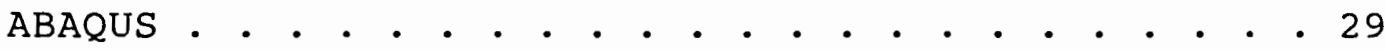

PATRAN . . . . . . . . . . . . . . . . . 30

Finite Element Mesh Development . . . . . . . 30

1 ksf Line Load Validation . . . . . . . . . . 32

PLANE STRAIN MODELING • . . . . . . . . . . . . . . 38

Fringe plot scaling . . . . . . . . . . . . 41

Geostatic Turn on . . . . . . . . . . . . 42

Incremental Modeling . . . . . . . . . . . . 42

NON LINEAR PLANE STRAIN ANALYSIS • • • • • • • • • . . 58

Introduction . . . . . . . . . . . . . . 58

RESULTS INTERPRETATION . . . . . . . . . . . . . . . 62

Interpretation of Instrument section \#2 Results . 62

Horizontal Soil Stresses . . . . . . . . . . 62

Vertical Soil Stresses . . . . . . . . . . 62

Nail Stresses . . . . . . . . . . . . . 63

Deflections . . . . . . . . . . . . . . . . 63

Section \#1 Results. . . . . . . . . . . . . 75

Horizontal Soil Stress . . . . . . . . . . . 75

Vertical stresses . . . . . . . . . . . . 76

Nail Stresses . . . . . . . . . . . . 76

Pile Stresses . . . . . . . . . . . . . 78

Deflections . . . . . . . . . . . . . 78 
COMPARISON BETWEEN FEM RESULTS AND INSTRUMENT

MEASUREMENTS . . . . . . . . . . . . . . . . . 80

Deflections . . . . . . . . . . . . . . 80

Measured Nail stresses.............. 82

CONCLUSIONS AND FURTHER STUDY . . . . . . . . . 128

APPENDICES . . . . . . . . . . . . . . 131 


\section{LIST OF TABLES}

TABLE I: Construction Equipment . . . . . . . . . . . 8

TABLE II: Triaxial Test Results . . . . . . . . . . . . . 22

TABLE III: Triaxial Test Results . . . . . . . . . . 23

TABLE IV: Summary of Pressuremeter Test Results . . . . 25

TABLE V: Model Material properties . . . . . . . . 60 
FIGURE 1: Location and Wall plan . . . . . . . . . . 10

FIGURE 2: Developed Elevation View. • . . . . . . . . 11

FIGURE 3: Instrument Section \#1 Cross section . . . . . 14

FIGURE 4: Instrument section \#2 Cross section . • . . . 15

FIGURE 5: Instrument section \#1 Nail Load Plots . . . . 16

FIGURE 6: Instrument Section \#2 Nail Load Plots . . . . 17

FIGURE 7: Pile Cap Extensometer Plot . . . . . . . . . 18

FIGURE 8: SD 129 Slope Inclinometer Plot . . . . . . . 19

FIGURE 9: SD 130 Slope Inclinometer Plot . . . . . . . 20

FIGURE 10: EX Probe Pressuremeter Test Results . . . . 26

FIGURE 11: BX Probe Pressuremeter Test Results . . . . 27

FIGURE 12: Pressuremeter Test Results Summary • . . . . 28

FIGURE 13: 1 ksf Line Load Vertical stress . . . . . . 34

FIGURE 14: Finite Element Mesh Instrument section \#1 . 35

FIGURE 15: Finite Element Mesh Instrument Section \#2 . 36

FIGURE 16: $1 \mathrm{ksf}$ Line Load Horizontal stress . . . . . 37

FIGURE 17: LIN1N Geostatic Turn on Model step 2 Horiz.

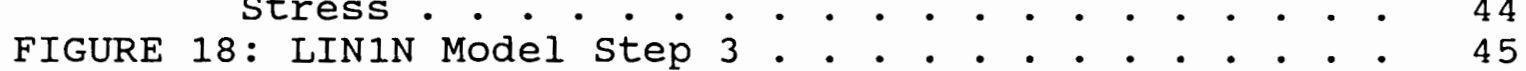

FIGURE 19: LININ Model Step 4. . . . . . . . . . . . . 46

FIGURE 20: LININ Model Step 5 . . . . . . . . . . . . . 47

FIGURE 21: LININ Model Step 6. . . . . . . . . . . . . 48

FIGURE 22: LININ Model step 8. . . . . . . . . . . . . 49

FIGURE 23: LININ Model Step 9. . . . . . . . . . . . . 50

FIGURE 24: LIN1N Model Step 3 . . . . . . . . . . . . . 51

FIGURE 25: LININ Model Step 4 . . . . . . . . . . . . . 52

FIGURE 26: LIN1N Model step 5 Major stress . . . . . . 53

FIGURE 27: Model Step 6 Major Stress . . . . . . . . . 54

FIGURE 28: LIN1N Model step 7 Major stress . . . . . . 55

FIGURE 29: NOLIN1N Step 8 Major Stress . . . . . . . . 56

FIGURE 30: LININ Model step 9 Major stress . . . . . 57

FIGURE 31: NOLIN2N Model step 3 Horiz stress . . . . . 64

FIGURE 32: Model NOLIN2N Static step 5 Horiz. Stress . 65

FIGURE 33: Model NOLIN2N Static step 8 Horiz. Stress . 66

FIGURE 34: Model LIN2N static step 3 Vert. Stress . . 67

FIGURE 35: Model NOLIN2N Static step 5 vert. Stress . . 68

FIGURE 36: Model NOLIN2N static step 8 vert. Stress . . 69

FIGURE 37: Model NOLIN2N Static step 3 Major stress . . 70

FIGURE 38: Model NOLIN2N static step 5 Major stress . . 71

FIGURE 39: Model NOLIN2N Static step 8 Major stress . . 72

FIGURE 40: Model NOLIN2N static step 8 Horiz. Strain . 73

FIGURE 41: Model NOLIN2N static step 8 vert. Disp. . . 74

FIGURE 42: Model NoLIN2N static step 8 Horiz. Disp. . . 84

FIGURE 43: Model NOLIN1N static step 3 Horiz. Stress . 85

FIGURE 44: Model NOLIN1P static step 4 Horiz. Stress - 86

FIGURE 45: Model NOLIN1N static step 5 Horiz. Stress . 87

FIGURE 46: Model NOLIN1P static Step 6 Horiz. Stress . 88

FIGURE 47: Model NOLIN1P Static Step 9 Horiz. Stress . 89

FIGURE 48: NOLIN1N Model static step 8 Horiz. Stress . 90

FIGURE 49: Model NOLIN1P Static step 8 Vert. Stress . . 91 
FIGURE 50: Model NOLIN1P Static Step 5 Vert. Stress . . 92

FIGURE 51: Model NOLINIP Static Step 6 Vert. Stress . . 93

FIGURE 52: Model NOLIN1P Static Step 7 Vert. Stress. . 94

FIGURE 53: Model NOLIN1P Static Step 9 Vert. Stress . . 95

FIGURE 54: Model NONLIN1N Static Step 3 Vert. Stress . 96

FIGURE 55: Model NONLIN1N Static Step 5 vert. Stress . 97

FIGURE 56: NONLININ Model Step 8 Vert Stress ..... . 98

FIGURE 57: Model NONLIN1N Static Step 3 Major Stress . 99

FIGURE 58: Model NONLIN1P Static Step 4 Major Stress 100

FIGURE 59: Model NONLIN1P static step 7 Major Stress 101

FIGURE 60: Model NONLIN1N Static Step 6 Major Stress 102

FIGURE 61: Model NONLIN1P Static Step 9 Major Stress 103

FIGURE 62: Model NONLIN1P static step 8 Major Stress 104

FIGURE 63: Model NONLIN1P Static step 3 Major Stress 105

FIGURE 64: Model NONLIN1P Static Step 4 Major Stress 106

FIGURE 65: Model NONLIN1P Static Step 6 Major Stress 107

FIGURE 66: Soil Excavation Lift Displacement . . . . 108

FIGURE 67: NONLIN1 Wall Face Deflection....... . 109

FIGURE 68: NONLIN1P Wall Face Deflection . . . . . . 110

FIGURE 69: Model NONLIN1P Step 8 Horiz. Disp. . . . . 111

FIGURE 70: Model NONLIN1P Step 7 Horiz. Disp. . . . . 112

FIGURE 71: Instrument section 1 Row 1 and 2 Nail Loads 113

FIGURE 72: Instrument section 1 Row 3 and 4 Nail Loads 114

FIGURE 73: Instrument Section 1 Row 5 Nail Loads . . 115

FIGURE 74: Instrument Section 2 Row 1 And 2 Nail Loads 116

FIGURE 75: Instrument Section 2 Row 3 And 4 Nail Loads 117

FIGURE 76: Instrument Section 2 Row 5 Nail Loads . . 118

FIGURE 77: NONLIN1N Nail 1 and 2 Stresses...... . 119

FIGURE 78: NONLIN1N Nail 3 and 4 Stresses...... . 120

FIGURE 79: NONLIN1N Nail 5 stress .......... . 121

FIGURE 80: NONLIN1P Nail 1 And 2 stresses...... . 122

FIGURE 81: NONLIN1P Nail 3 And 4 Stresses . . . . . . 123

FIGURE 82: NONLIN1P Nail 5 And 4 Stresses . . . . . 124

FIGURE 83: NONLIN2N Nail 1 And 2 Stresses..... . 125

FIGURE 84: NONLIN2N Nail 3 And 4 stresses . . . . . . 126

FIGURE 85: NONLIN2N Nail 5 . . . . . . . . . . . . . 127

FIGURE 86: Measured and Predicted Wall Face Deflection 130 
viii

\section{APPENDICES}

APPENDIX A: INSTRUMENTATION • • • • • • . • . . . . 132

APPENDIX B: NOLINIP INPUT FILE • . . • • • • • • • . 134

APPENDIX C: LINEAR ELASTIC PATRAN PLOTS . . . . . . . 141

APPENDIX D: NON-LINEAR PATRAN PLOTS . . . . . • . . . 145 


\section{INTRODUCTION}

Soil nailing is the term used for a technique of reinforcing the earth in-situ to provide stability for excavations and slopes. The technique employs the introduction of reinforcing elements into a soil mass. The elements, called nails, develop a tensile component in the soil mass and are fabricated of steel. An un-reinforced soil mass may not be stable, especially if it has a free face with a steeper angle than it's apparent cohesion and angle of repose can support. In which case the free face is stabilized with a structural facing element (e.g. shotcrete). The reinforcing elements interact with the soil mass to form a gravity block which can be used to hold back vertical faces. This process is called mechanical stabilized earth. Soil nailing uses passive inclusion to mechanically stabilize in-situ soils (cuts).

There are also methods for constructing mechanically stabilized embankments and fill walls (eg. geotextile walls).

Soil nail stress development (top down) is different than that of reinforced fill walls (bottom up). Stresses tend to be higher at the top of the wall and lower at the bottom. Therefore soil nail walls deflect the most at the top of the wall face as opposed to mechanically stabilized fill walls which show the most horizontal deflection at the bottom of the wall. Soil Nailing uses a top down construction sequence and 
was first used in Versias, France to construct an 18 meter high wall ${ }^{1}$ The first soil Nail wall in the U.S. was constructed in, Portland, oregon at, the Good Samaritan Hospital Expansion.

Since 1972 several design methods have been used in the United states and Europe. Most of these design methods are based on limit equilibrium principles. The major differences in analysis procedures being in the definition of factor of safety, soil reinforcement interaction, and resisting forces provided by the reinforcing nails.

The Federal Highway Administration has recognized soil nail walls as having large potential cost savings over other alternatives. Because of this, they are backing the development of nail wall technology and have provided financial support for this project.

The increasing need to provide high capacity roadways in restricted right of ways under structures such as bridges will require increased use of techniques such as combined nail and piling walls. Thus, it was considered necessary to understand the soil nail wall structure interaction in relation to the existing pile supported abutment. This research attempts to answer the following two issues:

1 Transportation Research Board, Report 290, New York, NY, 1980 , page 66 
1. Is there potential for the introduction of new bending stress to the existing piling?

2. Is the soil nail wall system influenced by the presence of the piling? 


\title{
SWIFT BOULEVARD DELTA PARK INTERCHANGE
}

\author{
SOIL NAIL WALL
}

\section{Project Scope}

The Swift Boulevard Delta Park Interchange is located in Portland, oregon approximately 1 mile south of the oregonwashington border. The interchange allows access from both north and south bound lanes of I-5, Swift Boulevard, and the Delta Park shopping area. The Swift Boulevard Delta Park Interchange is owned by the oregon Department of Transportation. The oregon Department of Transportation was responsible for reconstruction design, as well as construction contract administration and construction inspection. Partial funding was received, for the junction reconstruction, from the Federal Highway Administration (FHWA). As part of the interchange reconstruction, highway engineers were faced with widening Swift Boulevard from two lanes to four under extremely limited geometric and traffic constraints ( Figure 1). These are summarized:

Geometric: The proposed widening was located under the South end of the oregon slough bridge. The widening was bound by the oregon Slough, north of Swift Boulevard, and the oregon slough bridge abutment, south of Swift Boulevard. The existing bridge abutment was a pile 
supported spill through type with a $2 \mathrm{H}: 1 \mathrm{~V}$ end slope.

Traffic Closure of I-5 was not allowed. Swift Boulevard traffic volumes are extremely high and only temporary non-peak period lane closures were allowed.

Clearance Highway engineers decided that to accommodate the proposed widening, the existing abutment slope would be removed and that a retaining wall would be needed in it's place. A cast in place retaining wall was considered; but was not cost effective due to the anticipated cost of an extensive temporary shoring system. A tied-back soldier pile wall was also considered; but would require installing the soldier pile through the bridge deck. Thus interrupting I-5 traffic flow and extra cost for repair to the bridge. Soil nailing was considered feasible because it's top down construction method does not require temporary shoring. In addition soil nailing can be performed with relatively small equipment that would be clear of traffic and could also operate in tight spaces.

The permanent wall was next designed by the Oregon Department of Transportation Bridge section using the shen 
analysis method ${ }^{2}$. An approximately 250 foot long structure with a maximum height of 19 feet was proposed. Figure 2 shows the developed elevation view for the wall.

\section{Construction}

The prime construction contractor was Kewitt - Marmjaeo. The subcontractors that worked on the wall were schnabel Foundations (Nail Wall Construction), L.R. Squire and Associates (Instrumentation Installation), and Johnson Western Gunnite (Nail Wall Structural Shotcrete). Approximately 166 feet of the wall required removal of the abutment end slope and nailing between the existing 14 inch diameter pipe piling, on approximately 4.5 foot centers. It required 275 permanent nails. The nails consisted of \#8 ( 1.0 inch diameter) and \#9 (1.125 inch diameter) epoxy coated grade 60 Dywidag Bars. There were 28 sacrificial nails installed to prove that the design anchor capacity could be developed. The structural shotcrete had a 1.5 to 3.0 inch slump and an air entrainment of approximately $7.5 \%$ by volume. The nail grout consisted of Type I/II Portland cement, with a water cement ratio of $\approx 0.5$. The basic construction sequence used on this project is as follows:

2 Bang, S.; Shen, C.K.; Kim, J.; Kroetch, P. Investigation of soil Nailing systems. 'Transportation Research Record 1369, 1990. 
1. cut

2. Reinforcement

- Excavate to the back of shotcrete wall face.

(construction sequence continued) STEP PROCESS

3. Guide Wire

- Place guide wires to control the shotcrete lift thickness.

4. Shotcrete

- Apply shotcrete pneumatically.

5. Drill

- Drill nail holes.

6. Nail Installation -Insert \#8 and \#9 nails (Dwyidag bars) in dry nail hole.

7. Grout

- Pressure grout nails with a minimum 150 psi pressure.

8. Repeat - Start the next wall lift.

In general the construction equipment used was small and compact. Table I shows the equipment used, in the construction sequence above, and it's purpose.

\section{Construction Problem Areas}

The temporary cut face suffered sloughing problems during the project. Sloughing was attributed to loose material at the. face and accidental over excavation during the cut sequence. 


\begin{tabular}{|c|c|c|c|c|}
\hline \multicolumn{5}{|c|}{$\begin{array}{c}\text { TABLE I } \\
\text { Construction Equipment }\end{array}$} \\
\hline $\begin{array}{l}\text { Construction } \\
\text { Phase }\end{array}$ & $\begin{array}{l}\text { Process } \\
\text { Time } \\
\text { Hrs/Lift }\end{array}$ & Equipment & Model/Type & Purpose \\
\hline 1 -cut & .75 & Dozer & $\begin{array}{l}\text { Catapiller } \\
\text { D6 }\end{array}$ & $\begin{array}{l}\text { Rough cut } \\
\text { wall } \\
\text { excavation. }\end{array}$ \\
\hline 1 -cut & .5 & Loader & $\begin{array}{l}\text { Rubber } \\
\text { Tired }\end{array}$ & $\begin{array}{l}\text { Removal of } \\
\text { spoilings } \\
\text { from wall } \\
\text { cut. }\end{array}$ \\
\hline $1-$ cut & .75 & Dozer & $\begin{array}{l}\text { John Deer } \\
450\end{array}$ & $\begin{array}{l}\text { close up wall } \\
\text { excavation. }\end{array}$ \\
\hline 1 -cut & .5 & Backhoe & Case 580 & $\begin{array}{l}\text { close up wall } \\
\text { excavation. }\end{array}$ \\
\hline 2-Shotcrete & 2.0 & $\begin{array}{l}\text { Shotcrete } \\
\text { pump. }\end{array}$ & $\begin{array}{l}\text { Swing tube } \\
\text { type. }\end{array}$ & $\begin{array}{l}\text { Apply struct. } \\
\text { shotcrete. }\end{array}$ \\
\hline $\begin{array}{l}\text { 3-Nail } \\
\text { Installation }\end{array}$ & 12.0 & Drill & $\begin{array}{l}\text { Krupp } \\
\text { DHR-580A }\end{array}$ & $\begin{array}{l}\text { Drilled nail } \\
\text { holes. }\end{array}$ \\
\hline
\end{tabular}




\begin{tabular}{|l|l|l|l|l||}
\hline \multicolumn{3}{|c|}{ TABLE I } \\
\hline \multicolumn{3}{|c|}{ Construction Equipment } \\
Phase & $\begin{array}{l}\text { Time } \\
\text { Hrs/Lift }\end{array}$ & & $\begin{array}{c}\text { Equipl/Type } \\
.\end{array}$ & Purpose \\
\hline 3-Nail & 8.0 & Grout Pump & Positive \\
Installation & & & Press. grout \\
\hline
\end{tabular}

The sloughing was severe enough at times to influence the instrument readings, possibly giving misleading information relative to the specified wall construction procedure.

The project created a unique problem in that the stress states of the existing bridge foundation would be disturbed. Past experience has shown that soil nailed structures deflect horizontally about .1 - .4 percent relative to wall height ${ }^{3}$. At Swift Delta, predicted maximum horizontal deflection would then be approximately .75 - 1.26 inches. Since the wall face would be directly in front of the existing bridge piling, it is assumed that the piling also would deflect laterally and therefore a new bending stress would be induced.

${ }^{3}$ French Soil Nail Manual 


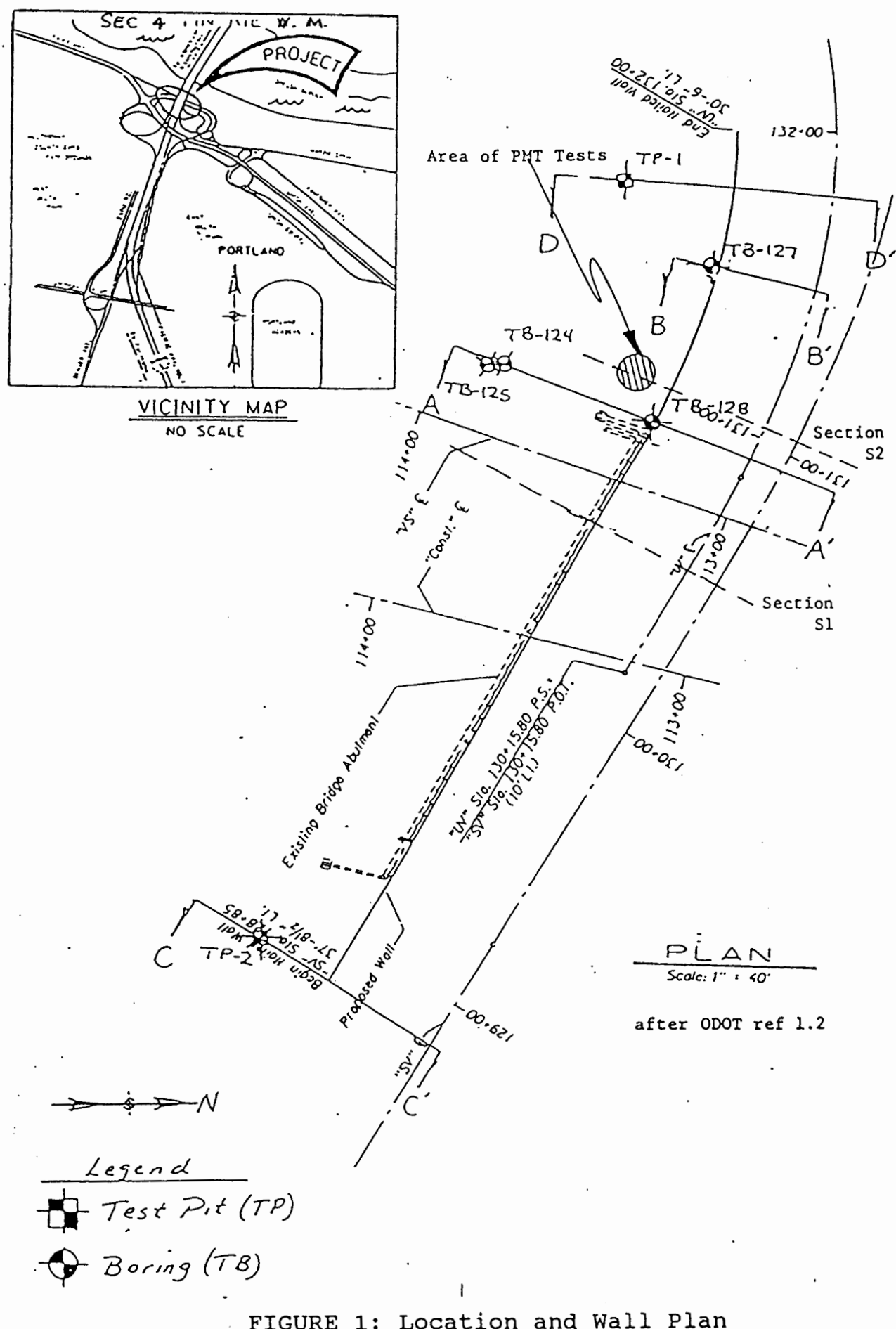




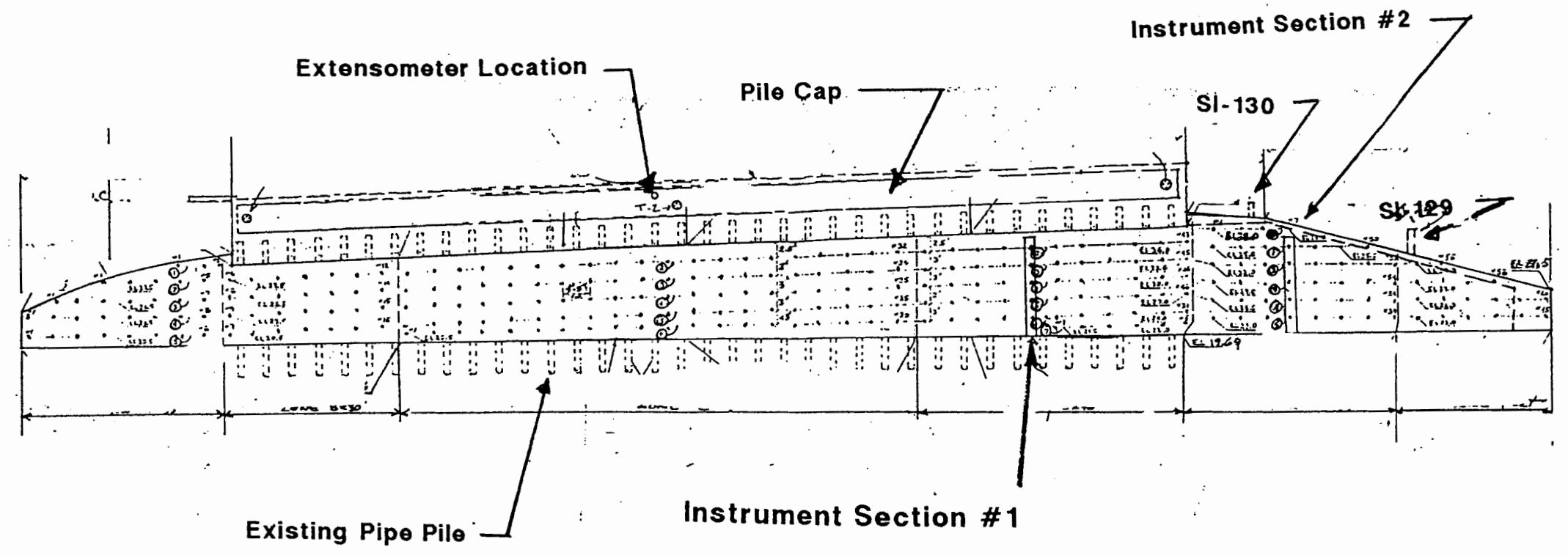

FIGURE 2: Developed Elevation View 


\section{INSTRUMENTATION}

The wall was fully instrumented with two separate sections located at UV line station $130+59$ (instrument section \#1) and UV line station $131+05$ (instrument section \#2). Figure 3 and Figure 4 show typical cross sections for the two instrumentation sections. The wall was instrumented to monitor nail stress distribution, pile cap deflection, wall deflection, pile bending strain, and wall earth pressure. The instrumentation consisted of vibrating wire strain gages, slope inclinometers, load cells, earth pressure cells, optical survey, and a single point extensometer. Table A-1 of Appendix A lists the instruments employed as well as the quantity, manufacturer, and accuracy. Vibrating wire strain gage locations were equally spaced down the dywidag bars(nails). Each location contained a gage on the top and bottom of the bar. Electronic load cells were located at the nail heads on rows one, three, and five at each instrument section and were cast into the final shotcrete face. The inclinometers were installed at UV line station $130+62$ (SI130) and UV station $131+25$ (SI-129) approximately 3.5 feet behind the wall face. During construction instrument readings were taken after each wall lift was completed. Figures 5 through 9 are typical plots from the reduced instrumentation data with the reading date given on each figure. Post construction instrument readings were taken on monthly intervals. The full data is not presented in this report but 
is available in the swift Delta Interchange Soil Nail Wall Instrumentation Data report, available from FHWA, Region 10. The vibrating wire strain gages were placed along the nails to measure both axial and bending strains. Load cells were placed at the nail heads to measure the nail load developed at the face. The single point extensometer was installed behind the pile cap to measure outward deflection of the pile cap. Four strain gages were also placed on two of the bridge piling at depths of approximately 5 and 12 feet. Earth pressure cells were placed behind the wall facing to measure the earth pressure behind the wall. Optical survey points were established along the wall face to measure horizontal deflection. Finally slope inclinometers were placed behind the wall as an additional means to monitor horizontal wall deflection. Instrumentation results for the earth pressure cells, pile strain gages and optical survey were found to be inconsistent and thought unreliable. Because of this they were not referenced for this report. 

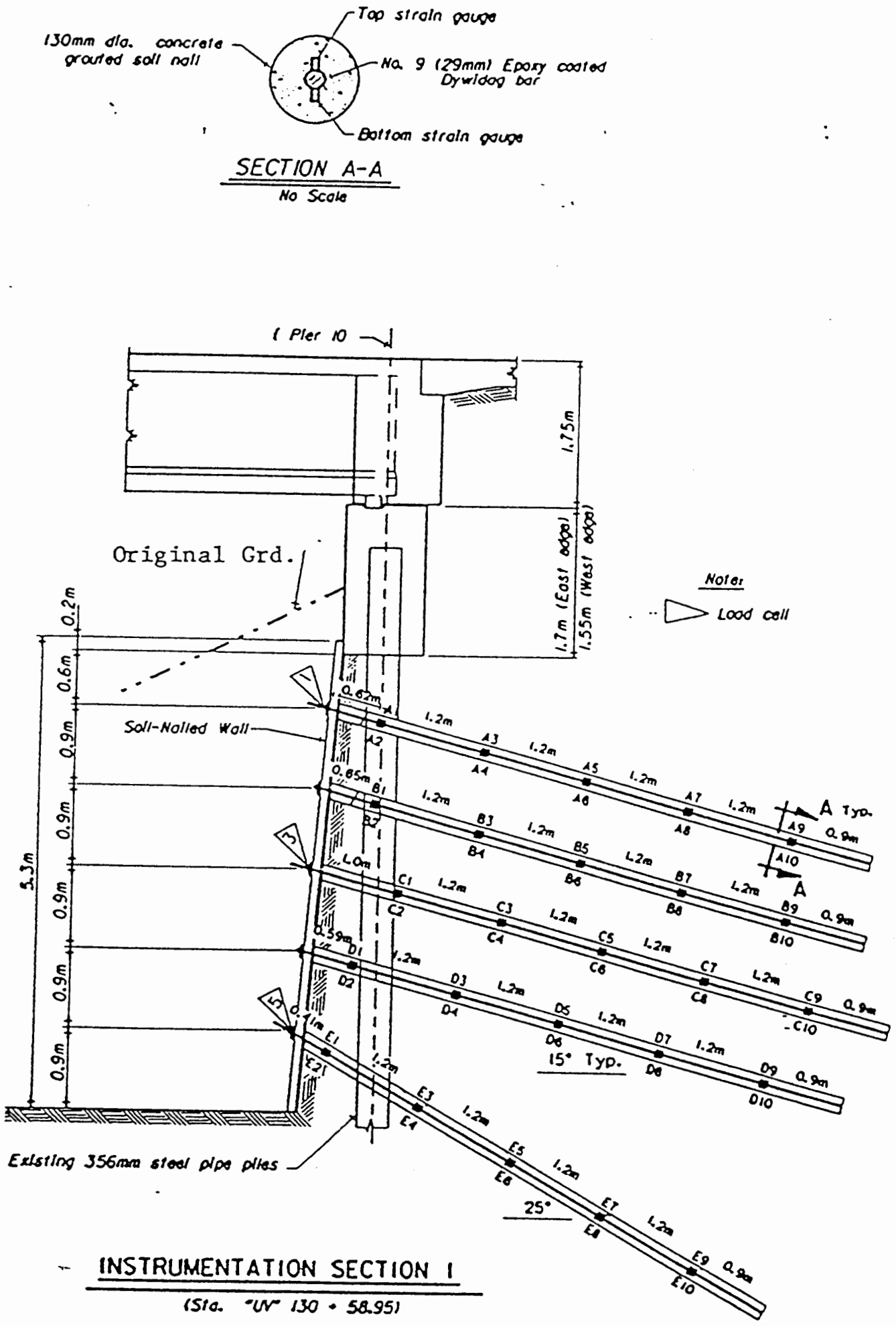

FIGURE 3: Instrument section \#1 cross section 

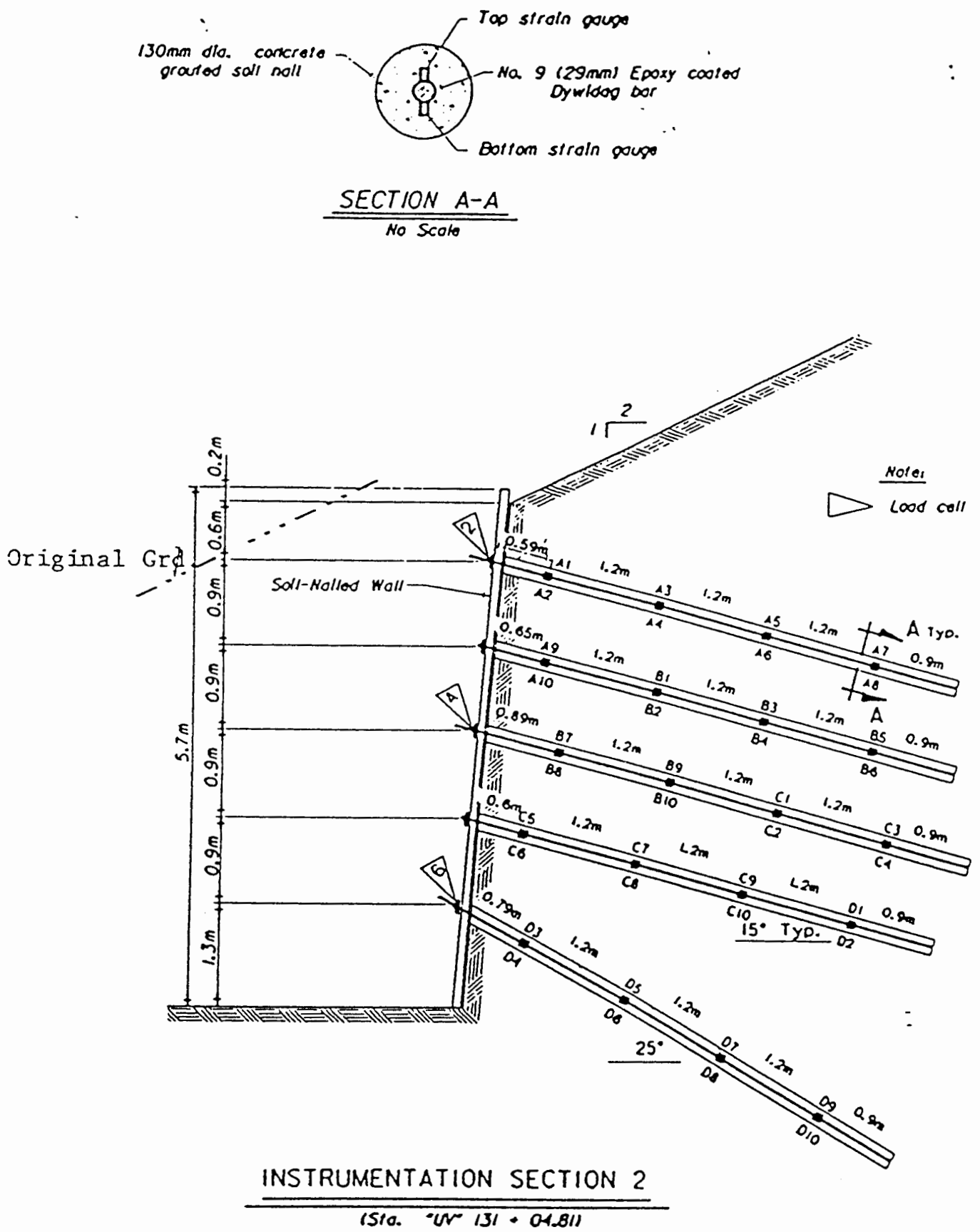

FIGURE 4: Instrument section \#2 cross section 


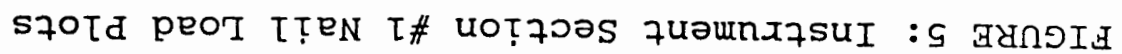

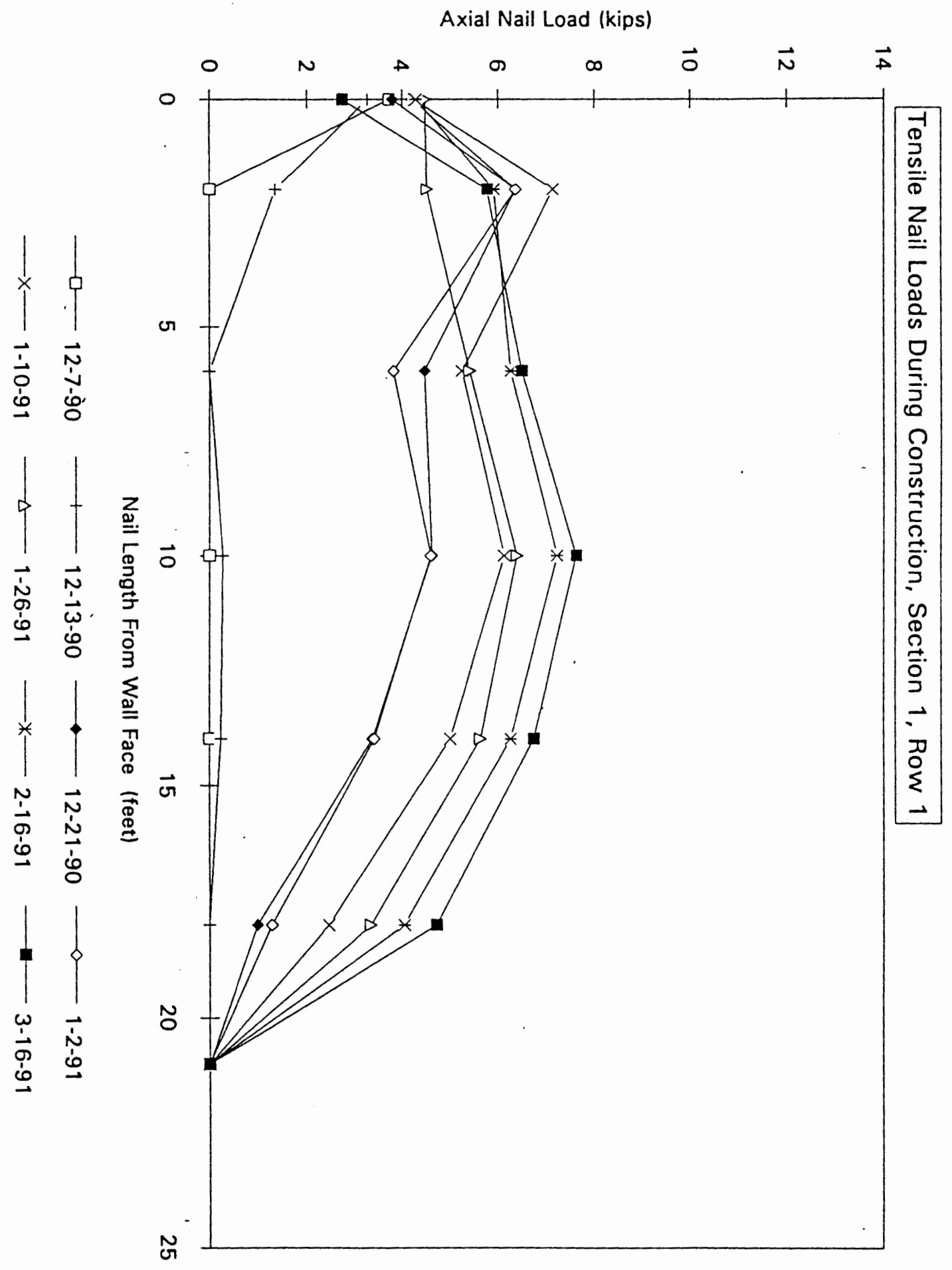




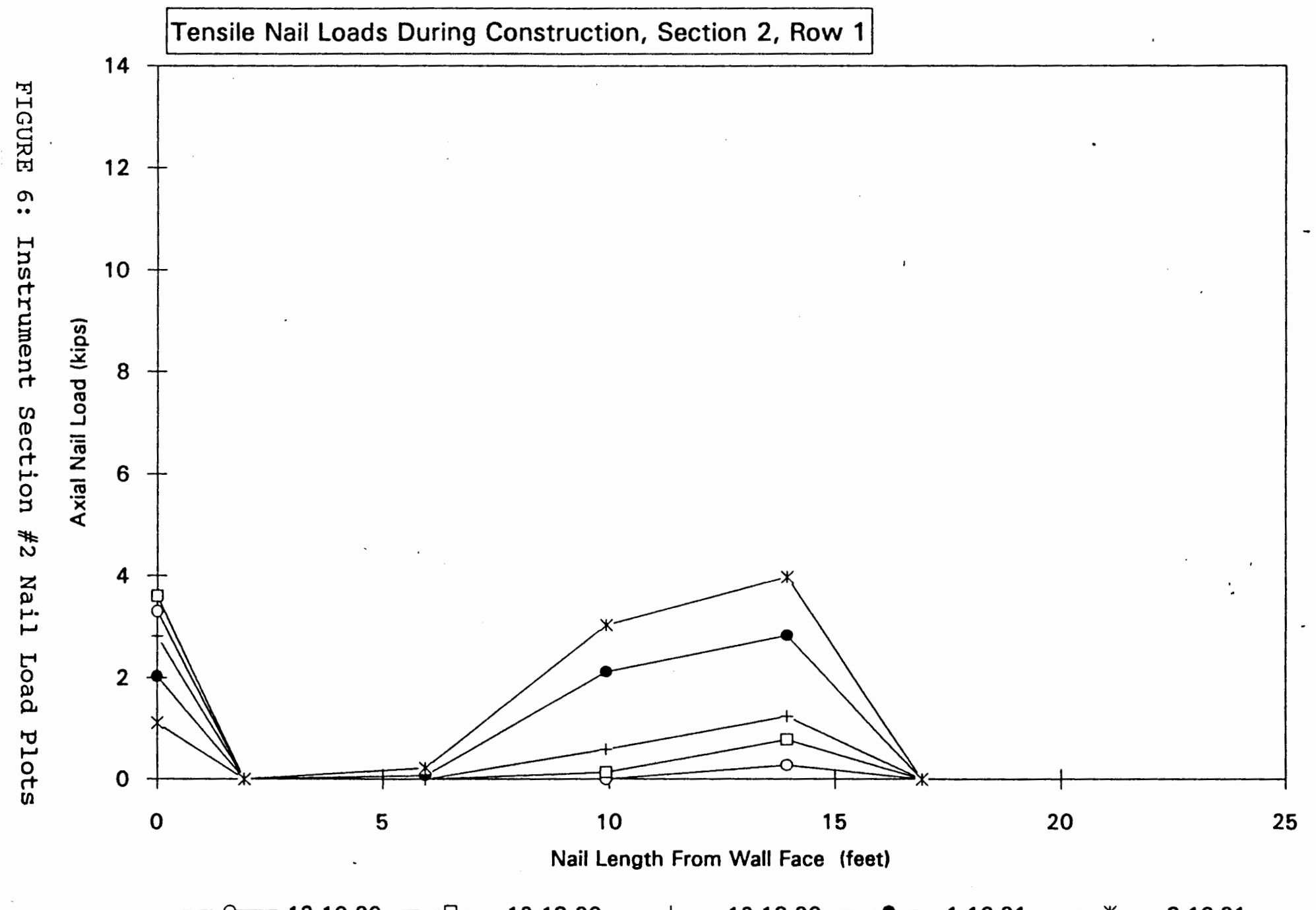


Swift - Deita Park Interchange

Single Point Extensometer @ Pile Cap

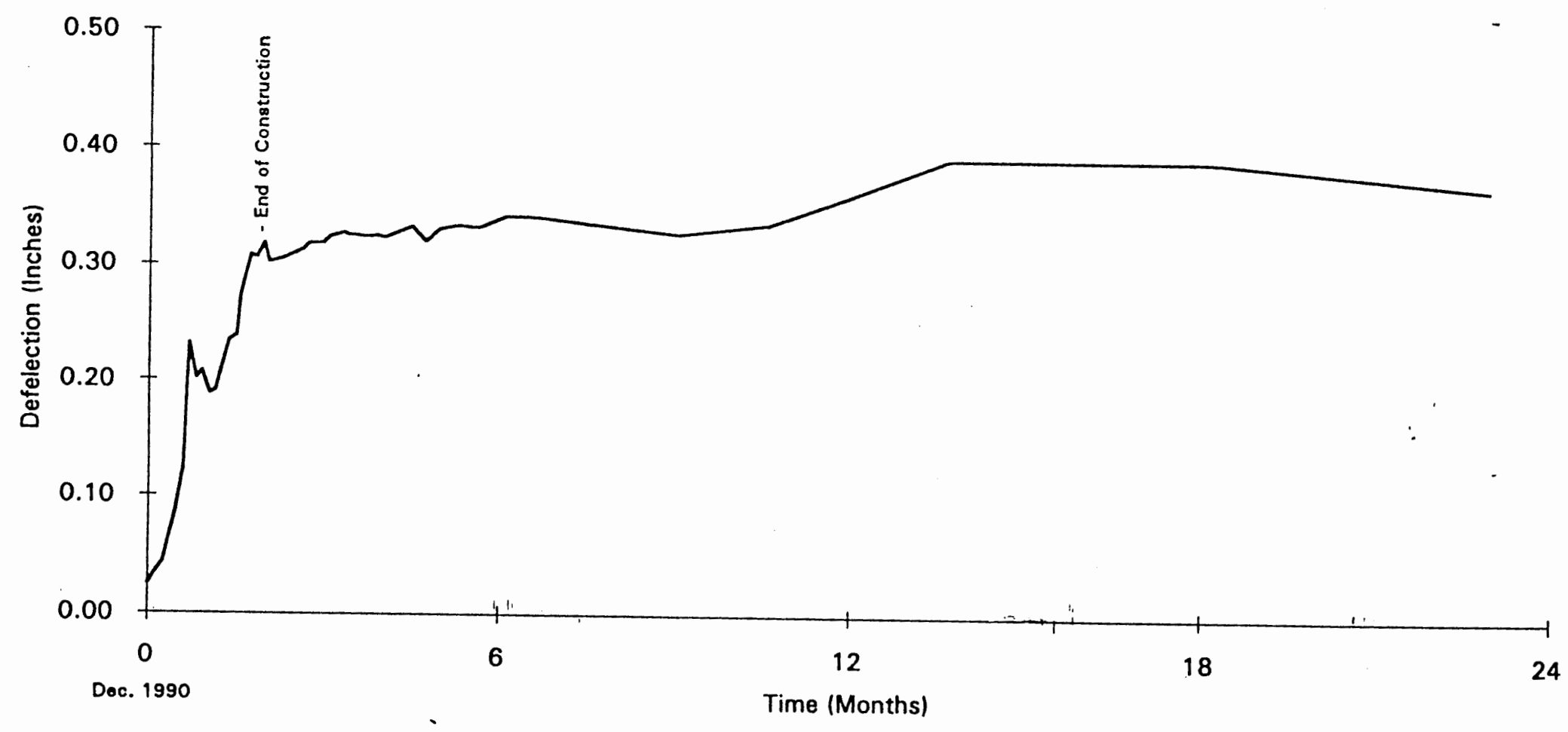

FIGURE 7: Pile Cap Extensometer Plot 


\section{Multi-Deflection Plot - SD129}

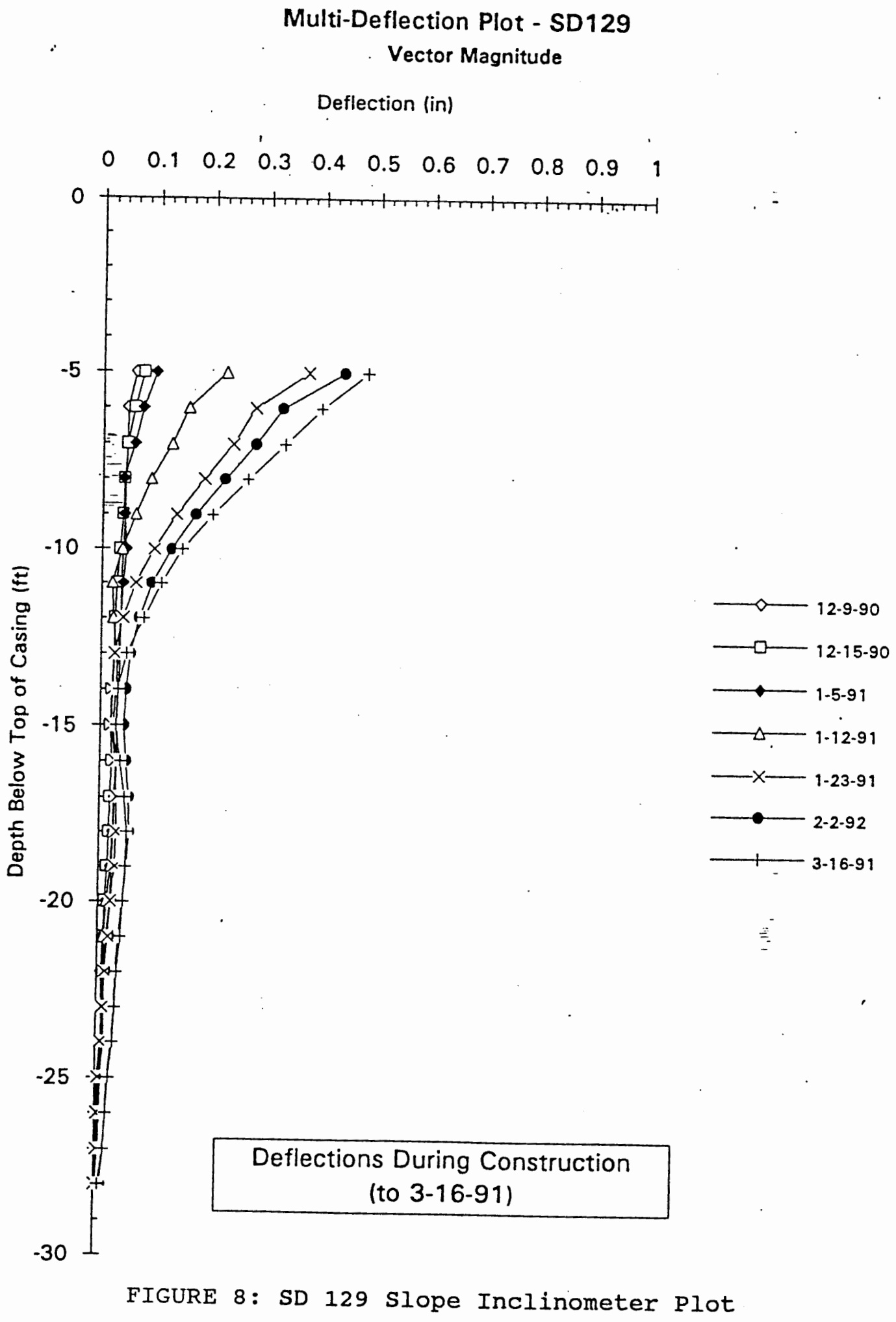


Multi-Deflection Plot - SD130

Vector Magnitude

Defiection (in)

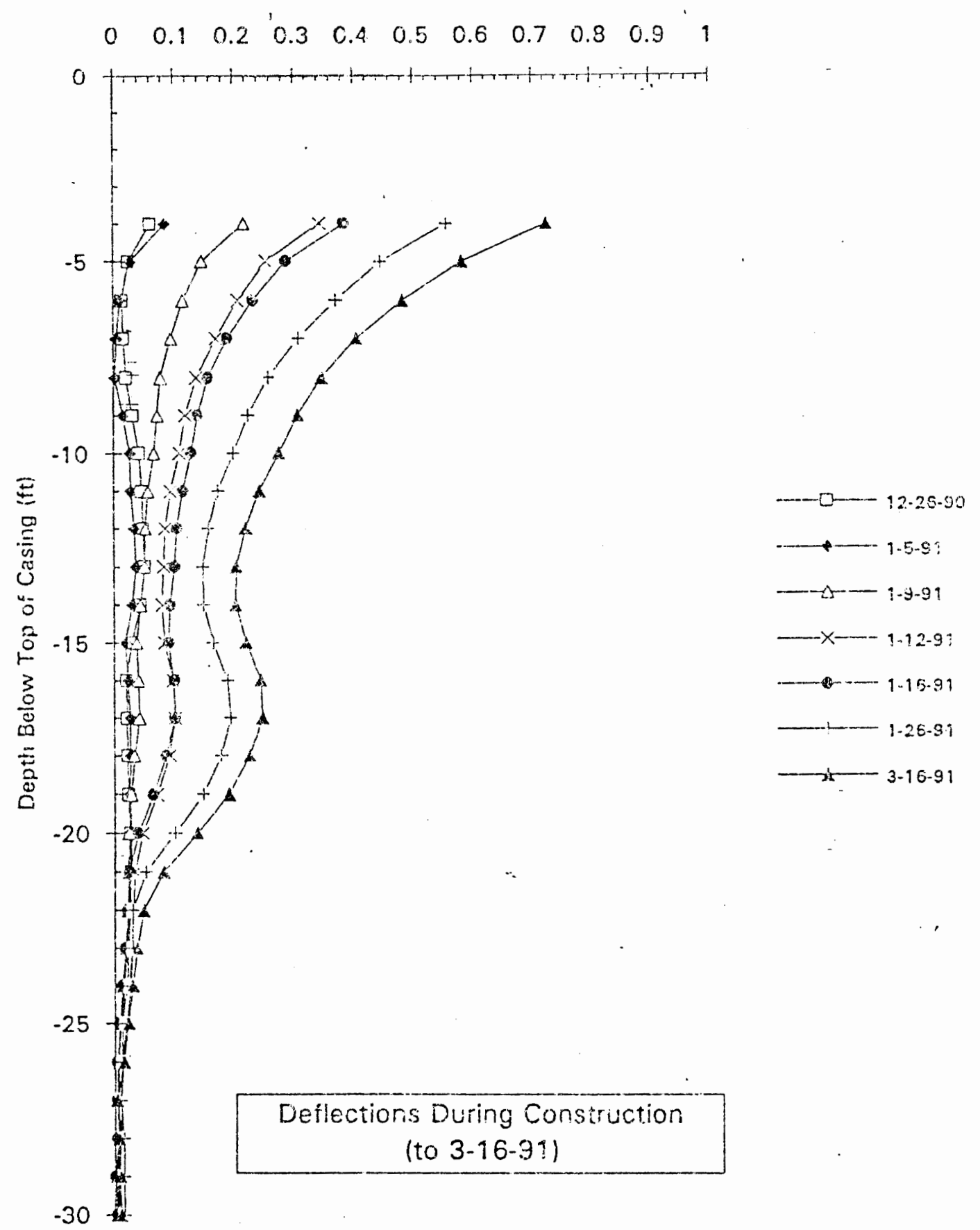

FIGURE 9: SD 130 slope Inclinometer Plot. 


\section{SOIL TESTING}

The soil fill behind the wall generally' consisted of clean, uniform grained, loose dredge sand, previously borrowed from the Columbia River. There were also zones of low plasticity silt fill material and large pieces of wasted concrete, asphalt and cast iron pipe.

Laboratory Soils Testing At Swift Delta

Laboratory testing was performed by the oregon state Highway Division (ODOT) during their investigation for the soil nail wall. Table II and III summarizes the laboratory testing results with the following notation:

LL - Liquid limit

IP - Plastic index

Gama dry - Dry unit weight (pcf).

Gama sat - Saturated unit weight (pcf).

Su (torv) - Undrained shear strength from torvane (psf).

Phi - Internal friction angle degrees.

USCS - Unified soil classification system.

Table II represents the results of the only triaxial testing performed for this project on an undisturbed sample taken from test boring $T B$ 115. This boring was not located in the immediate vicinity of the wall. The extent of shear strength testing conducted for wall design was not judged adequate for refined FEM input. 


\begin{tabular}{|c|l|l|l|l|l|l|l|l||}
\hline \multicolumn{10}{|c||}{ TABLE II } \\
\hline \hline Hole \# & Depth & LL & PI & $\begin{array}{l}\text { Gama } \\
\text { dry }\end{array}$ & Phi & $\begin{array}{l}\text { C } \\
\text { (psf) }\end{array}$ & $\begin{array}{l}\text { Su } \\
\text { (tsf) }\end{array}$ & USCS \\
\hline TB-115 & 16.0 & 38 & 12 & 90 & 23.5 & 129.6 & .37 & ML-CL \\
\hline
\end{tabular}




\begin{tabular}{|c|c|c|c|c|c|c|c|c|c|c|}
\hline \multicolumn{11}{|c|}{$\begin{array}{l}\text { TABLE III } \\
\text { Laboratory test results }\end{array}$} \\
\hline Hole \# & Sample \# & Depth & $\because \mathrm{MC}$ & LL & $\mathrm{Pi}$ & Gama dry & Gama Sat & $S$ (torv) & $\mathrm{Phi}$ & USCS \\
\hline \multirow[t]{3}{*}{$\mathrm{TP}-1$} & & 5.0 & & & & & & $0.6 \mathrm{tsf}$ & & SM-GM \\
\hline & & 8.0 & & & & & & .8 & & ML \\
\hline & & 11.0 & & & & & & $0.8-1.0$ & & SM. \\
\hline \multirow[t]{2}{*}{$\mathrm{TP}-2$} & & 6.0 & & & & & & 0.35 & & SP \\
\hline & & 9.0 & & & & & & 0.35 & & SP \\
\hline \multirow[t]{4}{*}{$\mathrm{TB}-124$} & $N-5$ & 10.0 & 33 & 36 & 1 & & & & & ML \\
\hline & $N-6$ & 13.5 & 38 & 40 & 10 & & & & & ML \\
\hline & $\mathrm{N}-15$ & 38.0 & 32 & 37 & 12 & & & & & ML \\
\hline & $\mathrm{N}-16$ & 43.0 & 45 & 45 & & & & & & ML \\
\hline \multirow[t]{2}{*}{$\mathrm{TB}-125$} & $\mathrm{U}-1$ & 10.0 & & & & & & & & \\
\hline & $\mathrm{U}-2$ & 40.0 & & & & & & & $\therefore$ & \\
\hline \multirow[t]{5}{*}{$\mathrm{TB}-127$} & $\mathrm{~N}-2$ & 8.0 & 40 & 38 & 10 & 78.4 & 109.9 & & & ML \\
\hline & $\mathrm{U}-1$ & 8.5 & & & & & & & & ML \\
\hline & $\mathrm{N}-3$ & 13.0 & 30 & 28 & 7 & 89.4 & 116.1 & & & CL-ML \\
\hline & $\mathrm{U}-2$ & 18.0 & 8 & & & & & & 32.4 & SP \\
\hline & $N-7$ & 33.0 & 36 & 34 & 10 & 84.6 & 115.4 & & & ML-CL \\
\hline $\mathrm{TB}-128$ & $\mathrm{~N}-2$ & 8.0 & 33 & 34 & 10 & 84.7 & 112.3 & & & $M L-C L$ \\
\hline
\end{tabular}




\section{Insitu Testing At Swift Delta}

To supplement the laboratory test program and form a test basis to develop constitutive parameters, Pressuremeter testing (PMT) was done in December 1990 and May 1991. Five pressuremeter tests were performed behind the wall in the vicinity of instrument section \#2. A Texam pressuremeter unit (manufactured by Rocktest Inc.) utilizing EX and BX (32mm dia. and $62 \mathrm{~mm}$ dia respectively) probe sizes was used for these tests. The primary soil parameter used in the following report was the soil modulus $E_{0}$. From the pressuremeter testing a modulus value ranging from 200 - $500 \mathrm{ksf}$ was estimated. It is interesting to note that French soil nail wall preliminary designs are based on correlations to pressuremeter test data ${ }^{4}$. The following table summarizes the pressuremeter test results for this project, in terms of net limit pressure, Pl*, with Po as the at rest pressure.

Al1 holes were drilled by hand augers and each test conducted in accordance with ASTM D4719. The results shown in Figures 10 and 11 illustrate the high quality data which is generally consistent with testing uniform sand at increasing depth. Figure 12 is a summary of the limit pressure and modulus at depth for the testing.

${ }^{4}$ page 11, FHWA Tour for Geotechnology-Soil Nailing, June 


\begin{tabular}{|c|c|c|c|c|c|c|}
\hline \multicolumn{7}{|c|}{$\begin{array}{c}\text { Table IV } \\
\text { Pressuremeter }\end{array}$} \\
\hline Test \# & Probe & $\begin{array}{l}\text { Depth } \\
(f t)\end{array}$ & $\begin{array}{l}\text { Po } \\
\text { (ksf) }\end{array}$ & $\begin{array}{l}\text { Eo } \\
\text { (ksf) }\end{array}$ & $\begin{array}{c}\text { Pl* } \\
\text { (ksf) }\end{array}$ & $\mathrm{Eo} / \mathrm{Pl}$ * \\
\hline 1 & $\mathrm{BX}$ & 2.5 & 0.1 & 98.3 & 14.9 & 6.6 \\
\hline 2 & $\mathrm{EX}$ & 4.25 & 0.2 & 28.8 & 4.8 & 6.0 \\
\hline 3 & $\mathrm{BX}$ & 6.29 & 0.3 & 56.9 & 7.7 & 7.4 \\
\hline 4 & $\mathrm{BX}$ & 8.96 & 0.5 & 55.8 & 9.0 & 6.2 \\
\hline 5 & $\mathrm{BX}$ & 4.38 & 0.2 & 47.3 & 6.3 & 7.5 \\
\hline
\end{tabular}




\section{SWIFT DELTA PMT 5/29/91 \\ TESTS $1,3,4$ and 5}

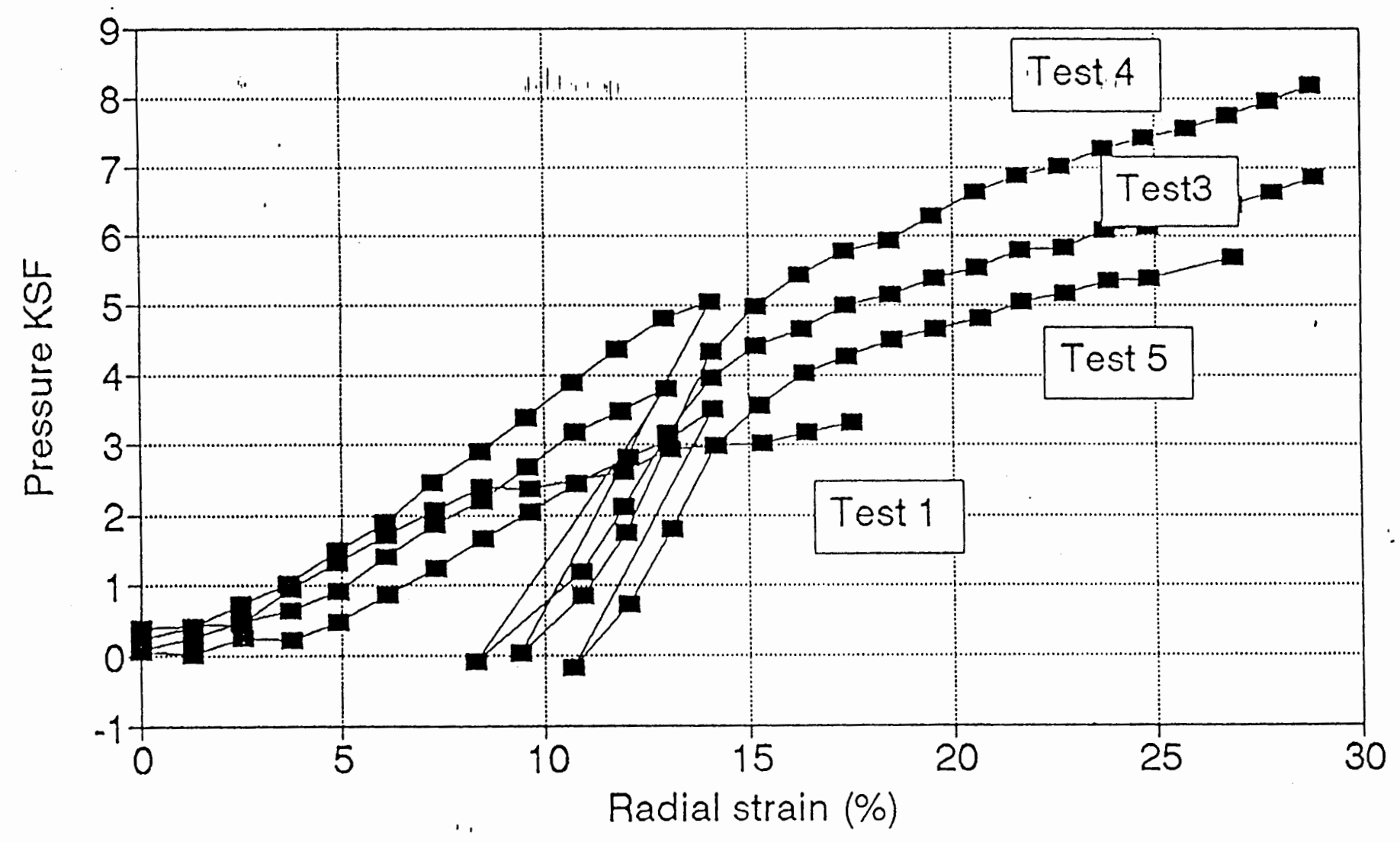

FIGURE 10: EX Probe Pressuremeter Test Results 


\section{SWIFT DELTA PMT 1/10/91 TEST 2 4.25ft Deep"}

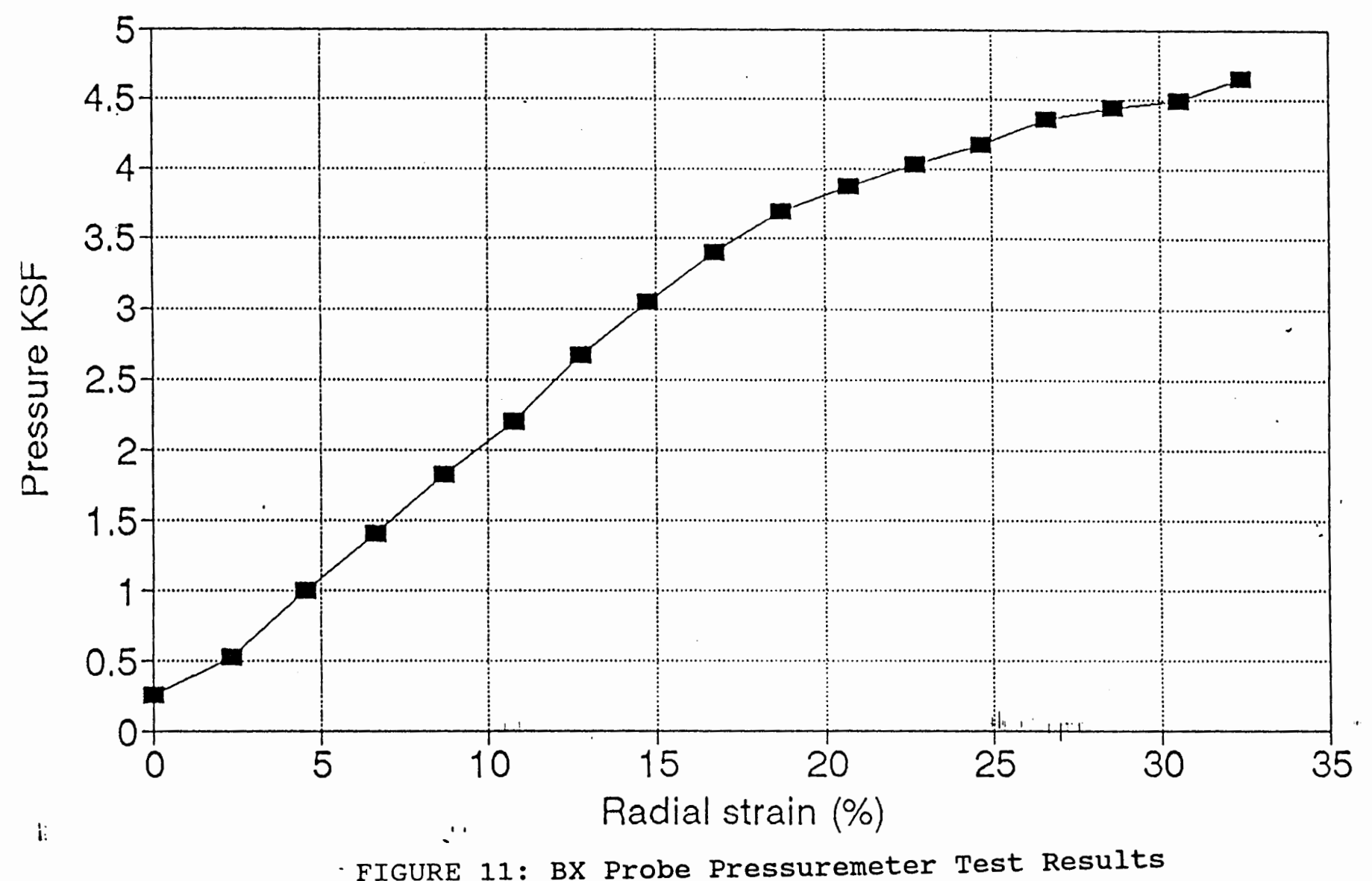




\section{Swift Delta PMT Summary}

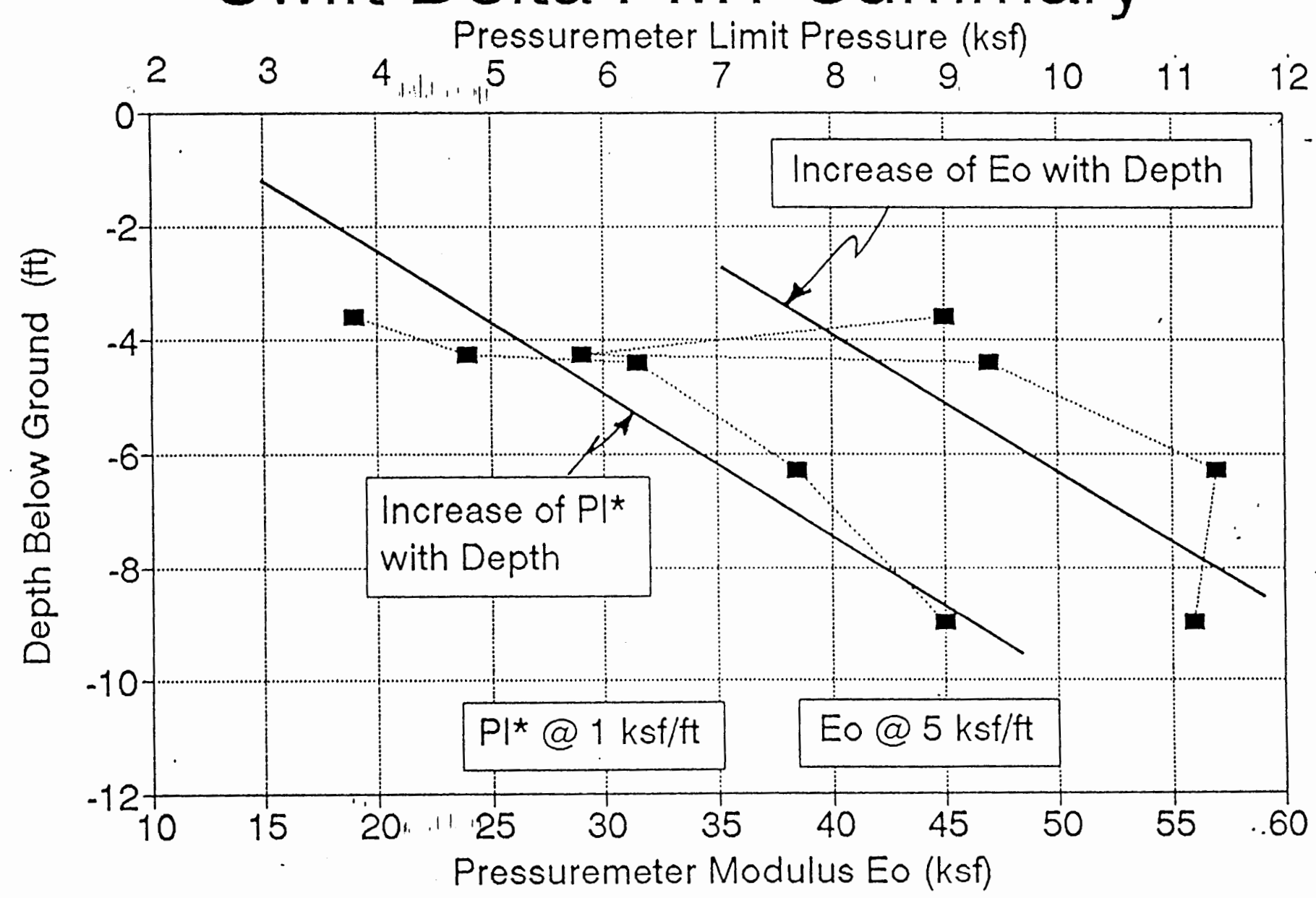

FIGURE 12: Pressuremeter Test Results Summary 


\section{TWO DIMENSIONAL FINITE ELEMENT MODELING}

The monitored results of the project instrumentation are not enough alone to ánswer the questions presented in section 1. Instrumentation data in conjunction with soil nail wall/bridge foundation modeling was performed to provide a more thorough analysis. Limit equilibrium based analysis can only describe the wall soil stress state at plastic failure and has no provision for linking the pile into the soil nail model. Limit equilibrium modeling was not suitable for the scope of this report. Finite element modeling was chosen as it had the ability to model the stress state of the soil nails, wall face, piling, and the soil during construction.

Instrumentation data was used to assist in calibration of the soil parameters. Attempting to correctly predict the exact soil stresses would not be practical, because of the limitations of two dimensional modeling and the limited information available on the soil strength parameters.

\section{$\underline{\text { ABAQUS }}$}

All modeling was performed with the commercial finite element code ABAQUS versions 4.8 - 5.2. ABAQUS is produced by 
Hibbitt, Karlson, and Sorenson Inc ${ }^{5}$. It is a general purpose finite element program widely used for geotechnical analysis. It's capabilities are well documented for solving non-linear soil deformation problems. ABAQUS was run on both SUN SPARC one UNIX based work stations, and on the San Diego super Computing center's cray MXP computer.

\section{PATRAN}

Pre-finite and post-finite element work was done using the UNIX based program PATRAN (produced by PDA Engineering). The pre-processor generated the finite element meshes used in the modeling. The post-processor generated all stress, strain, and deformation fringe plots. These fringe plots proved to be a very powerful tool in analyzing the complex output from ABAQUS. Figure 13 is an example of PATRAN postprocessing graphics.

\section{Finite Element Mesh Development}

The soil nail wall/pile foundation system was simplified to two dimensions. This was necessary due to the extremely large computational effort that a full non-linear, three dimensional model would require. Wherever the mesh geometry would allow,

${ }^{5}$ ABAQUS USER MANUAL, Volumes 1 and 2 , Hibbitt, Karlson, and Sorenson, Inc. 1992 
4 node quadrilateral elements were used, to achieve the slope, 3 node triangular elements were also used. Past research has indicated that the behavior of anchors in. sand is concentrated in it's near vicinity. Anchor influence is considered to be insignificant at a maximum distance of 30 diameters. The location of the boundary of discrete semi-infinite zones was found to be 20 diameters by Deasi et. al. ${ }^{6}$ An 84 foot long by 35 foot high mesh boundary was used. The back of the wall face was placed a minimum of 80 diameters from the rear boundary (behind the nails). The nails were modeled with a single column of elements using a hexagon shape. The shotcrete face was modeled as two columns of elements; the first column to simulate the shotcrete wall face being placed in a "lift by lift" sequence; the second (outer) column to simulate the single application of shotcrete that was applied to the entire wall face. Bridge piling were modeled similar to the nails, with one column of elements and a hexagon shape. Two wall geometries were modeled, the first of which is located under the bridge Figure 14 (instrument section \#1 UV Station 130+59). Figure 13 also shows the intensity of the mesh in the areas of interest such as the nails and wall face. The second is located outside the influence of the bridge foundation system (instrument section \#2 UV - Line station 131+05) Figure 15. Instrument section \#1 consisted of

${ }^{6}$ C.S. Deast, A Muqladir, F. Sheele; Interactive Analysis of Anchored Soil Systems; ASCE Geotechnical Journal, May 5, 1986, Volume 112 
approximately 450 elements and instrument section \#2 consisted of approximately 435 elements. The two sections were analyzed for comparison of the effects of the pile foundation relative to a section that was not influenced by the pile foundation. Both plain strain and nonlinear analysis were performed on the same finite element meshes.

\section{1 ksf Line Load Validation}

The global geometry for the two finite element (FE) meshes is very similar, with the difference being the removal of elements near the pile cap for instrument section \#1 to create a $2 \mathrm{H}: 1 \mathrm{~V}$ slope above the wall face. This removal creates instrument section \#2. Thus instrument section \#1 was constructed first and verified by placing a $1 \mathrm{ksf}$ surface line load behind the pile cap and then analyzing it under purely elastic conditions. Figure 13 is the horizontal stress fringe plot and shows very reasonable results with a maximum compressive stress of approximately 1 ksf transitioning to lower compressive stress states below and outward from the load initiation area. Figure 13 is a combined deformed mesh and vertical deflection fringe plot. It can easily been seen that the maximum vertical deflection is at the surface and is on the order of two tenths of a foot. This deflection was compared with a closed form approximation to the vertical line 
load on a finite layer ${ }^{7}$. The closed form solution predicted approximately .16 foot deflection. This is a very good comparison to the FE results. Appendix B contains additional fringe plots of horizontal stress, vertical strain, horizontal strain, and maximum shear stress for the $1 \mathrm{ksf}$ line load condition. The results presented show that there are no obvious defects in the $\mathrm{FE}$ model and that it is ready for more advanced $\mathrm{FE}$ modeling as follows.

${ }^{7}$ Poulos and Davis, Solutions for Soil and Rock Mechanics, pages $28-32$. 
Fringe: $L C=2.1-R E S=4.1-P 3 / P A T R A N$ R.1-(Vector- $Y)-A B A Q U S-18-F e b-94$ 12:55:01

Deformed_plot: $L C=2.1-R E S=4.1-P 3 / P A T R A N ~ R .1 .2-D e f o r m a t i o n-A B A Q U S-18-F e b-94$ 13:3

Swift Delta 1KSF Line LoaDeflection

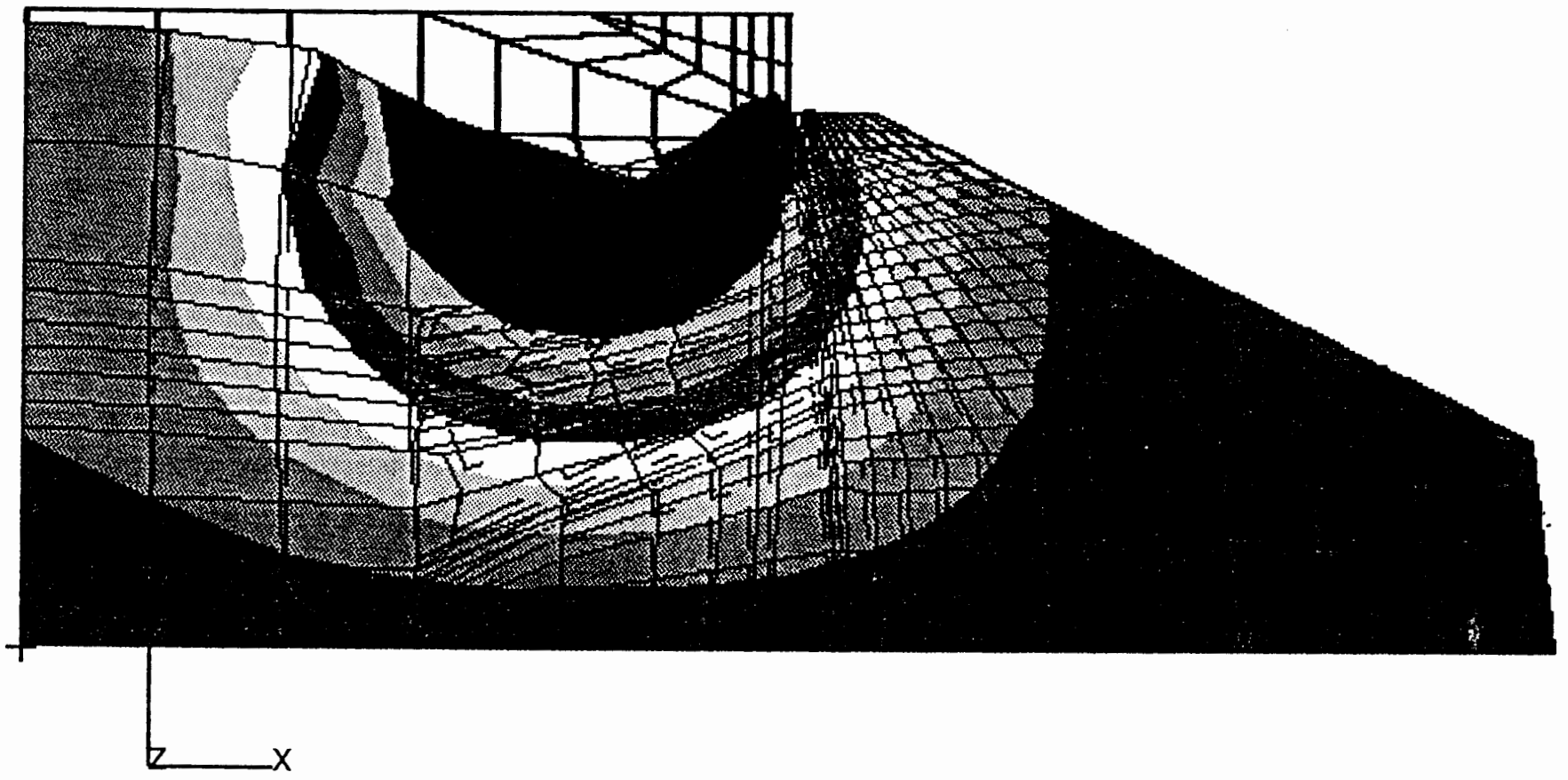

$-.02663$

$-.03994$

$-.05325$

$-.06657$

$-.07988$

$-.09319$

$-.1065$

$-.1198$

$-1331$

$-.1464$

$-.1598$

FIGURE 13: $1 \mathrm{ksf}$ Line Load Vertical Stress

$-.1731$

$-.1864$

$-.1997$ 


\section{SWIFT DELTA FINITE ELEMENT MESH}

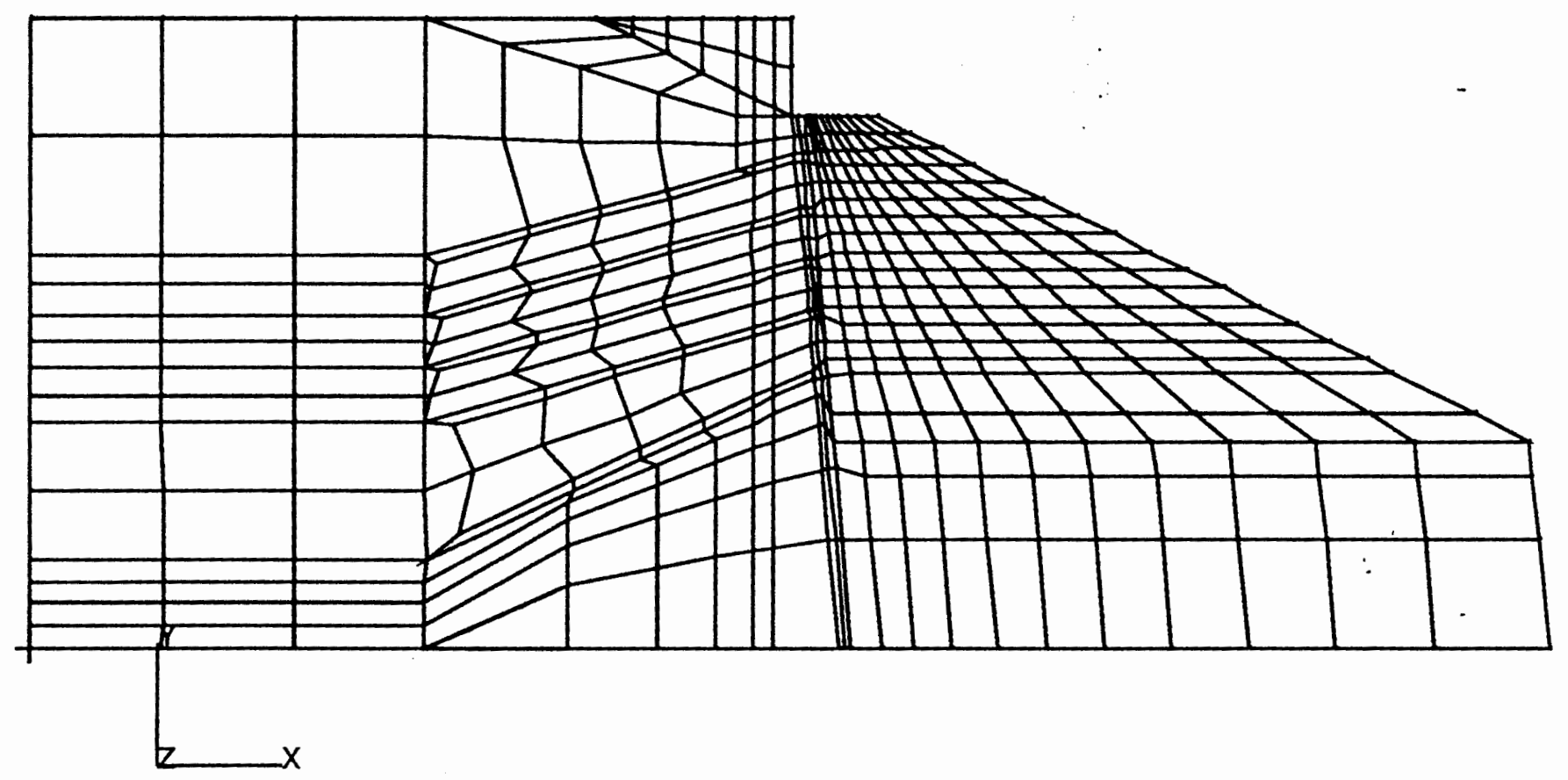

FIGURE 14: Finite Element Mesh Instrument section \#1 
SWIFT DELTA SOIL NAIL WALL INSTRUMENT SECTION 2

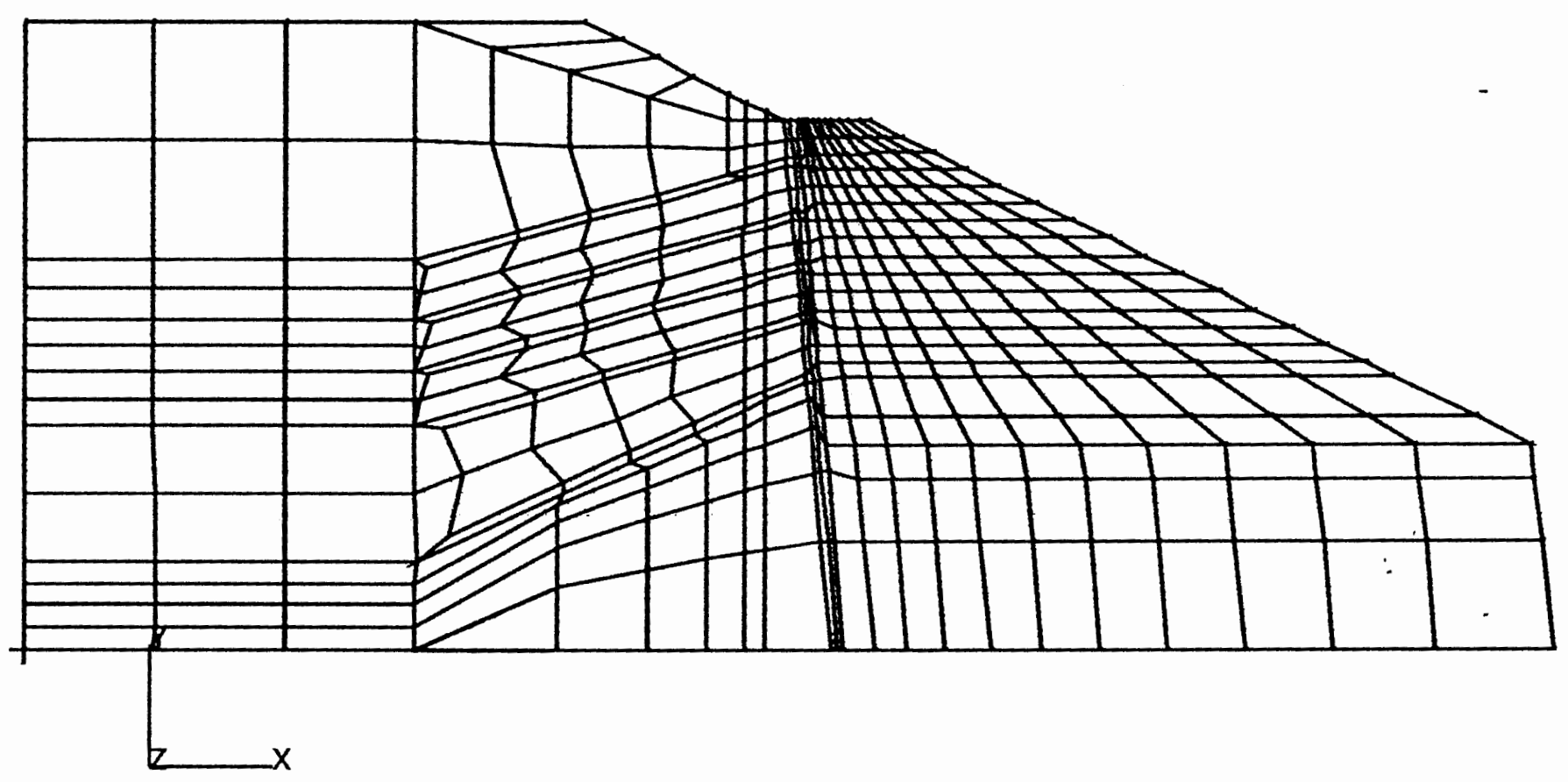

FIGURE 15: Finite Element Mesh Instrument section \#2 
Fringe: $L C=2.1-R E S=1.1-P 3 / P A T R A N R .1-(T e n s o r-X X)$-ABAQUS-18-Feb-94 12:23:02

Swift Delta 1KSF Line Load $s^{-} \cdot s^{\prime}, \quad 09416$

.03374

$-.02669$

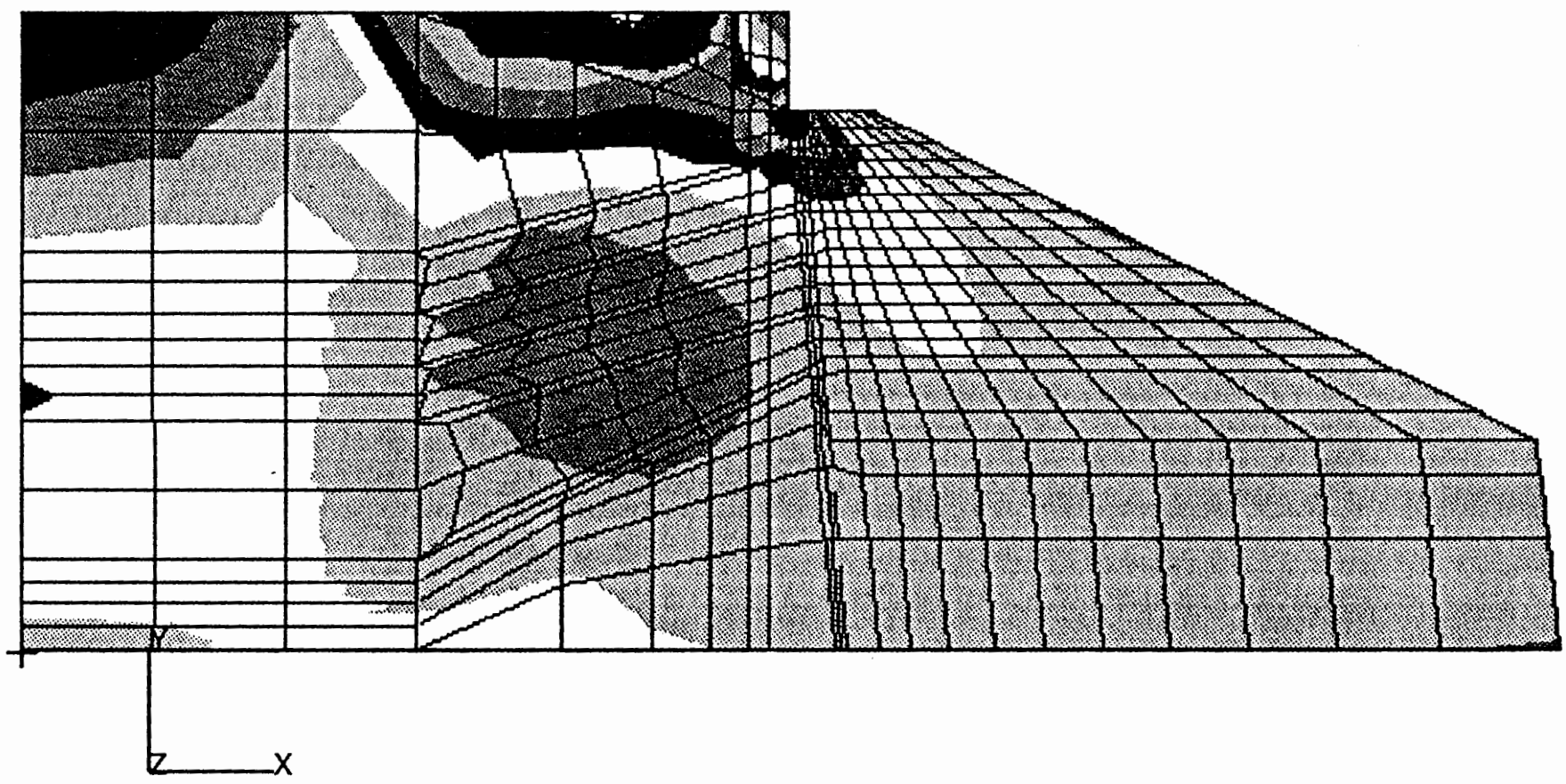

$-.08711$

$-.1475$

$-.2080$

$-.2684$

$-.3288$

$-.3892$

$-.4497$

-.5101 .

$-.5705$

$-.6309$

$-.6913$

FIGURE 16: $1 \mathrm{ksf}$ Line Load Horizontal stress

$-.7518$

$-.8122$ 


\section{PLANE STRAIN MODELING}

Finite element modeling steps were first performed in plane strain elasticity for all models. This simplified the initial debugging process of the models. Three models were developed, two for instrument section \#1 and one for instrument section \#2. The instrument section \#1 models consisted of one with the nails active (file name = IinIn) and the other with the nails and pile active (file name $=$ Iinlp). In order to model the actual construction process a dynamic excavation process was developed. This process included removing elements to simulate the excavation of a soil lift, removing elements to simulate the drilling of the soil nail hole, replacing the nail drill hole elements with steel/grout elements to simulate the nail insertion, and adding shotcrete elements to the exposed soil face to simulate the structural shotcrete wall face. ABAQUS would not allow two different material properties to be assigned to one element. This would be needed at the nail locations to model the removal of soil and the insertion of a grouted nail by changing the soils material property to that of a nail section. Since this could not be permitted, dual elements had to be developed at the nail locations so that both soil and nail material properties could be used there at various stages of the model execution. 
The nails and pile are connected to each other as one material where they cross each other in the mesh. The nails are modeled in all cases as a 6 inch tall cross section with a 1 foot width. The nail modulus was proportioned to take into account its width and steel/grout properties. The instrument section \#2 model ( $f$ ile name $=$ lin $2 n$ ) contained just the nails.

The FE modeling steps are listed below for the lininp model and are based on the actual construction process that was used to construct the swift Delta soil Nail Wall as discussed in the construction section of this report. 


\section{lin1p (nolin1p) Instrument section \#1 soil Nail}

\section{Modeling steps}

Step 1 - Removal of shotcrete, Nail, and pile elements. Step 2 - Geostatic Turn on Step 3 - Pile Installation Step 4 - a) Excavation \#1 (3.5 Ft)

b) Add shotcrete to face.

c) Drill nail hole by removing slope elements.

d) Install Nail \#1 (15 degrees $21.0 \mathrm{Ft}$ ) Step 5 -

a) Excavation \#2 (5.5 Ft)

b) Add shotcrete to face.

c) Drill nail hole by removing slope elements.

d) Install Nail \#2 (15 degrees $21.1 \mathrm{Ft}$ )

Step 6 - a) Excavation \#3 (2.0 Ft).

b) Add shotcrete to face.

C) Drill nail hole by removing slope elements.

d) Install Nail \#3 (15 deg. $22.3 \mathrm{Ft}$ ).

Step 7 - a) Excavation \#4 (3.0 Ft)

b) Add shotcrete to face.

C) Drill nail hole by removing slope elements.

d) Install Nail \#4 (15 degrees $20.9 \mathrm{Ft}$ )

Step 8 - a) Excavation \#5 (3.0 Ft).

b) Add shotcrete to face.

C) Drill nail hole by removing soil elements.

d) Install Nail \#5 (25 degrees 20.3 Ft) 
(Model Steps, continued)

\author{
9 - a) Excavation \#6 (1.5 Ft) \\ b) Add shotcrete to excavation \#6 and the \\ second shotcrete application to the entire \\ wall face. \\ 10 - Geostatic turn on.
}

Fringe plot scaling

All of the vertical and horizontal stress fringe plots have been scaled to show soil response. Therefore, fringe plot ranges start at zero stress and end at a maximum compressive stress of -3500 psf. All of the major stress fringe plots were scaled to show nail response. These fringe plots start at zero stress and end at 10,000 psf (tension). 


\section{Geostatic Turn on}

The FE modeling, begins with the activation of a geostatic stress field. This stress field sets the mesh to a gravity stress state which increases with depth in proportion to overburden pressure. ABAQUS requires that all non-horizontal boundaries be fixed in the horizontal direction. This results in a pseudo-geostatic stress field for slopes, such as the $2 \mathrm{H}: 1 \mathrm{~V}$ at Swift Delta. With this, good comparison was still obtained between ABAQUS for step 2 geostatic turn on of horizontal and vertical stress (Figures 17 and 18) and the predicted stress states for instantaneously loaded linear elastic embankments by Poulos et al $1972^{7}$.

Incremental Modeling

All three models were checked in linear elasticity through the complete incremental modeling process. This included the introduction of the five nails and the separate application of a final shotcrete lift. For the sake of redundancy, IinIn are the only linear elastic results presented in Figures 18 through 23, which are the horizontal stress fringe plots and illustrate the sequential modeling steps. The plots show reasonable results except for a small stress anomaly below nail \#5 at the wall face. It appeared to be a defect in the.

\footnotetext{
${ }^{7}$ Poulos and Davis
} 
mesh but after analyzing the input data it could not be isolated. It did not appear to interfere with the models functioning. Analysis of the major s.tress fringe plots, (Figures 24 through 30), show the behavior of the nails. Figure 24 shows that the 1st nail installed is in an extremely high state of stress (maximum $3,300 \mathrm{psf}$ ) relative to the surrounding soil. This elevated stress state is not what would be expected from a typical nail installation, there the nail would be at a zero state of stress until a soil lift was excavated below the nail. The reason for the ABAQUS model high nail initial stress state is probably do to high soil strains developed after the soil cut lift was made. The problem occurs when the nail elements are introduced as a material with a much higher modulus that must undergo the same amount of strain as the lower modulus soil did originally. Therefore a correspondingly high state of nail stress is the result. Figures 25 and 26 show that the second nails initial stress of approximately maximum 3,300 psf dissipates to approximately 2,000 psf with the subsequent excavation of 1 ift \#3. This same phenomenon is repeated for nails \#3 and \#4, but is not seen in nail \#5 which is installed at a high stress state and seems to remain at a high stress state. This FEM anomaly illustrates the difficulty in modeling soil nails. 
Fringe: LC=2.1-RES=1.1-P3/PATRAN R.1-(Tensor-XX)-ABAQUS-05-Mar-94 14:20:32

SWIFT DELTA FINITE ELEMENT MESH

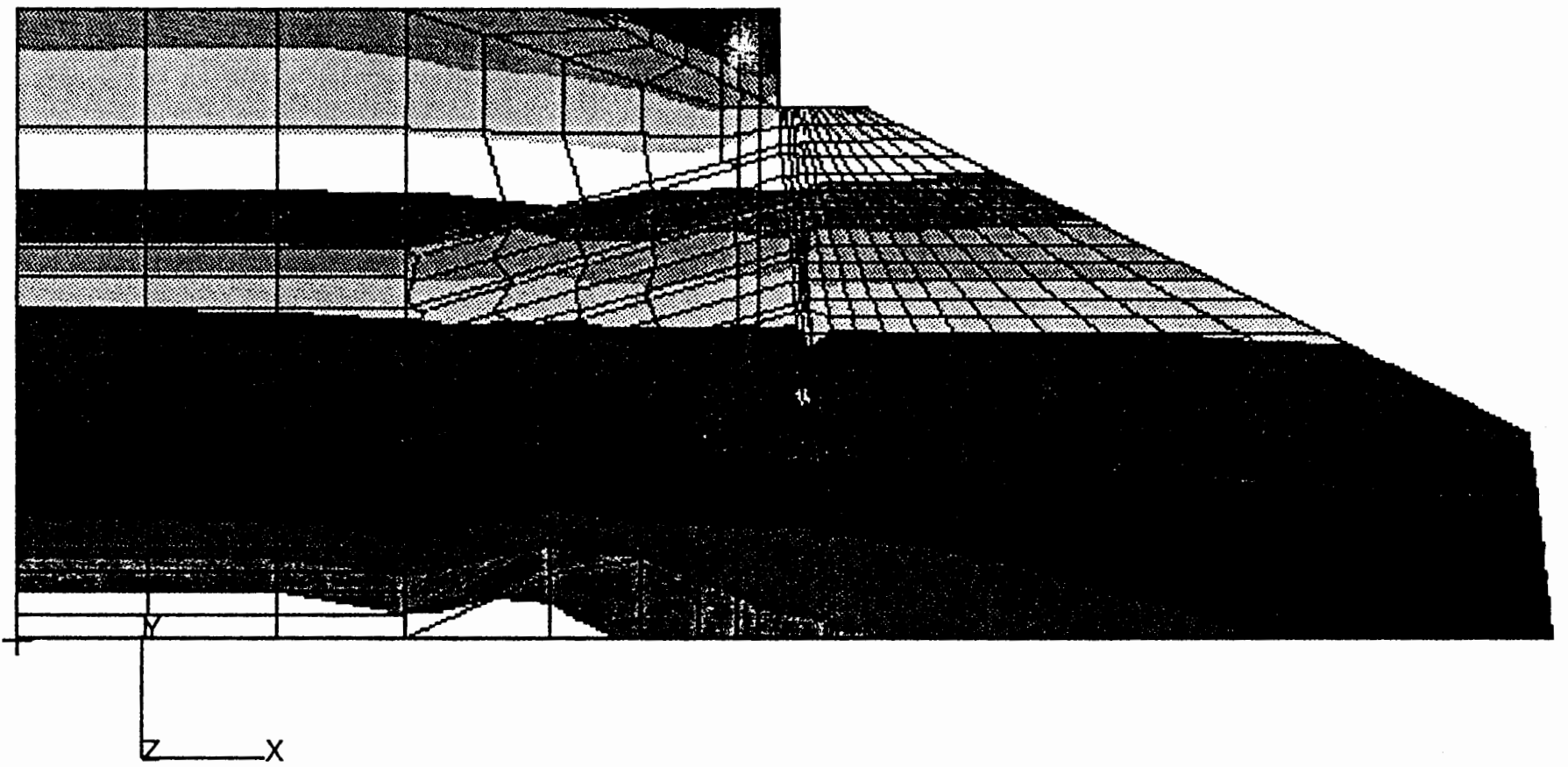


Fringe: LC=3.2-RES=1.1-P3/PATRAN R.1-(Tensor-XX)-ABAQUS-05-Mar-94 14:26:22

SWIFT DELTA FINITE ELEMENT MESH

\begin{tabular}{l}
0. \\
-233.3 \\
-466.7 \\
-700.0 \\
-933.3 \\
-1167. \\
-1400. \\
-1633. \\
-1867. \\
-2100. \\
-2333. \\
-2567. \\
-32600. \\
-3500. \\
\hline
\end{tabular}

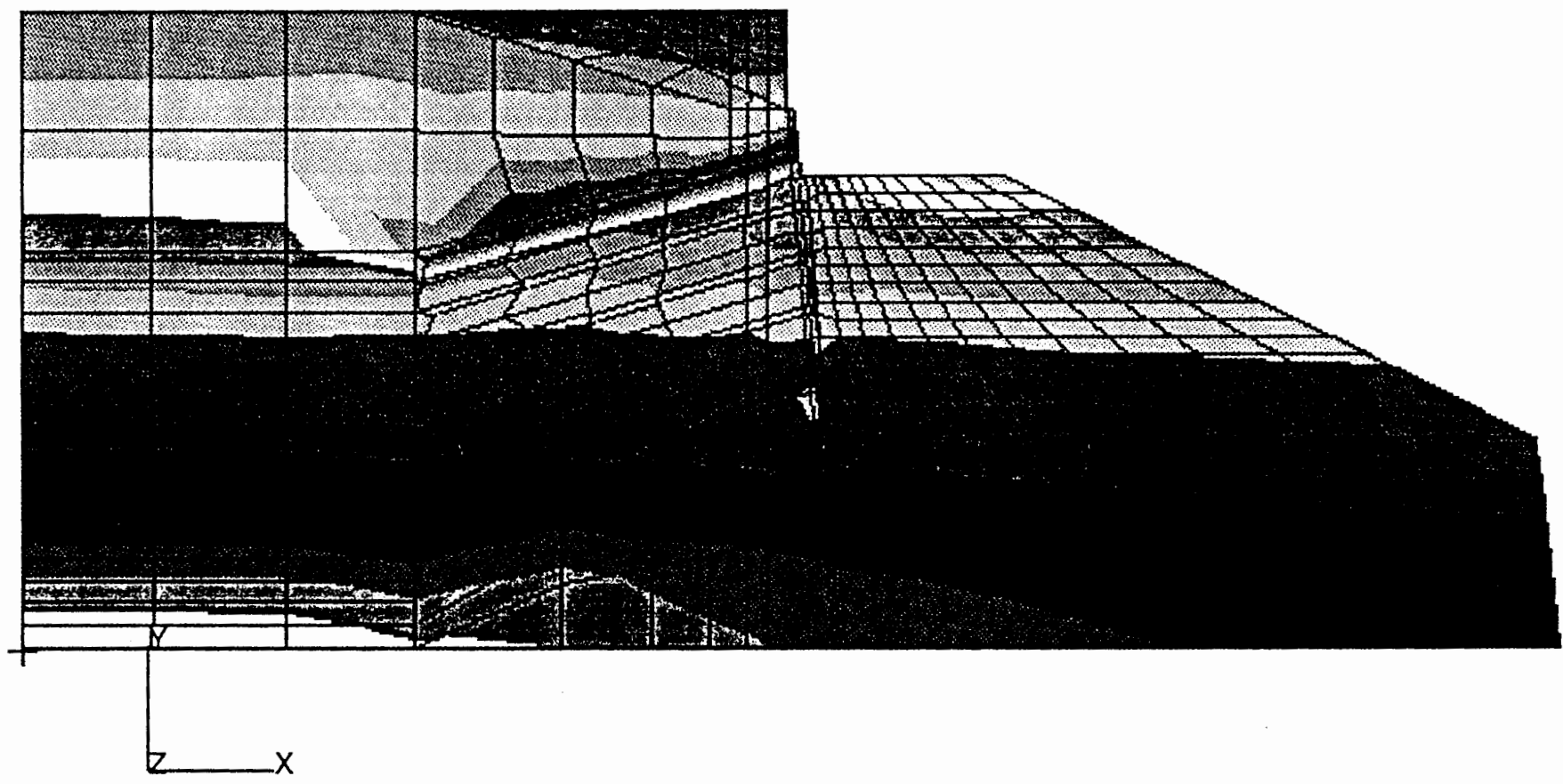


Fringe: $L C=3.3-R E S=1.1-P 3 / P A T R A N$ R.1-(Tensor-XX)-ABAQUS-05-Mar-94 14:57:19

SWIFT DELTA FINITE ELEMENT MESH

LIN1N MODEL STEP 4

0.

\begin{tabular}{l}
0. \\
-233.3 \\
-466.7 \\
-700.0 \\
-933.3 \\
-1167. \\
-1400. \\
-1633. \\
-1867. \\
-2100. \\
-2333. \\
-2567. \\
-3033. \\
-3500. \\
\hline
\end{tabular}




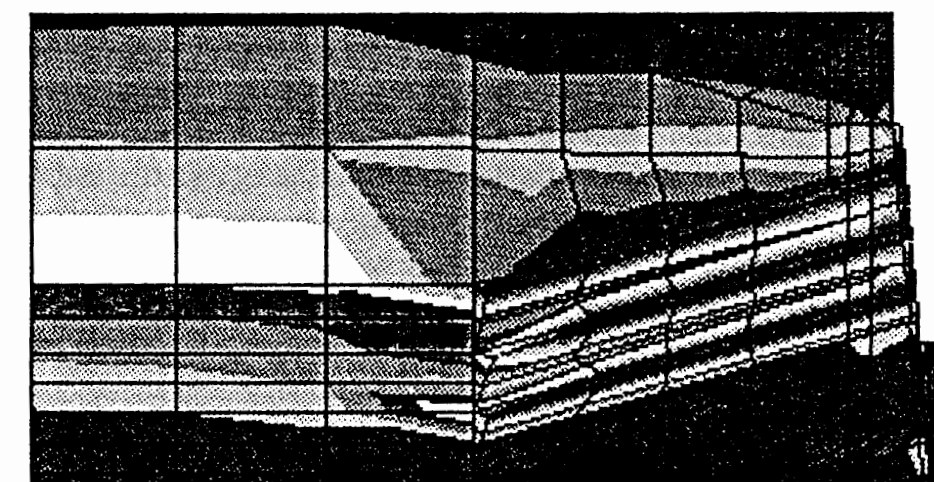


Fringe: LC=3.5-RES=1.1-P3/PATRAN R.1-(Tensor-XX)-ABAQUS-05-Mar-94 15:24:58

SWIFT DELTA FINITE ELEMENT MESH

LIN1N MODEL STEP 6

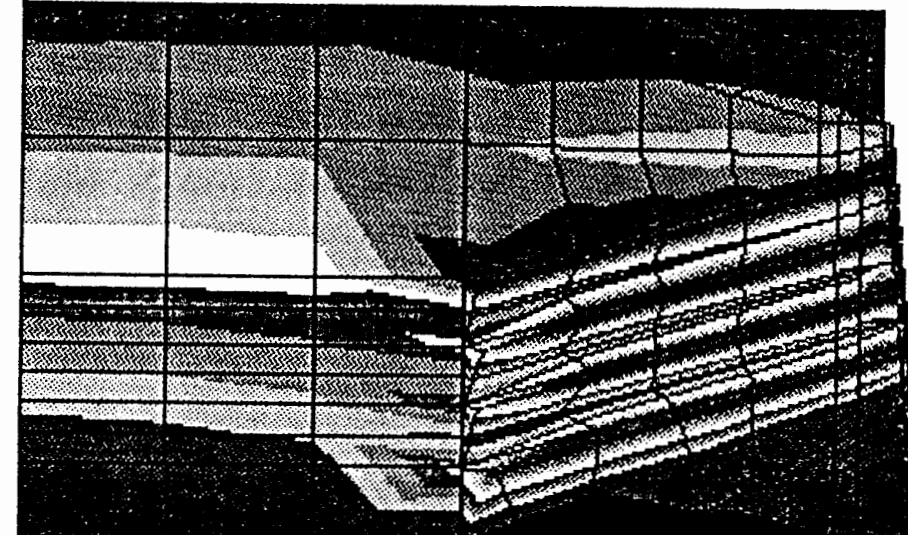

$-700.0$

$-933.3$

$-1167$.

-1400 .

$-1633$.
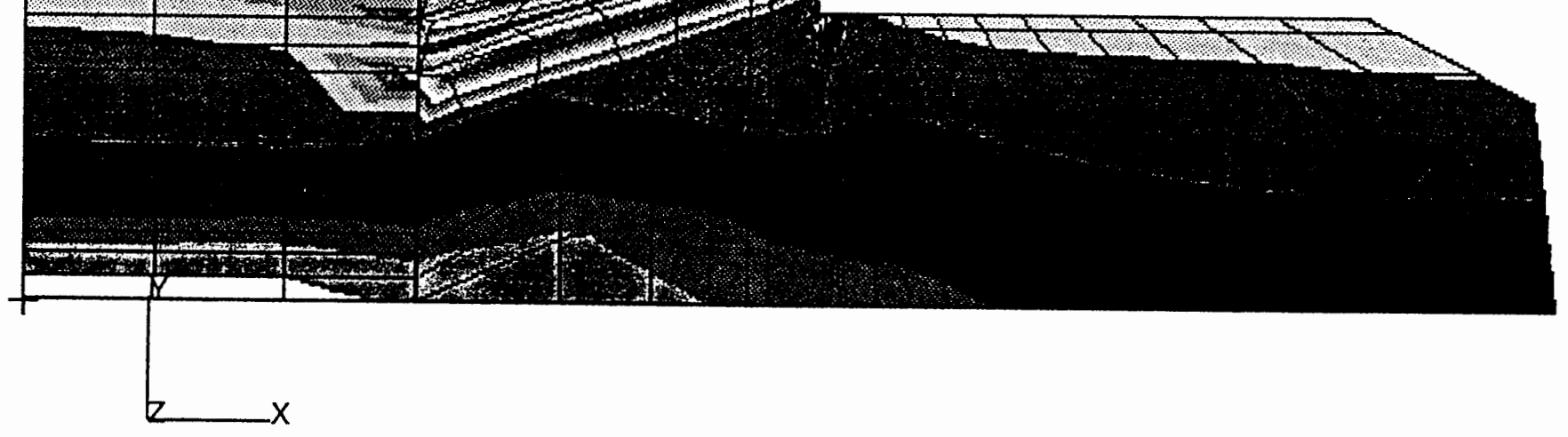

$-2100$

$-2333$

$-2567$

-2800 .

$-3033$

$-3267$.

FIGURE 21: LININ Model step 6

$-3500$. 
Fringe: LC=3.7-RES=1.1-P3/PATRAN R.1-(Tensor-XX)-ABAQUS-05-Mar-94 15:49:49

SWIFT DELTA FINITE ELEMENT MESH

\begin{tabular}{c}
0. \\
-233.3 \\
-466.7 \\
-700.0 \\
-933.3 \\
-1167. \\
-1400. \\
-1633. \\
-1867. \\
-2100. \\
-2333. \\
-2567. \\
-2800. \\
-3033. \\
\hline
\end{tabular}

FIGURE 22: LIN1N Model step 8 


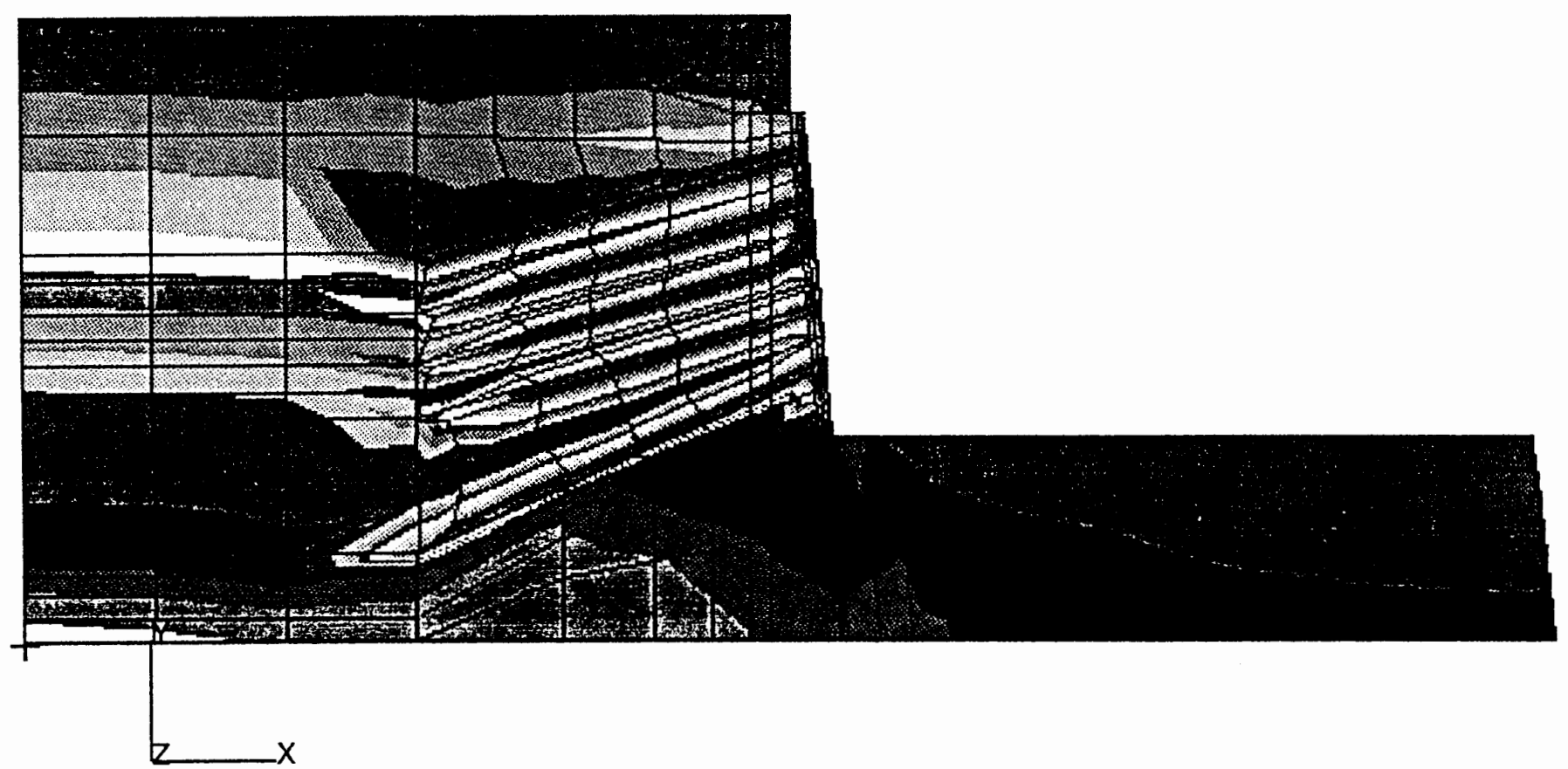




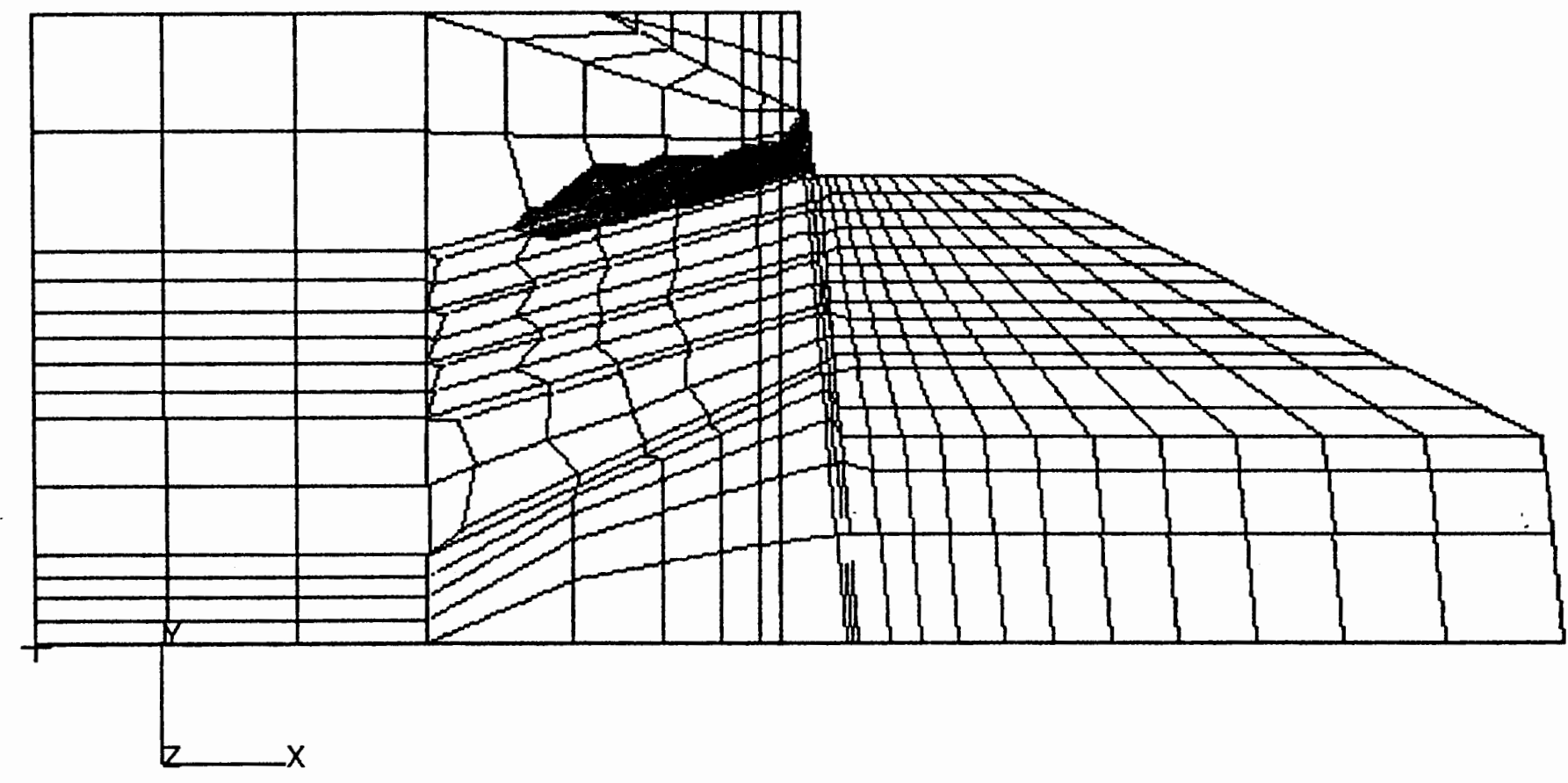




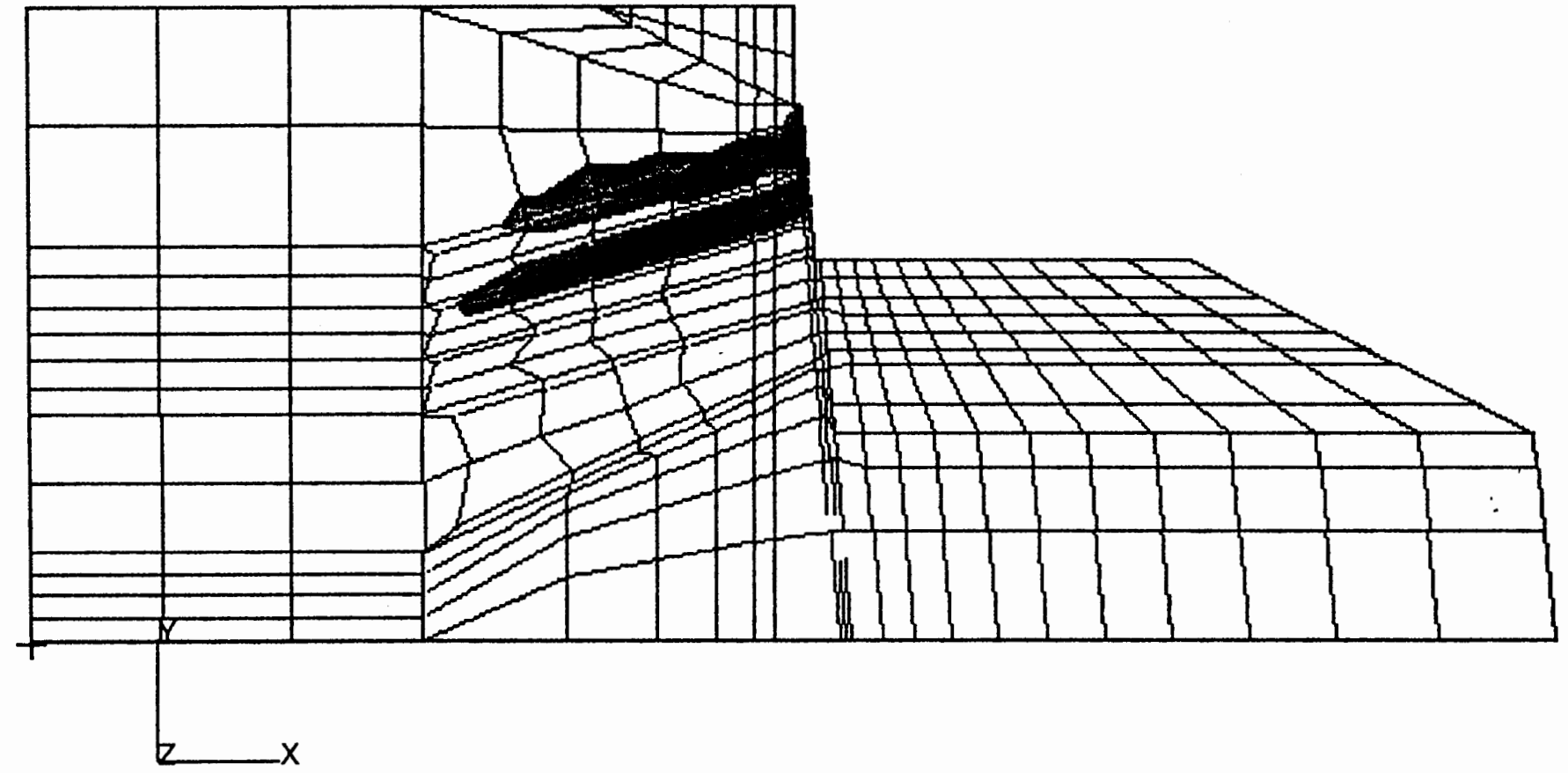

8000

7333.

6667.

6000.

5333

4667.

4000

3333.

2667.

2000.

1333

FIGURE 25: LININ Model Step 4 


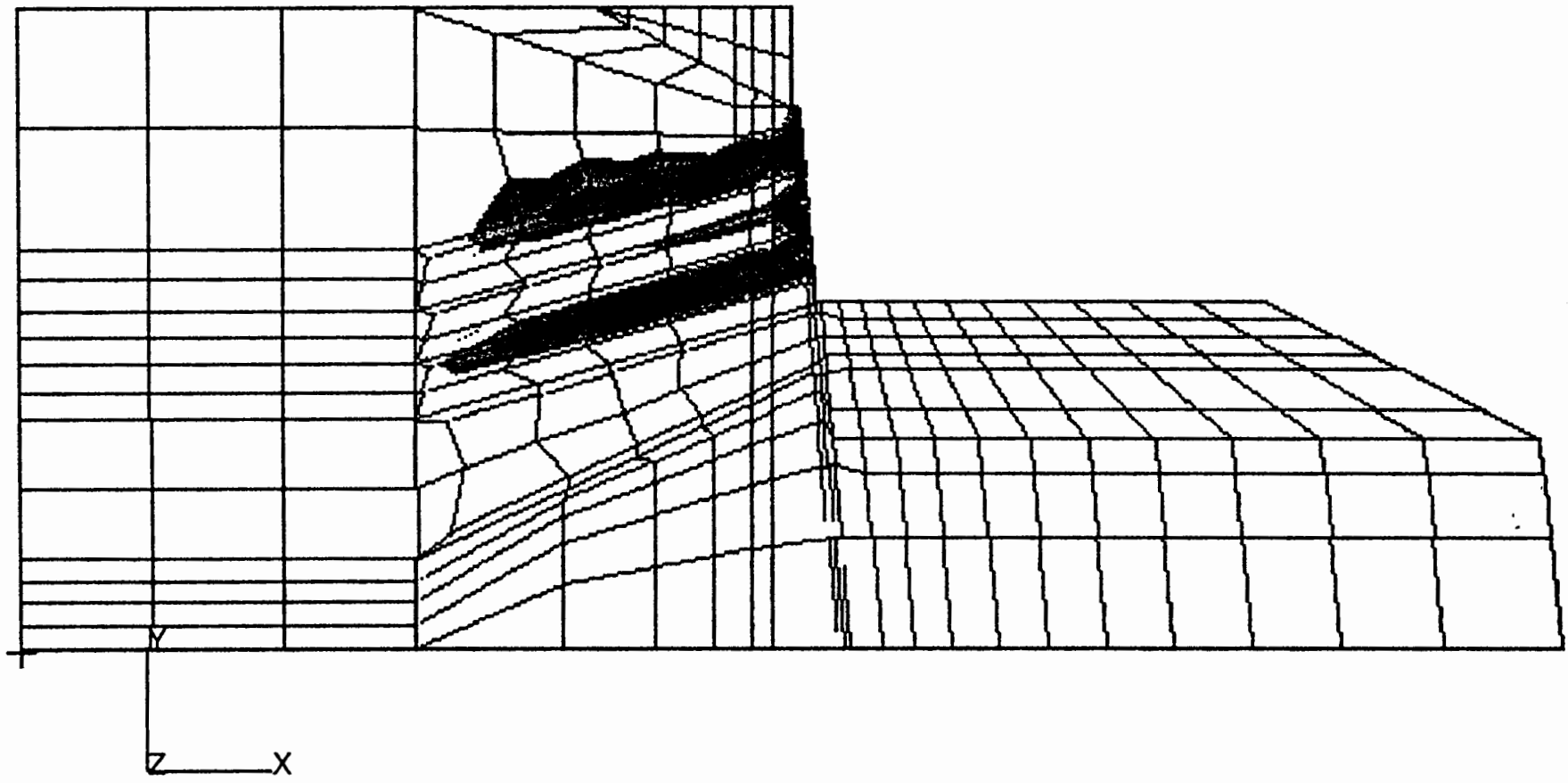

8000

7333.

6667.

6000.

5333

4667.

4000 .

3333.

2667.

2000.

1333.

666.7

FIGURE 26: LIN1N Model step 5 Major Stress 
Fringe: LC=3.5-RES=1.1-P3/PATRAN R.1-(Major)-ABAQUS-05-Mar-94 15:18:11 SWIFT DELTA FINITE ELEMENT MESH

LIN1N MODEL STEP 6

9333.

8667.

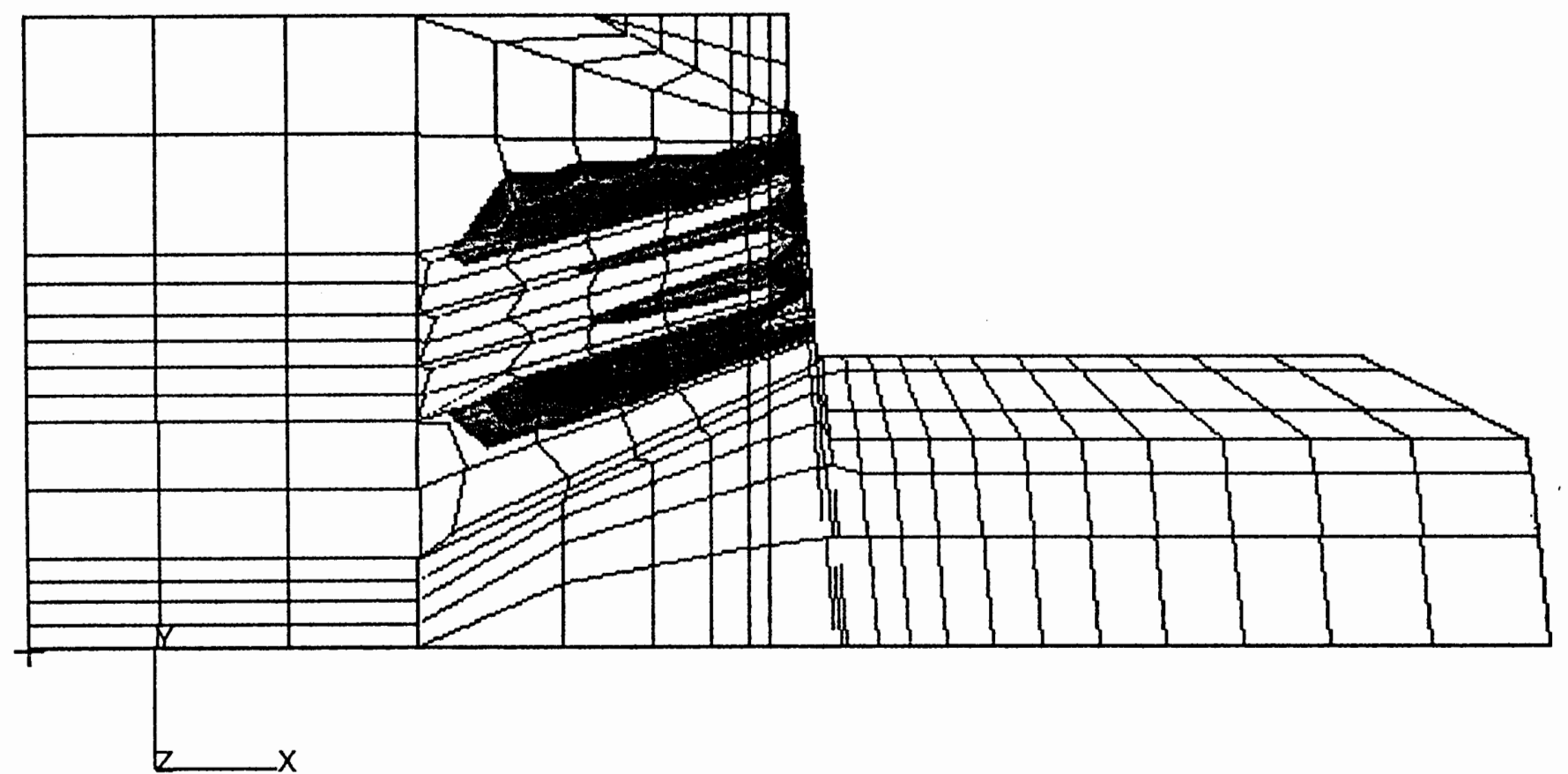

$-8000$.

7333.

6667.

6000.

5333.

4667.

4000.

.3333.

2667.

2000.

1333.

FIGURE 27: Model Step 6 Major Stress 
Fringe: $L C=3.6-R E S=1.1-P 3 / P A T R A N$ R.1-(Major)-ABAQUS-05-Mar-94 15:40:43 SWIFT DELTA FINITE ELEMENT MESH

10000.

LIN1N MODEL STEP 7

9333

8667

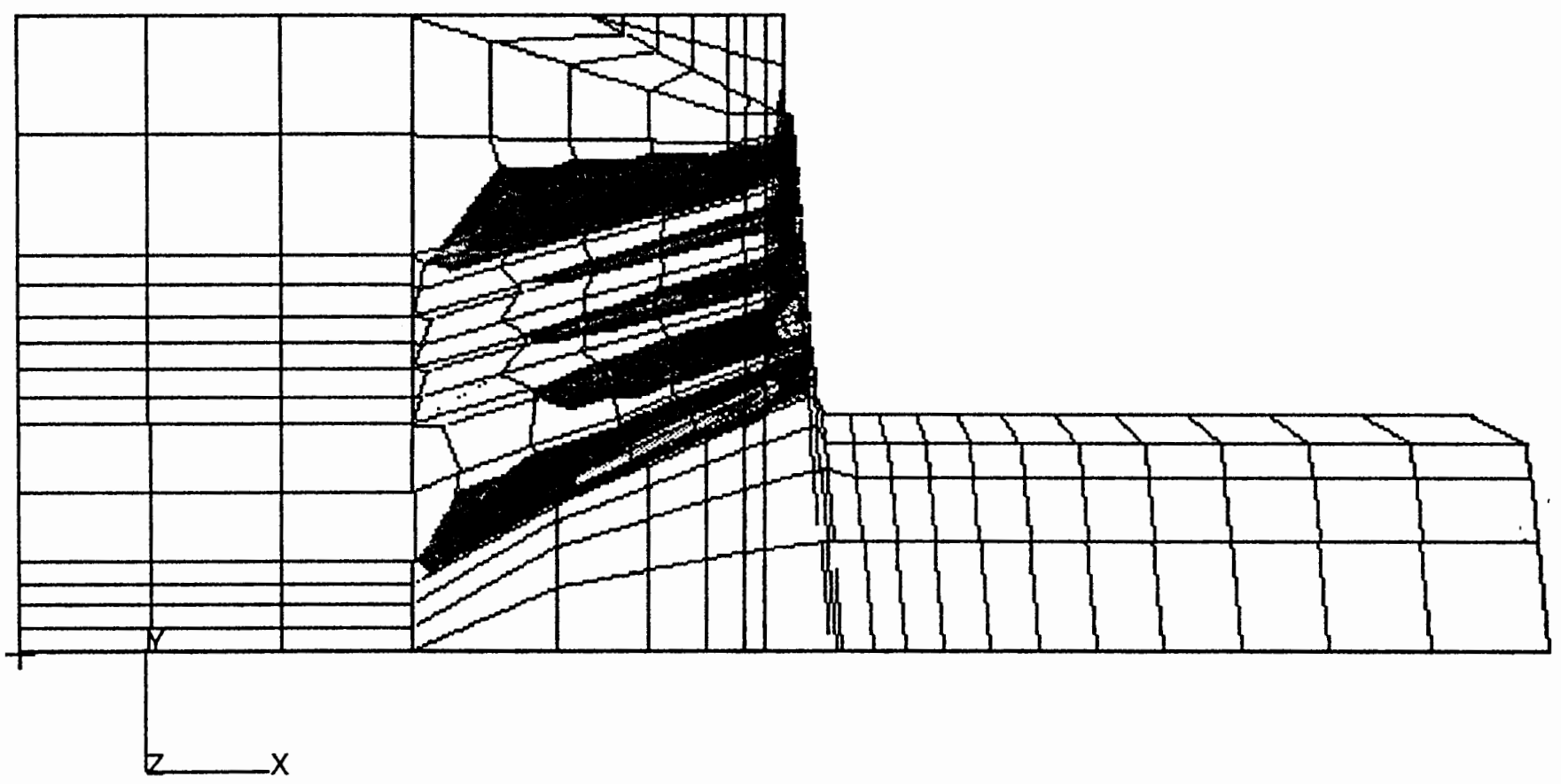

$-8000$

7333.

6667.

6000

5333.

4667.

4000.

3333.

2667.

2000.

1333.

FIGURE 28: LIN1N Model Step 7 Major Stress

666.7 


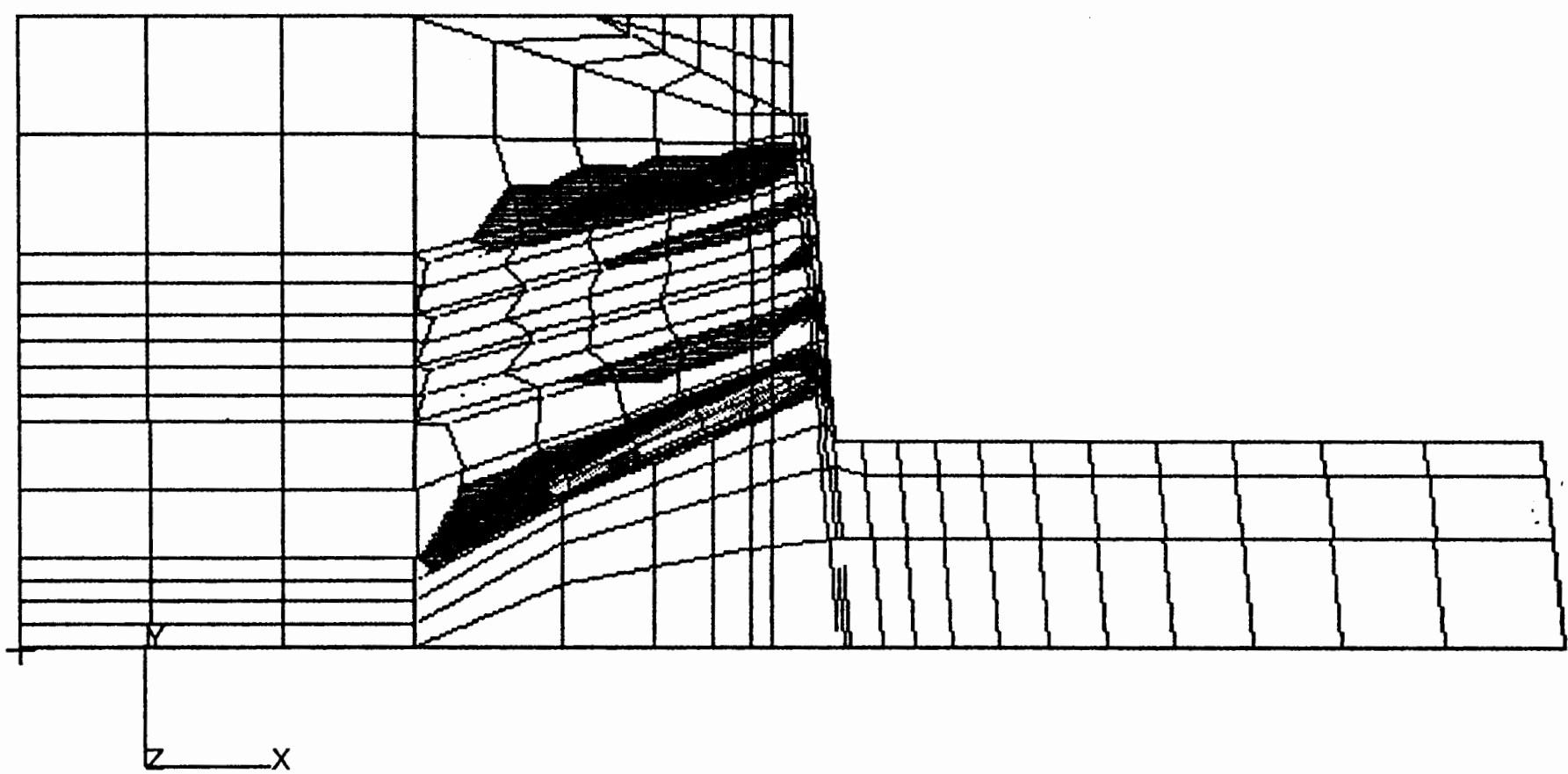

$-8000$.

7333.

6667.

6000.

5333.

4667.

4000 .

3333.

2667.

2000.

1333.

FIGURE 29: NOLIN1N Step 8 Major Stress

666.7 
Fringe: LC=2.8-RES=1.1-P3/PATRAN R.1-(Major)-ABAQUS-18-Mar-94 13:14:24 SWIFT DELTA FINITE ELEMENT MESH

LIN1N MODEL STEP 9

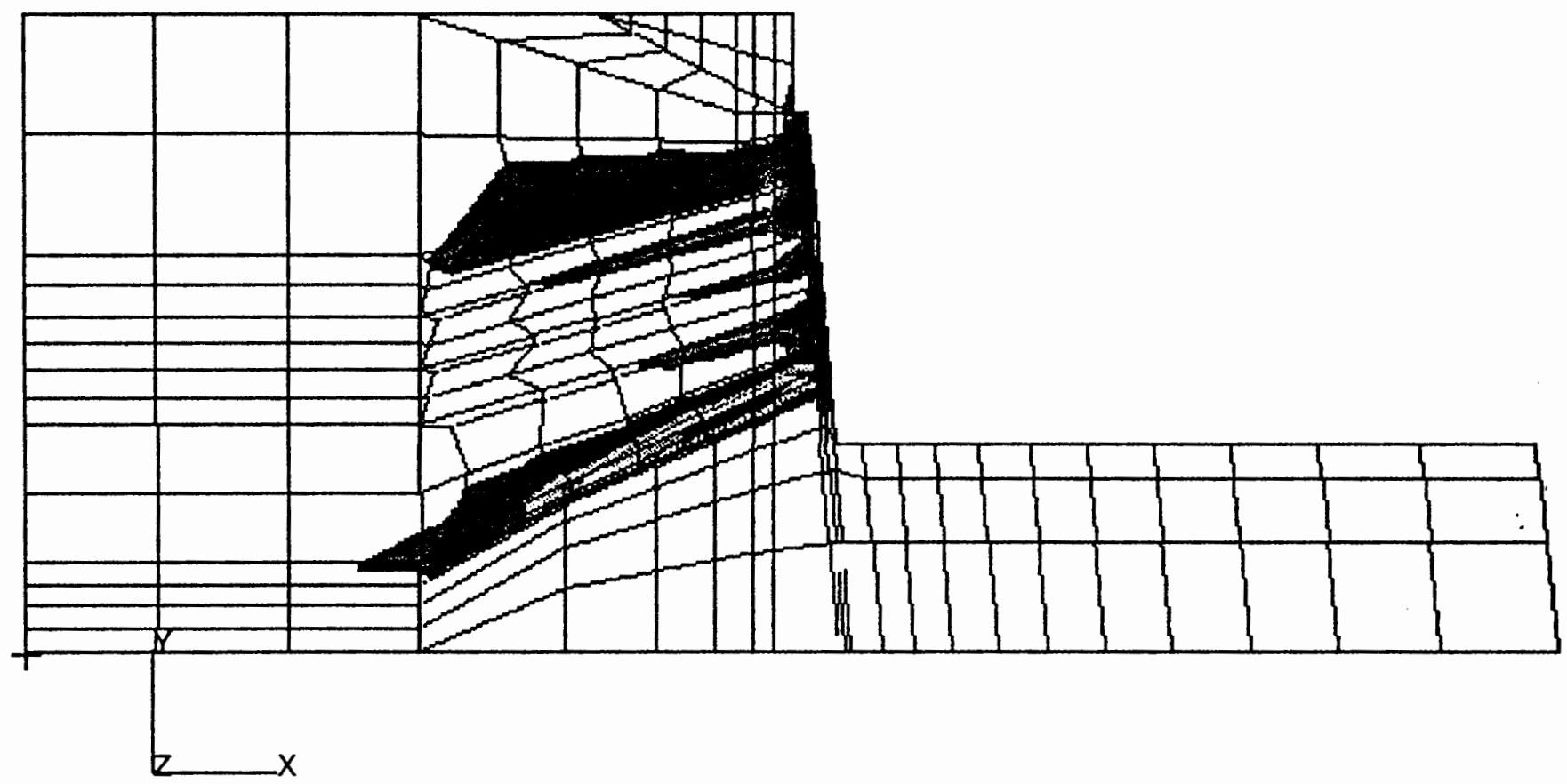

$-8000$.

7333.

6667.

6000

5333.

4667.

4000

3333.

2667.

2000.

1333

FIGURE 30: LIN1N Model step 9 Major Stress

666.7

$-.0001221$ 


\section{NON LINEAR PLANE STRAIN ANALYSIS}

\section{Introduction}

Most engineering construction materials, including soils, initially respond elastically on loading. Elastic behavior implies that when a material is loaded and then unloaded, the deformation is fully recoverable and the materials shape is left un-deformed. If the load exceeds the yield load then deformation will occur. Plasticity theories model a material's mechanical response as it undergoes nonrecoverable deformation in a ductile fashion. Plasticity theories have been developed mostly for metal, but they can also be applied to soils, rock, concrete, ice, and other materials. Metals and soils behave very differently when loaded but the fundamental concepts of plasticity theories are sufficiently general that models based on this concepts have been developed and proven for a wide range of materials. Most of the plasticity models that ABAQUS uses are based on incremental theories, in which the strain is decomposed into an elastic part and inelastic (plastic) part. Plasticity models that do not use the above method are usually called "deformation" based plasticity models, in which stress is defined from the total mechanical strain. Incremental plasticity models are usually formulated in terms of a yield surface, which generalizes the concept of yield load into a test function, which can be used to determine if a material will behave purely elastic at a particular state of stress. A flow rule, 
that defines the inelastic deformation that must occur if the material point is no longer performing purely elastically, and some evolution laws that define the hardening, the way in which the yield and or flow definitions change as inelastic deformation occurs. These models also need an elasticity definition to deal with the recoverable part of strain.

Rate independent, yield behavior does not depend on soil pressure state. Due to the lack of sophisticated soils testing at the Swift Delta site, a complex soil plasticity model is not appropriate. A simple soil model using bilinear material idealization was used. The kinematic hardening model used in ABAQUS was the Prager-Ziegler model. This model gives good results up to about $20 \%$ strain, but does not take into account rate effects or soil pressure state in relation to yield behavior.

The elastic region of the soil model was defined the same way as the purely linear finite element analysis, with an elastic modulus and a Poisons Ratio. The plastic region is defined by the yield stress, hardened stress, and hardened strain ${ }^{8}$.

In the past two decades many formulations of nonlinear soil behavior have been published. The most successful being the hyperbolic soil model proposed by J.M. Duncan, which has 
been incorporated into numerous geotechnical problems ${ }^{9}$. There are many short comings of the classical solution such as the parameters describing the soil behavior being derived from conventional triaxial tests. The hyperbolic, stress-dependent soil model proposed by J.M. Duncan et al utilizes a total of nine parameters to describe stress-strain characteristics of the soil.

\begin{tabular}{|c|c|c|c|c|}
\hline \multicolumn{5}{|c|}{$\begin{array}{c}\text { TABLE V } \\
\text { Model Material Properties }\end{array}$} \\
\hline & $\begin{array}{l}\text { Modulus } \\
\text { (ksf) }\end{array}$ & $\begin{array}{l}\text { Poisons } \\
\text { Ratio }\end{array}$ & $\begin{array}{l}\text { Unit } \\
\text { Weight } \\
\text { (Ibs) }\end{array}$ & \\
\hline $\begin{array}{l}\text { Soil } \\
\text { Layer \#1 }\end{array}$ & 250 & .25 & 105 & \\
\hline $\begin{array}{l}\text { Soil } \\
\text { Layer \#2 }\end{array}$ & 350 & .25 & 105 & \\
\hline $\begin{array}{l}\text { Soil } \\
\text { Layer \#3 }\end{array}$ & 500 & .25 & 105 & \\
\hline Nail & $8.352 \mathrm{E} 5$ & .3 & & \\
\hline
\end{tabular}

${ }^{9}$ Duncan, J.M. ; Byrne, P.; Wong KL.S.; Mabry, P. Strength, Stress-strain and Bulk Modulous Parameters For Finite Element Analyses of stresses and Movements in soil Masses. Geotechnical Engineering. 1980. Department of Civil Engineering, University of California, Berkeley. 


\begin{tabular}{||l|l|l|l|l||}
\hline \multicolumn{5}{|c|}{ Model Material Properties } \\
\hline \hline & $\begin{array}{c}\text { Modulus } \\
\text { (ksf) }\end{array}$ & $\begin{array}{l}\text { Poisons } \\
\text { Ratio }\end{array}$ & $\begin{array}{c}\text { Unit } \\
\text { Weight } \\
\text { (lbs) }\end{array}$ & \\
\hline Shotcrete & $2.16 \mathrm{E} 5$ & .17 & 145 & \\
\hline Concrete & $6.0 \mathrm{E} 5$ & .2 & 155 & \\
\hline Pile & $2.65 \mathrm{E} 4$ & .5 & 200 & \\
\hline
\end{tabular}

The non-linear ABAQUS models were developed by modifying the linear models discussed previously and incorporating the material properties shown in table 4. The modification consisted of replacing the single layer linear elastic soil. properties with a three layer elasto-plastic system. The nonlinear file names are as follows:

nolinln - Instrument section \#1 nails in, pile out. nolinlp - Instrument section \#1 nails in, pile in. nolin2n - Instrument section \#2 nail in, pile out. An example input file nolinlp is located in appendix D. 


\section{RESULTS INTERPRETATION}

\section{Interpretation of Instrument section \#2 Results}

The interpretation of the results consist of PATRAN fringe plots and $x-y$ plots generated in a spread sheet using PATRAN output data results. Instrument section \#2 has the least complicated model and the least number of variables. Because of this detailed discussion of Instrument section \#2 results are presented first:

\section{Horizontal soil stresses}

Horizontal stress fringe plots for models 3,5 , and 8 are shown in Figures 31,32 , and 33 respectively. In comparison to the elastic results, there is only a slight difference in horizontal stresses. The soil stresses within the limits of the nails are somewhat discontinuous.

\section{Vertical soil stresses}

Vertical stress plots for model steps 3,5 , and 8 are shown in Figures 34,35 , and 36 respectively. As with the horizontal stresses, the soil stress within the limits of the nails are somewhat broken up. The vertical stresses behind the nails however, are not discontinuous and are at the same approximate stress as before the nails were introduced. There is considerable stress change in front of the wall facing. As Figure 36 shows for step 8 , the compressive stress is higher 
near the wall face, rapidly dissipating to zero vertical stress, as would be required for the stress level, at the ground surface in front of the wall.

\section{Nail stresses}

Major stress plots for model steps 3, 5, and 8 are presented in Figures 37,38 , and 39 respectively. These plots show the nails being introduced at what appears to be an elevated state of stress. This must be due to a modulus incompatibility that has previously been discussed under plain strain modeling. In Figure 39 model step 8 , the nail stress conforms reasonably well to what would be anticipated, which is to have the highest nail forces at the top of the wall incremental decreasing to the bottom of the wall. This is with the exception of the newly introduced nail 5. Since tension in a row of nails starts only when the lower levels are being excavated.

\section{Deflections}

The soil deflection in front of the wall facing is shown in model step 8 (Figures 41 and 42 ). The plots show that the soil in front of the wall face along the lift excavation boundary heaves up slightly. The heave is on the order of .05 feet for all three lifts plotted. This heave does correlate with the vertical stress changes across the excavation lift , boundary discussed above. 


\section{SWIFT DELTA SOIL NAIL WALL FEM RESULTS}

MODEL NOLIN2N STATIC STEP 3

nolin2n1.fil 
Fringe: $L C=2.14-R E S=1.1-P 3 / P A T R A N$ R.1-(Tensor-XX)-ABAQUS-31-Aug-94 13:36:13

Horiz Stress

(psf)

\section{SWIFT DELTA SOIL NAIL WALL FEM RESULTS}

MODEL NOLIN2N STATIC STEP 5

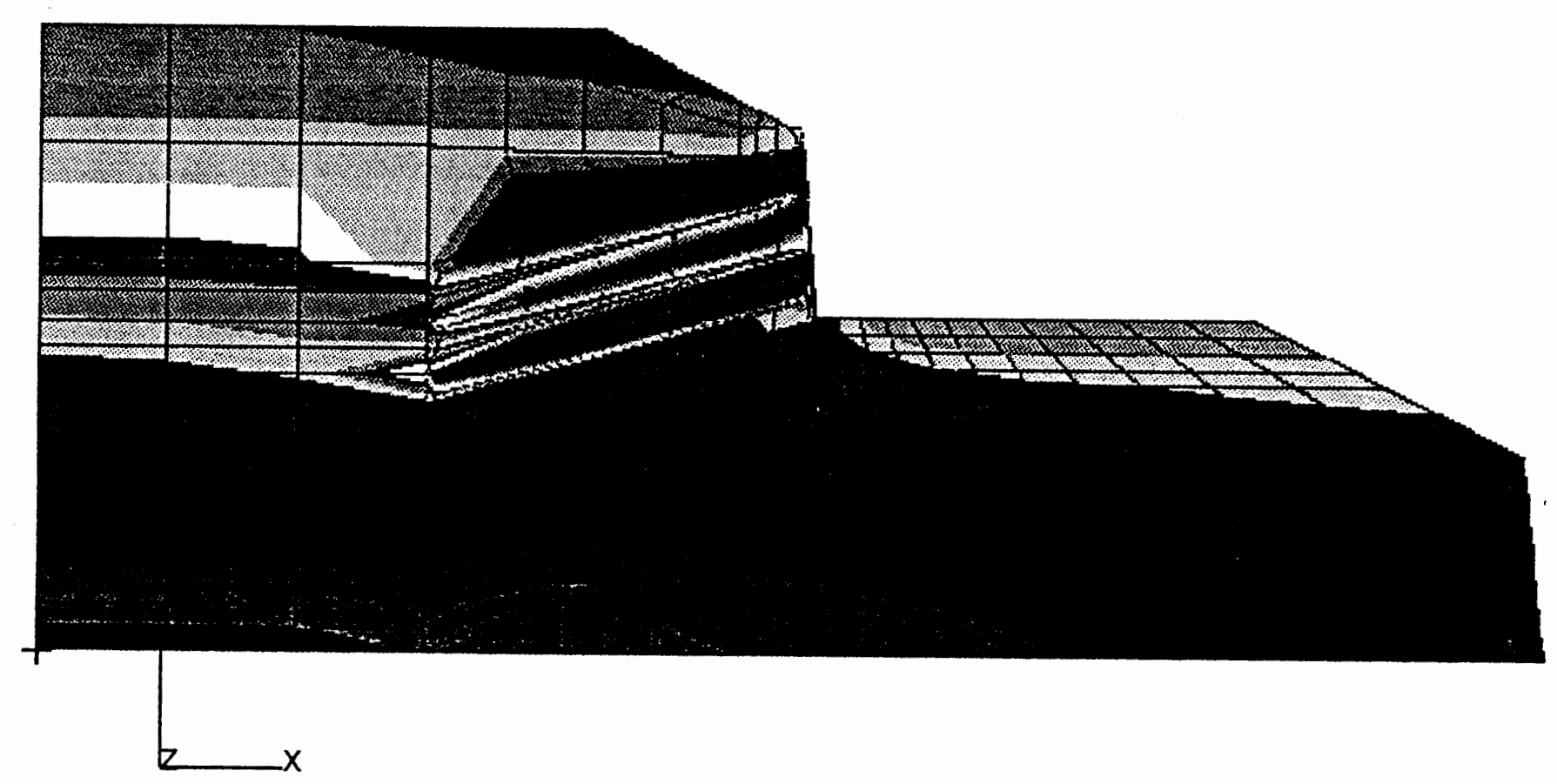

FIGURE 32: Model NOLIN2N static step 5 Horiz. Stress.
$-233.3$

$-466.7$

$-700.0$

$-933.3$

$-1167$

-1400 .

$-1633$.

$-1867$.

$-2100$.

$-2333$.

$-2567$.

$-2800$.

-3033 .

$-3267$.

-3500 . 
Fringe: LC=2.17-RES=1.1-P3/PATRAN R.1-(Tensor-XX)-ABAQUS-23-Jul-94 16:30:49

\section{SWIFT DELTA SOIL NAIL WALL FEM RESULTS} MODEL NOLIN2N STATIC STEP 8

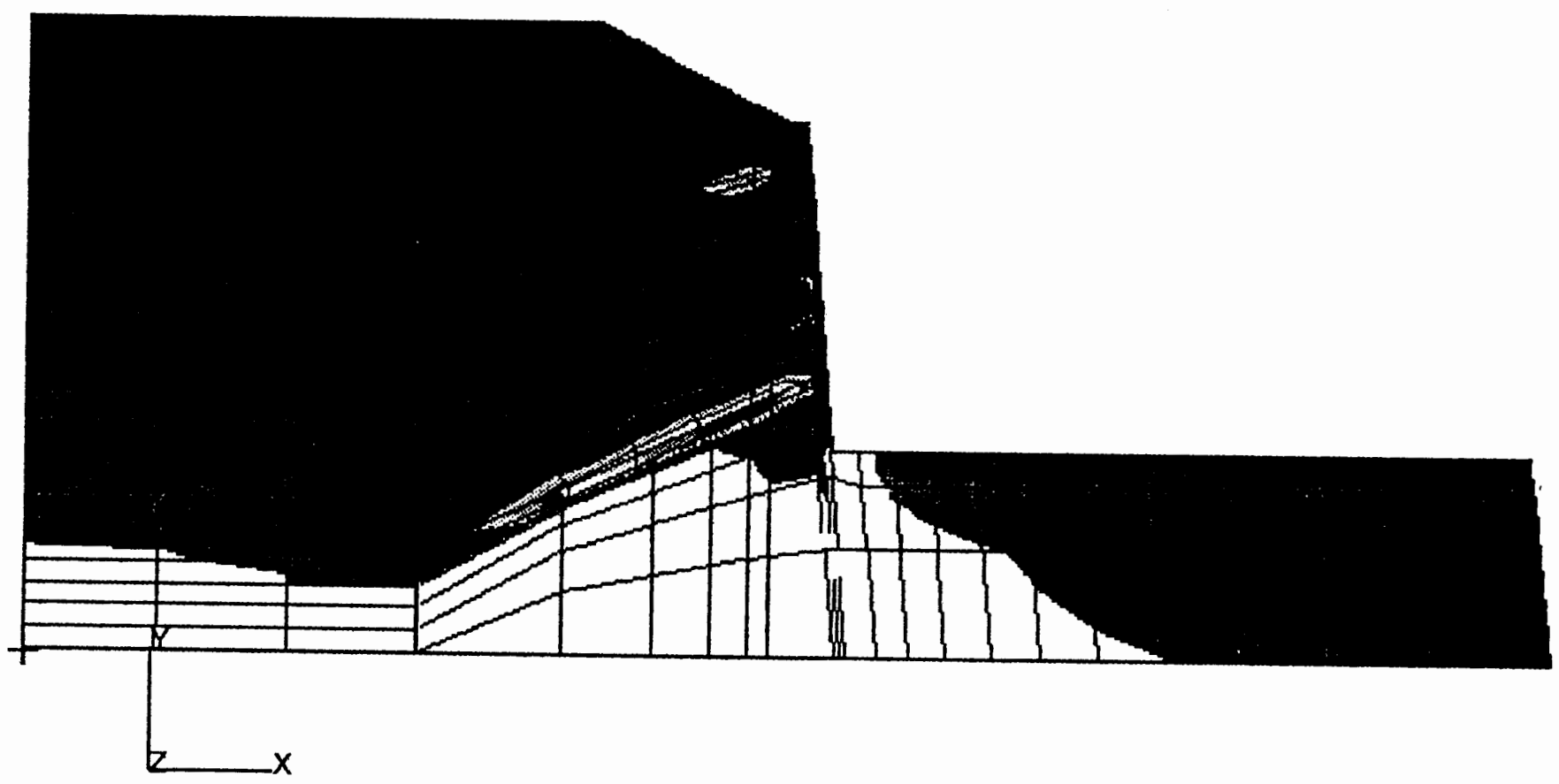

6710

5873

5036.

4199.

3362.

2525.

1688.

850.5

13.44

$-823.6$

$-1661$.

$-2498$.

nolin2n1.fil

FIGURE 33: Model NOLIN2N static step 8 Horiz. Stress 


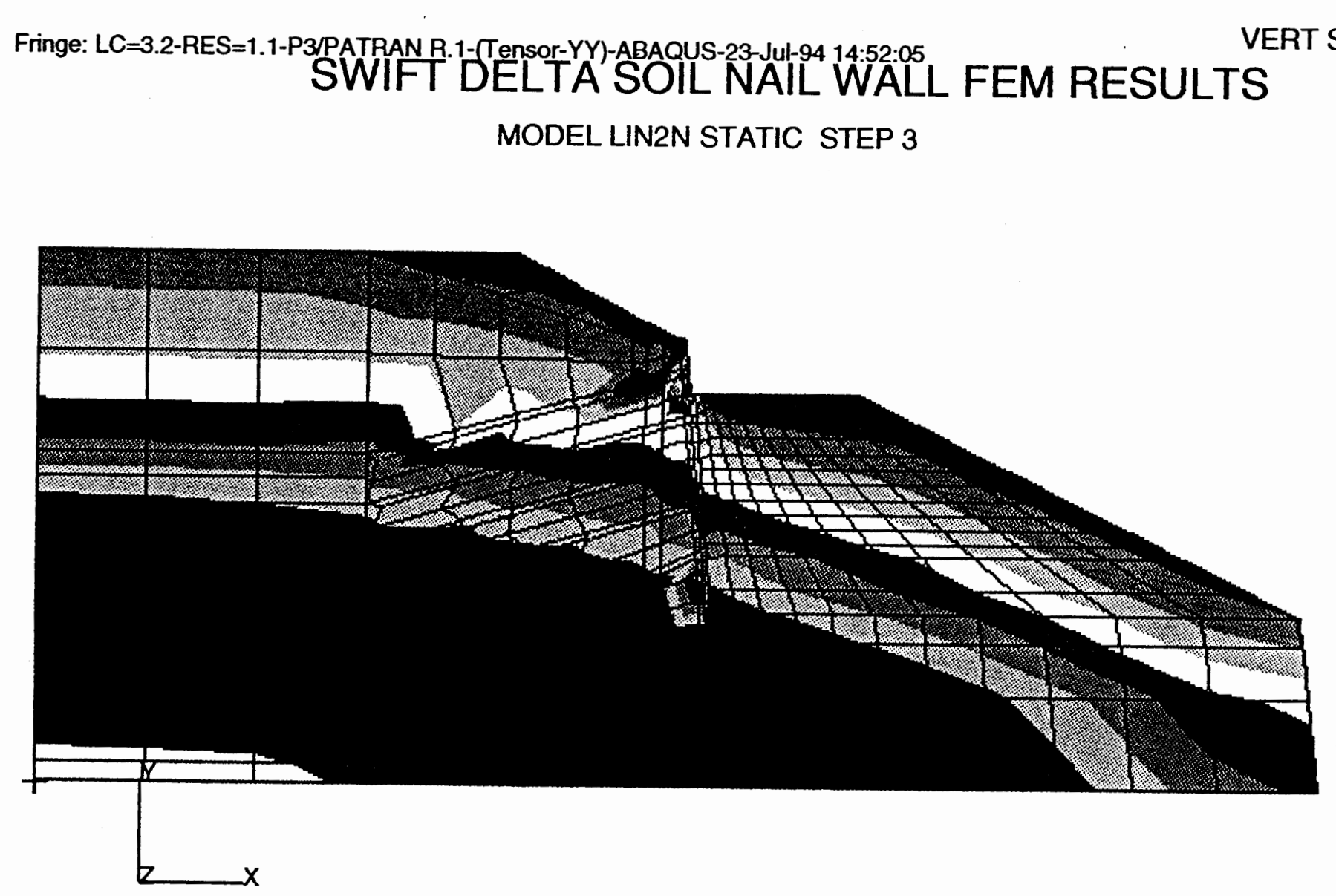

\begin{tabular}{c} 
TRESS \\
0. \\
-233.3 \\
-466.7 \\
-700.0 \\
-933.3 \\
-1167. \\
-1400. \\
-1633. \\
-1867. \\
-2100. \\
-2333. \\
-2567. \\
-2800. \\
-3033. \\
-3500. \\
\hline
\end{tabular}

$\operatorname{lin} 2 n 1 . f i l$

FIGURE 34: Model LIN2N Static step 3 Vert. Stress 
Fringe: $L C=2.14-R E S=1.1-P 3 / P A T R A N$ R.1-(Tensor-YY)-ABAQUS-31-Aug-94 13:41:12

Vert Stress

SWIFT DELTA SOIL NAIL WALL FEM RESULTS

(psf)

0.

MODEL NOLIN2N STATIC STEP 5

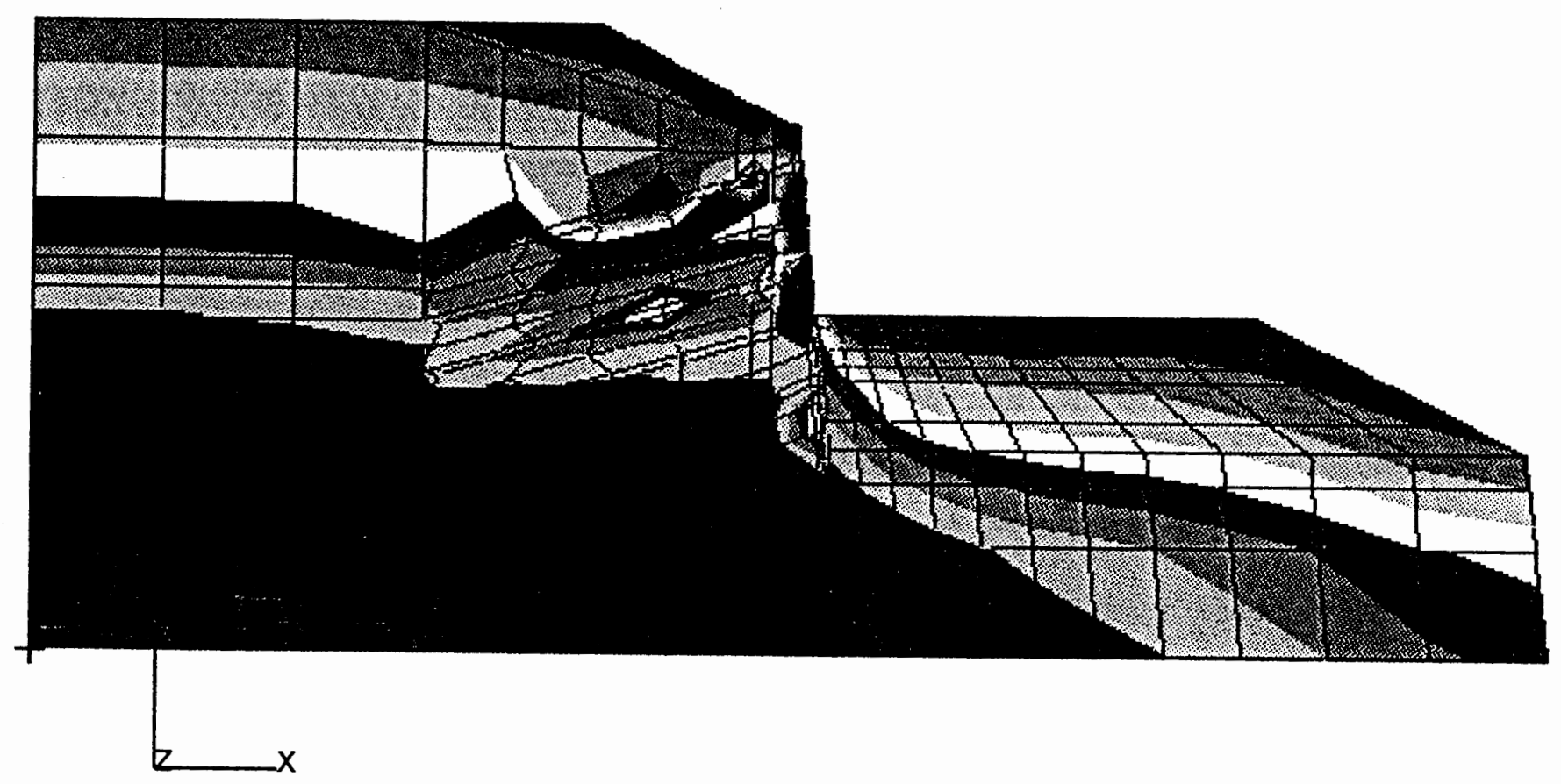

$-233.3$

$-466.7$

$-700.0$

$-933.3$

$-1167$.

-1400 .

$-1633$.

$-1867$.

$-2100$

$-2333$.

$-2567$

$-2800$

$-3033$.

-3267 .

FIGURE 35: Model NoLIN2N static step 5 vert. Stress 
Fringe: LC=3.7-RES=1.1-P3/PATRAN A.1-(Tensor-YY)-ABAOUS-23-Jut-94 13:43:55
SWIFT DELTA SOIL NAIL WALL FEM RESULTS

VERT STRESS

\section{MODEL LIN2N STATIC STEP 8}

$-233.3$

$-466.7$

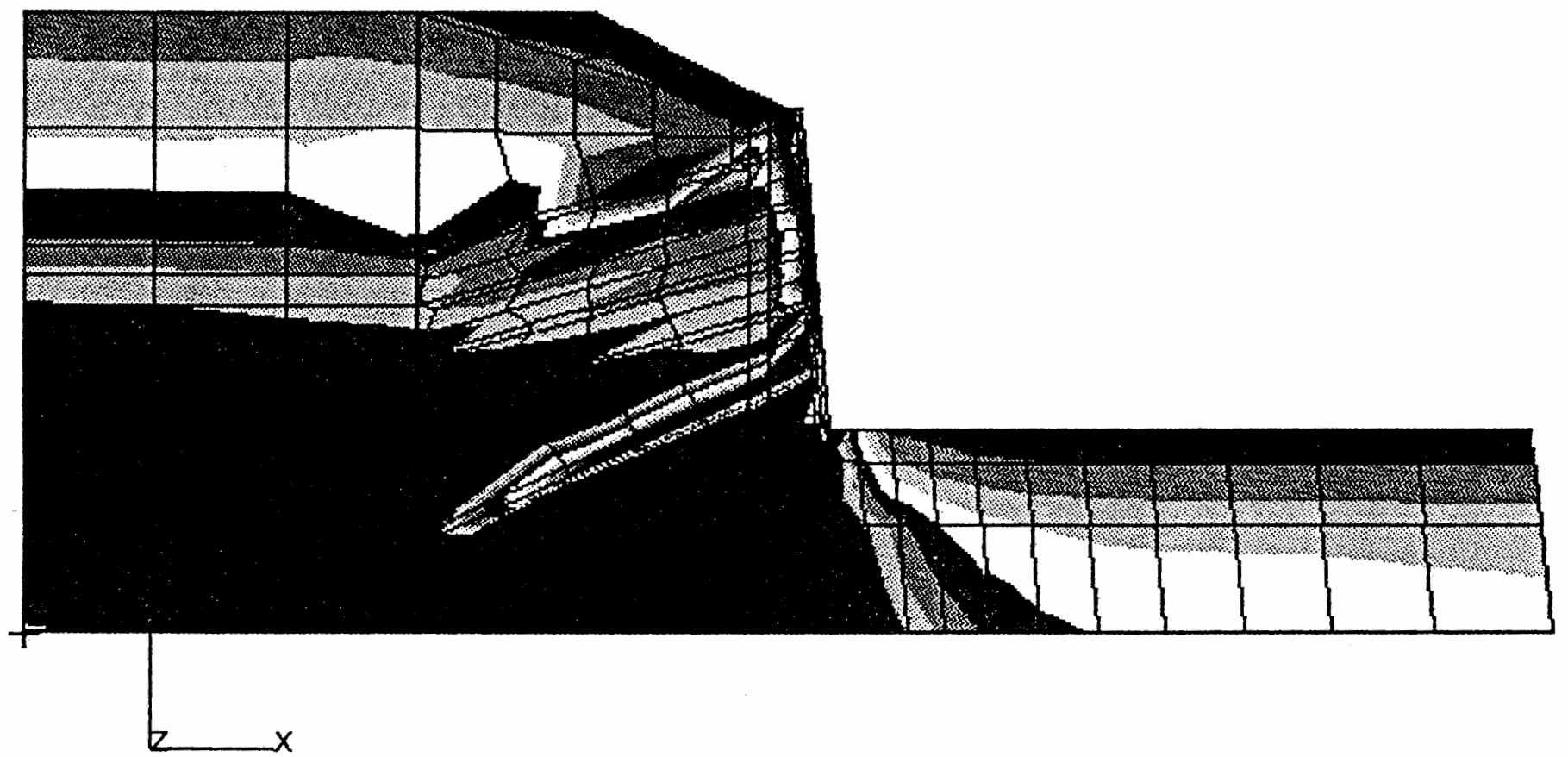

$-700.0$

$-933.3$

$-1167$.

-1400 .

$-1633$.

$-1867$.

-2100 .

$-2333$.

$-2567$.

$-2800$.

$-3033$.

$-3267$.

$\operatorname{lin} 2 n 1 . f i l$

FIGURE 36: Model NOLIN2N static step 8 .Vert. Stress

-3500 . 
Fringe: $L C=2.12-$ RES=1.1-P3/PATRAN R.1-(Major)-ABAQUS-31-Aug-94 13:32:27

Major Stress

(psf) 10000 .

\section{SWIFT DELTA SOIL NAIL WALL FEM RESULTS} MODEL NOLIN2N STATIC STEP 3

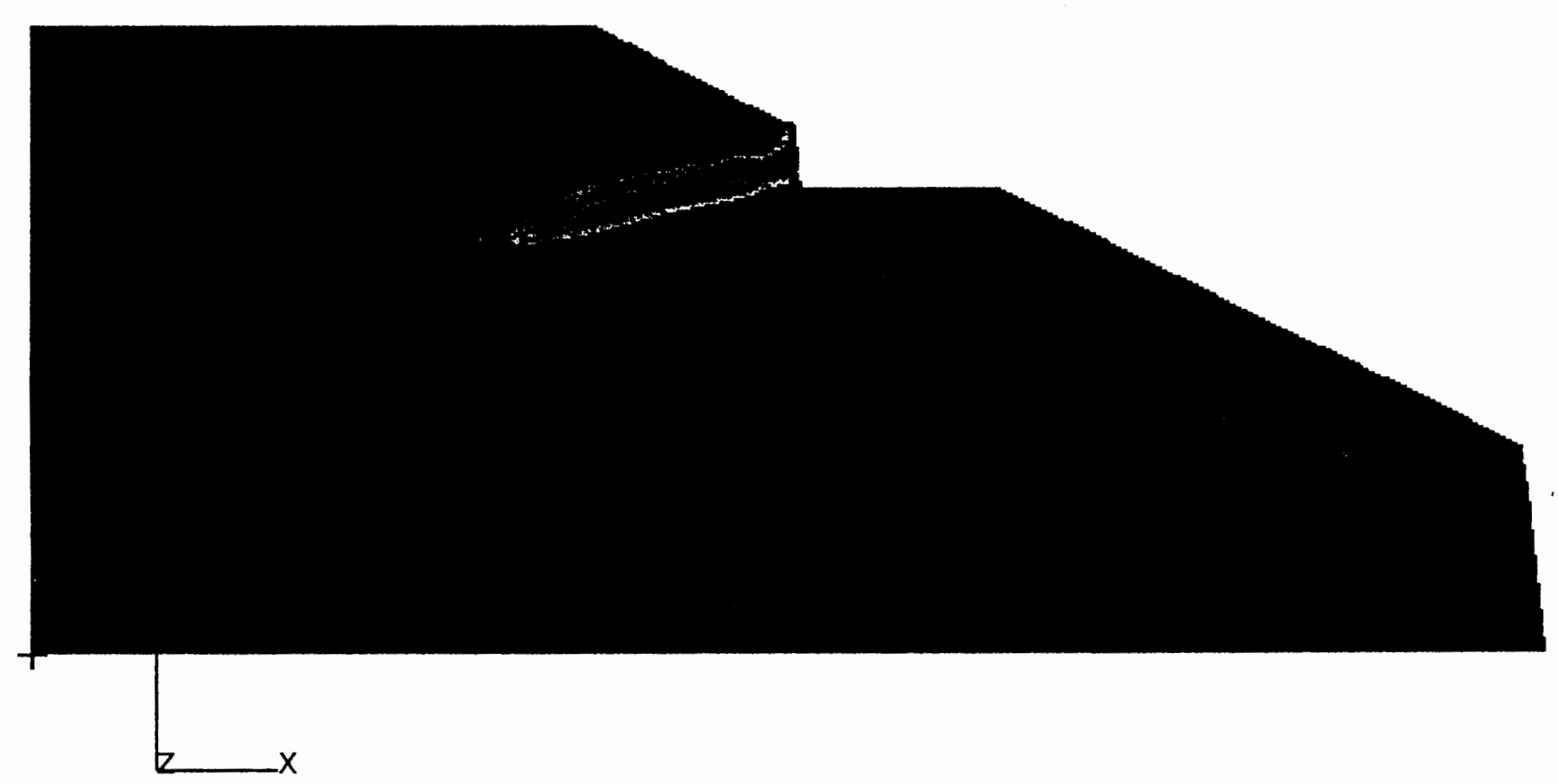

FIGURE 37: Model NOLIN2N Static step 3 Major stress
9333

8667

$-8000$.

7333.

6667.

6000

5333.

4667.

4000 .

3333

2667.

2000

1333.

666.7

$-.0001221$ 


\section{SWIFT DELTA SOIL NAIL WALL FEM RESULTS}

MODEL NOLIN2N STATIC STEP 5

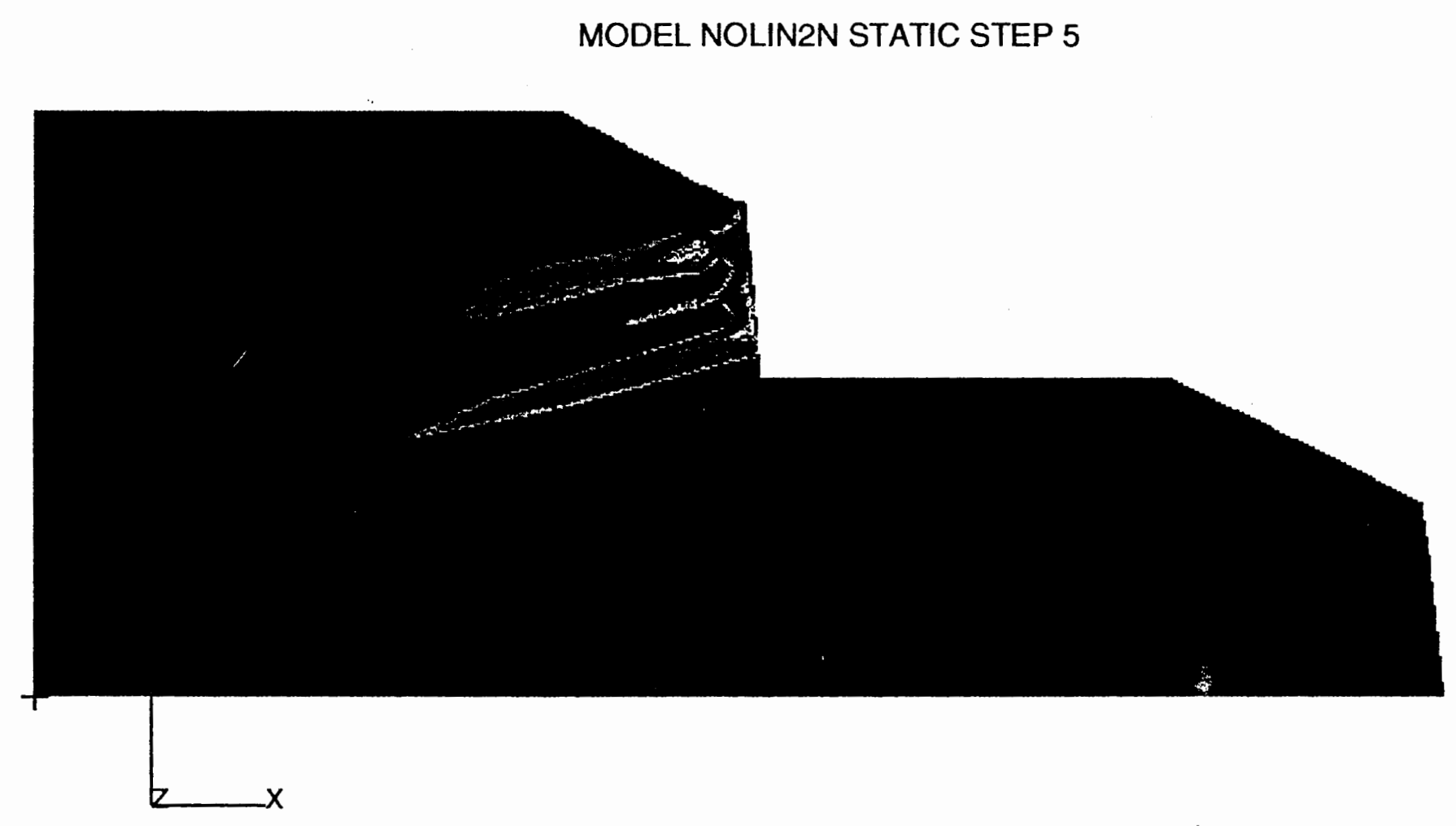

(psf) 10000 .

9333.

8667

8000

7333.

6667.

6000

5333

4667.

4000 .

3333.

2667.

2000.

1333.

666.7

FIGURE 38: Model NOLIN2N Static step 5 Major stress

$-.0001221$

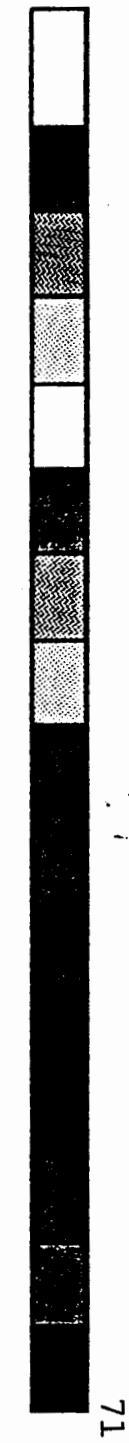


Fringe: LC=3.7-RES=1.1-P3/PATRAN R.1-(Major)-ABAQUS-12-Oct-94 18:33:29

SWIFT DELTA SOIL NAIL WALL FEM RESULTS

Major Stress

MODEL NOLIN1N STATIC STEP 8

(psf)

10000.

9333

8667

8000

7333.

6667.

6000

5333.

4667.

4000

3333

2667

2000

1333.

nolin1n2.fil

666.7

FIGURE 39: Model NOLIN2N Static step 8 Major Stress

$-.0001221$ 
SWIFT DELTA SOIL NAIL WALL FEM RESULTS

.001308 MODEL NOLIN2N STATIC STEP 8

.001061

.0008126

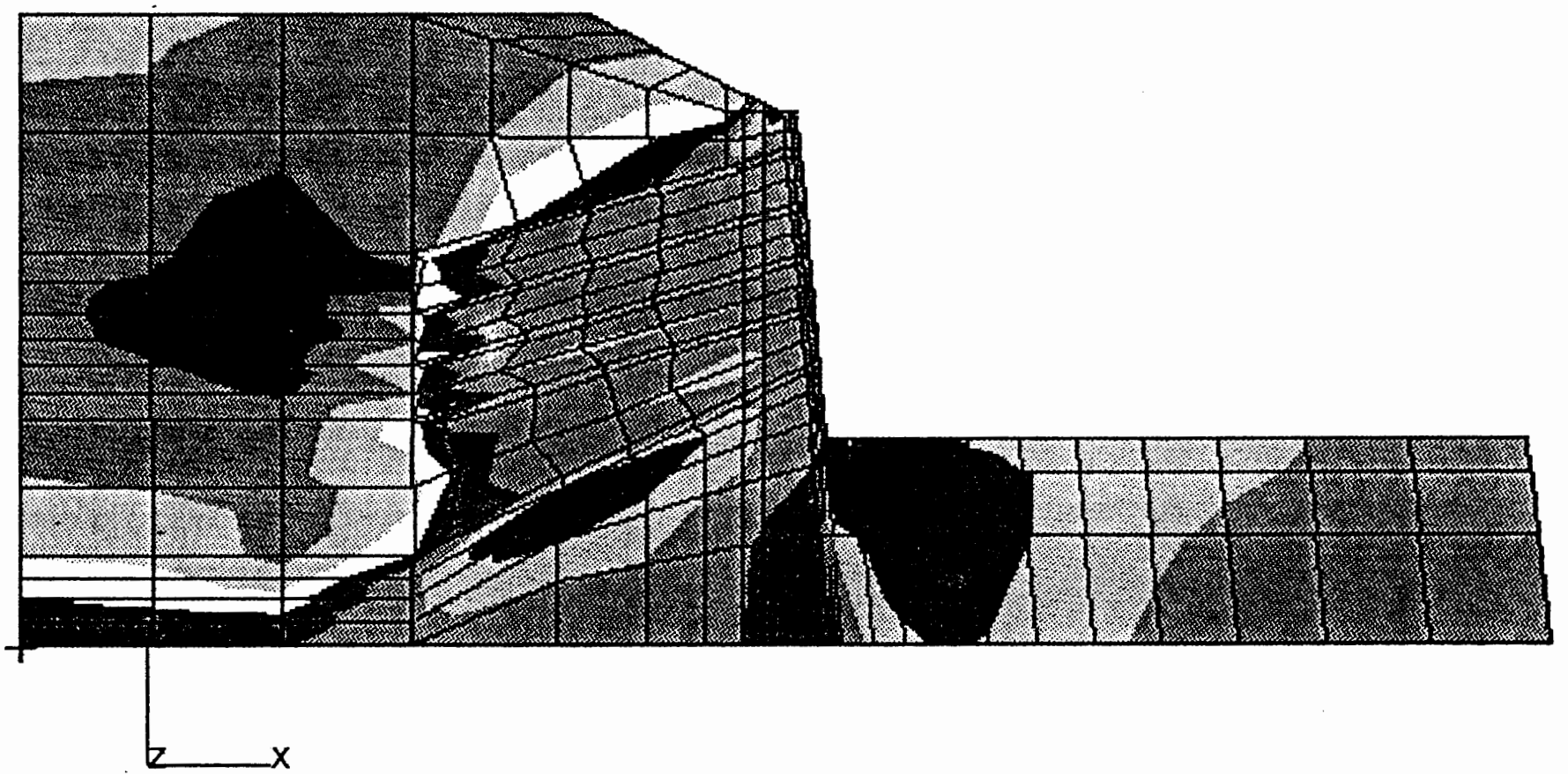

.0005647

.0003168

.00006884

$-.0001791$

$-.0004270$

$-.0006749$

$-.0009229$

$-.001171$

$-.001419$

$-.001667$

$-.001915$

$-.002163$

nolin2n1.fil

FIGURE 40: Model NOLIN2N static step 8 Horiz. Strain

$-.002410$ 
Fringe: LC=2.17-RES=4.1-P3/PATRAN R.1-(Vector-Y)-ABAQUS-23-Jul-94 17:06:55

VERT DISP

SWIFT DELTA SOIL NAIL WALL FEM RESULTS

MODEL NOLIN2N STATIC STEP 8

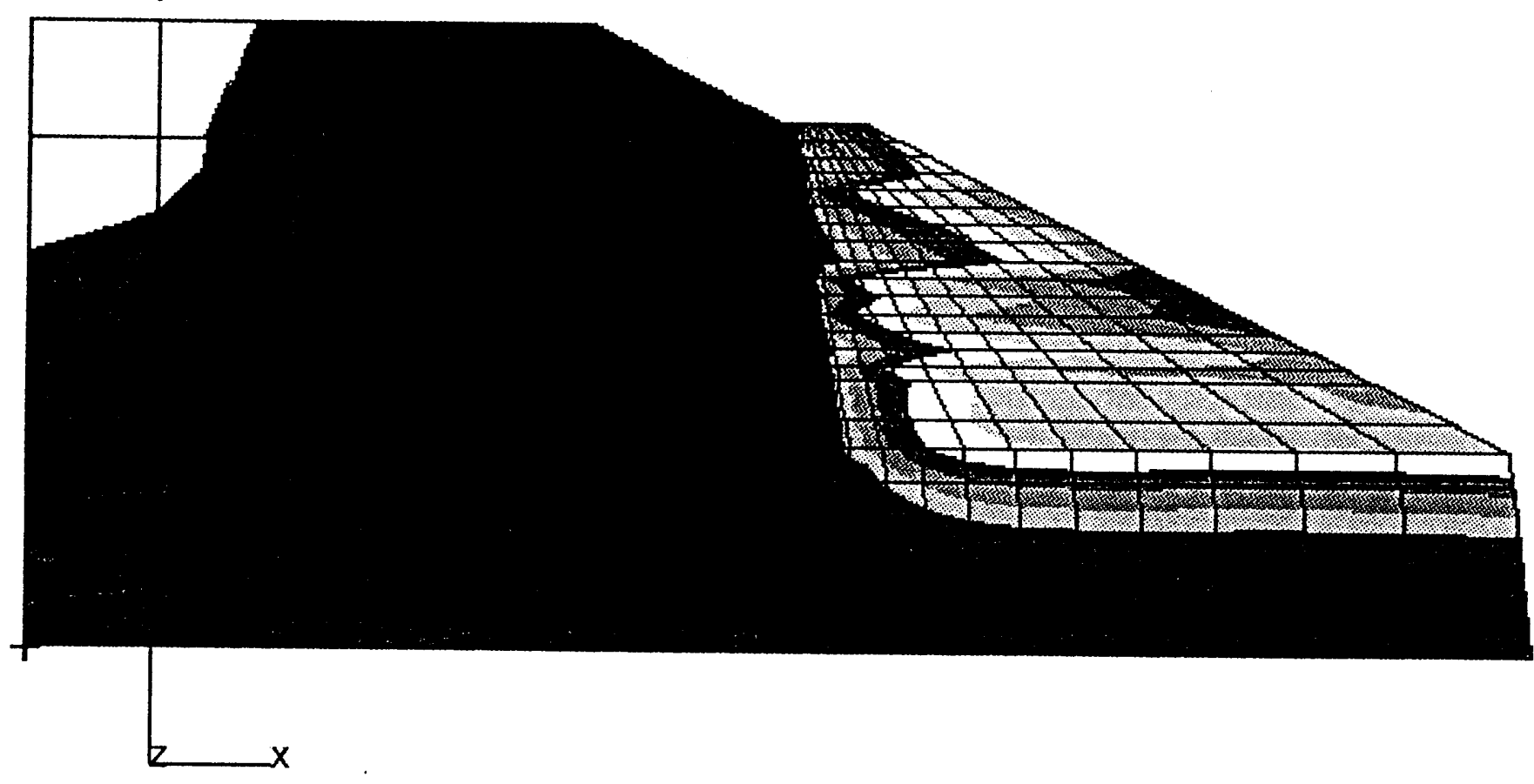

.04994

.04547

.04099

.03651

.03203

.02756

.02308

.01860

.01412

.009645

.005167

.0006895

$-.003788$

nolin2n1.fil

FIGURE 41: Model NOLIN2N Static step 8 Vert. Disp.

$-.008266$ 


\section{Section \#1 Results}

This report attempts the difficult task of solving a three dimensional problem in two dimensions. Two separate models were developed one with piles and nails present (nolinlp) and the other with just the nails present (nolinln). The bridge pile was inserted into the nolinlp model immediately after the geostatic turn on was completed. This put the pile in the model in a un-stressed state and the piles own self weight stresses are not accounted for. Because of this it is important to realize when analyzing the fringe plots for the nolinlp and nolinln models that the nolinlp model has an additional step and the same two model steps will not correspond with the same excavation lifts. The following sections presents the data for the two models simultaneously and discusses the results in detail:

\section{Horizontal Soil stress}

The horizontal stress fields for the two instrument section \#1 models appear to be identical. Figures 43 through 48 present the patran horizontal stress fringe plot results for nolinin and nolinlp model steps 3, 5, and 8. The stress plots show a very reasonable geostatic stress field at locations away from the nail inclusions and clearly show the presence of the nails as tensile elements. 


\section{Vertical stresses}

The nolinlp fringe plot (Figure 49) clearly shows that the piling was introduced at a zero stress state. In addition there is some vertical stress imbalance in the pile at the elevation of the bottom of the excavation lift. This vertical stress imbalance is a sign that bending stresses are being generated as a result of the excavation. Figures 50 and 51 show that new pile stresses are not introduced during excavation lifts two and three. After excavation lift four ( Figure 52) some minor stress changes in the pile can be seen above nail three. Again after excavation lift five, changes in pile vertical stress can be seen (Figure 53). At the location were nail three intersects the pile continued minor bending stresses have been developed. For reference nolinin fringe plots are shown in Figure 3, 5, and 8 (Figures 54 through 56). These plots show vertical stress fields that are consistent with the nolin2n plots and appear reasonable.

\section{Nail Stresses}

As discussed previously the nails in the first excavation lift of nolinin and nolinlp appear to be introduced at a stress level higher than the actual (Figures 57 and 58 respectively). The major stress fringe plot for step 3 of the nolinin model (Figure 57) also shows much higher tensile stresses in the wall face (maximum 5,333 psf) than the corresponding maximum tensile stress of 1,333 psf for the nolinlp model (Figure 58). 
It is important to note that the peak stresses for the nolinin model are present at the back of the shotcrete wall face were as the peak stresses for the nolinlp model are directly behind the piling. This is because the nail and the pile are tied together in the nolinlp model. Although this is not geometrically correct it could be an approach to modeling arching effects between the existing piling, nails, and shotcrete face. Excavation step four shows a considerable reduction in nail stress for nails three through four in the nolinlp model (Figure 59) as compared with the nolinln model (Figure 60). Closer inspection of figures 59 and 60 reveal that there maybe significant pile nail interaction. This is based on the fact that the nolinlp models stress is distributed down a much shorter length of the nail than the nolinln model. Logically if the pile had no nail interaction effect in the nolinlp model than the nail stresses would be the same as the nolinln model and shifted to the back of the nail a distance equal to the pile diameter. This phenomenon is also apparent in the last excavation lift (Figures 61 and 62 ) but not as pronounced as in the previous excavation lift. The effect maybe some what masked in the last excavation lift, because a large overall stress redistribution takes place in the existing nails due to the large lift height and the steeper angle of the last nail. 


\section{Pile stresses}

Most fringe plots were scaled in major stress from 0 to 1500 psf (tension), for clarity other ranges were also used. Figure 63 illustrates the true zero stress state that the pile was installed under. After the first excavation lift ( Figure 64) shows the pile under going a stress change from zero stress to one that is tensile. This appears to be a result of the excavation unloading. The stress change is not completely uniform and it is certain that some minor bending stresses are introduced. Figure 65 further confirms that tensile major stresses are induced in the pile as the excavation sequence advances. Unfortunately it is very difficult to determine true bending stresses. With this model it is only safe to say that some bending stresses are being developed.

\section{Deflections}

The same heaving of the excavation lift base has been identified for both the nolinln and the nolinlp models as was seen in the nolin2n model. The horizontal and vertical node deflections for excavation lift 6 is identical for all three models. An $x-y$ plot of those displacements is presented in Figure 66. This is reasonable since for the most part the three models have identical conditions in front of the wall face. 
Again the deflections correspond well with the vertical stress fields in front of the wall as can be seen in Figure 56.

Figure 67 and 68 are $x-y$ plots of the shotcrete wall facing deflection profiles for the nolinln and nolinlp models respectively. Both models show reasonable deflection of the wall face with the maximum being at the top. The wall face deflection are in proportion to the size of the excavation lifts, which can be seen between excavation lifts one and two. There is not a major contrast between the deflections for the nolinln and nolinlp model and interestingly the nolinlp model shows slightly more deflection $(.033 \mathrm{ft})$ than the nolinin model $(.031 \mathrm{ft})$.

Figure 69 is a horizontal displacement fringe plot for the nolinlp model after the insertion of the fifth nail (model step 8). This plot clearly shows that the pile deflection is in direct proportion to wall face deflection. Therefore the pile cap translates the full $.033 \mathrm{ft}$ that the wall face did at the end of excavation lift 6 . This supports the fact that some bending stresses were identified in early sections of this report. For assistance in visualizing the pile bending see figure 70 an exaggerated deformed mesh plot for the nolinlp model. 
COMPARISON BETWEEN FEM RESULTS AND INSTRUMENT

\section{MEASUREMENTS}

The following section identifies the similarities and discrepancies with the instrument data collected at the swift Delta wall.

\section{Deflections}

The field measurement data that will be used for comparison is the single point pile cap extensometer located at Approx UV Station $128+00$ and the slope inclinometers SI 129 and SI 130 located at UV Stations $131+25$ and $130+62$ respectively. It is important to note that SI 130 was a replacement inclinometer for one that was destroyed during construction. Therefore it does not cover full wall construction.

When interpreting soil nail wall deflection data it is important to recall the following factors that effect wall displacement:

Rate of construction

Height of excavation phases and spacing between nails Extensibility of nails

Global safety factor of the wall

$\mathrm{L} / \mathrm{H}$ ratio

Inclination of the nails and, in this case, their bending stiffness 
Bearing capacity of the foundation soils ${ }^{10}$

The nolin2n and nolinln wall face displacements are identical. apparently the removal of the concrete pile cap was an even exchange of overburden pressure for the $2 \mathrm{H}: 1 \mathrm{~V}$ soil slope. This gives some validation to the nolinin model as being a control section without the influence of the bridge pile to the nolinlp model. Modeled wall displacements were slightly less than those predicted by the h/1000 - 4h/1000 rule of thumb however exceptionally good agreement was obtained between the single point extensometer (max deflection= .32 inches from figure 7) and the ABAQUS models (max deflection= .4 inches from figure 68). The two slope inclinometers recorded higher deflections than those of the abaqus model and the extensometer. SI 130 had a maximum deflection of approximately .7 inches (Figure 9) and SI 129 had a maximum deflection of approximately .5 inches (Figure 8). The higher deflections can be attributed in part to excessive sloughing of material during construction. This slough occurred in the vicinity of both SI 130 and SI 129. Another reason for the higher monitored deflections was the length of time it took for construction in the area of the two slope inclinometers. In this area it took longer than that under the bridge near instrument section \#1. This may be something to consider for

10 Recommendations clouterre 1991 (Presses Ponts et chaussees), p.55 
future FE modeling and that is to incorporate a time function. The horizontal displacement fringe plot in figure 69 clearly shows that the nailed zone behaves as a gravity block. This is the way soil nail walls are suspected to behave and give strong validation to the ABAQUS modeling techniques used.

\section{Measured Nail stresses}

The field measurement data that will be used for comparison are the nail strain gages and load cells. Due to the modelia soil nail with ABAQUS and the resulting high initial stress states, direct comparison of nail stresses or loads will not be made. Instead the nail stress distributions from the ABAQUS models will be compared to the reduced nail loads that were developed from the instrument data (figures 71 through 76). The measured data is not plotted with respect to lift sequence but rather the date it was recorded on. The actual construction lift dates are as follows: Lift 1 - completed $12 / 10 / 90$

$$
\begin{aligned}
& \text { Lift } 2 \text { - Completed 12/12/90 } \\
& \text { Lift } 3 \text { - Completed 1/8/90 } \\
& \text { Lift } 4 \text { - Completed } 1 / 16 / 91 \\
& \text { Lift 5.- Completed 1/24/91 }
\end{aligned}
$$

For ease of comparison of the model data to the instrument data the nolinln, nolinlp, and nolin2n nail stresses were plotted versus nail length (figures 77 through 85). In general the stress trends in the ABAQAS models 
nolin1n, nolinlp, and nolin2n compare well with the measured loads. In particular the instrument section one - nail one, load distribution compares well with the nolinln and nolinlp models. Some of the apparent random load measured in instrument section two compares well enough to the nolin2n model to make one reconsider it's randomness. 


\section{SWIFT DELTA SOIL NAIL WALL FEM RESULTS} MODEL NOLIN2N STATIC STEP 8

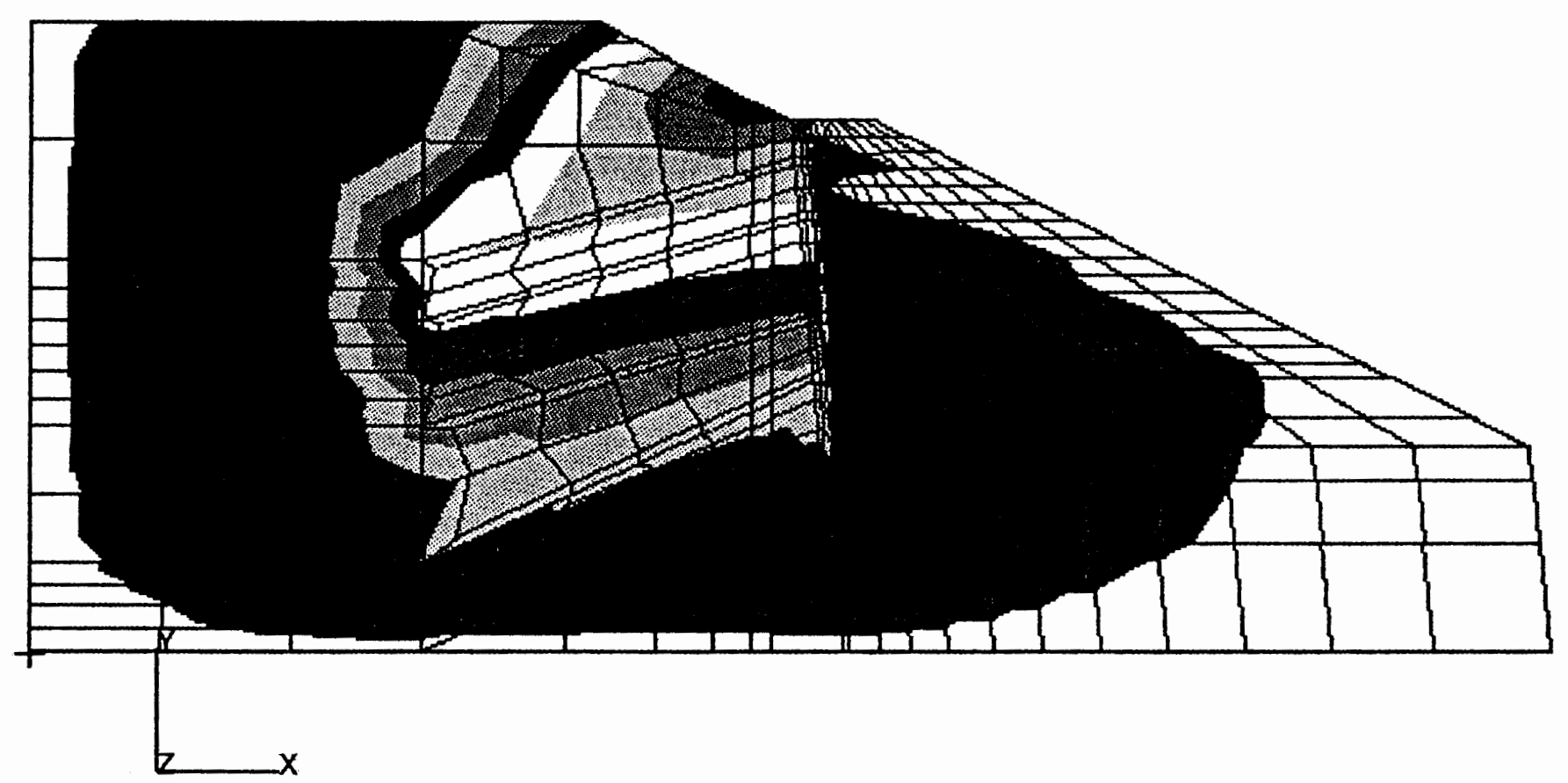

.03021

.02788

.02556

.02323

.02090

.01857

.01624

.01391

.01159

.009259

.006930

.004602

.002274

nolin2n1.fil

FIGURE 42: Model NOLIN2N static Step 8 Horiz. Disp.

$-.00005384$ 
Fringe: $L C=3.2-R E S=1.1-P 3 / P A T R A N$ R.1-(Tensor-XX)-ABAQUS-31-Aug-94 09:51:11 SWIFT DELTA SOIL NAIL FEM RESULTS MODEL NOLIN1N STATIC STEP 3

Horiz Stress

(psf)

0

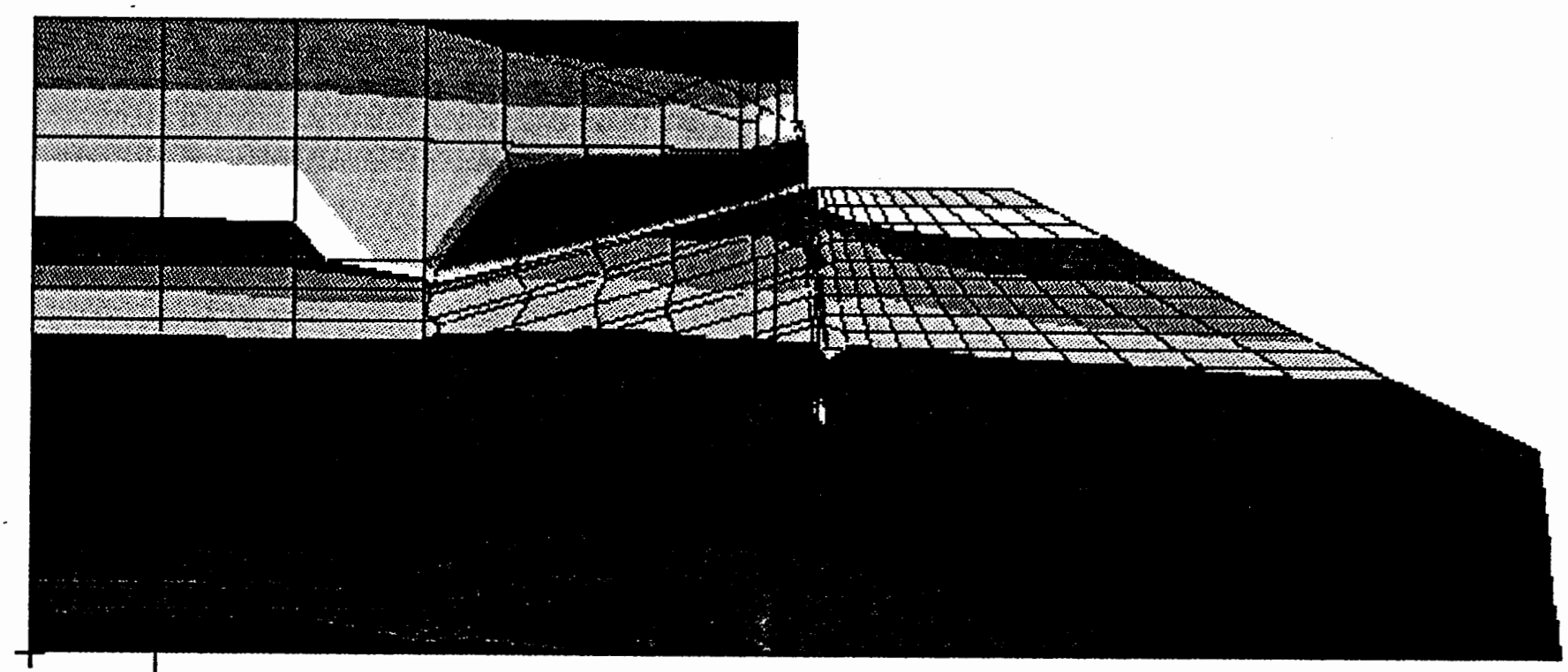

$-700.0$

$-933.3$

$-1167$.

-1400 .

-1633 .

$-1867$.

-2100 .

$-2333$.

$-2567$.

$-2800$.

$-3033$.

$-3267$.

nolin1n3.fil FTGURE 43: Model NOLIN1N static step 3 Horiz. Stress 
Fringe: $L C=3.3-R E S=1.1-P 3 / P A T R A N$ R.1-(Tensor-XX)-ABAQUS-13-Aug-94 12:49:31 SWIFT DELTA SOIL NAIL WALL FEM RESULTS

Horiz Stress MODEL NOLIN1P STATIC STEP 4 (psf)

$-233.3$

$-466.7$

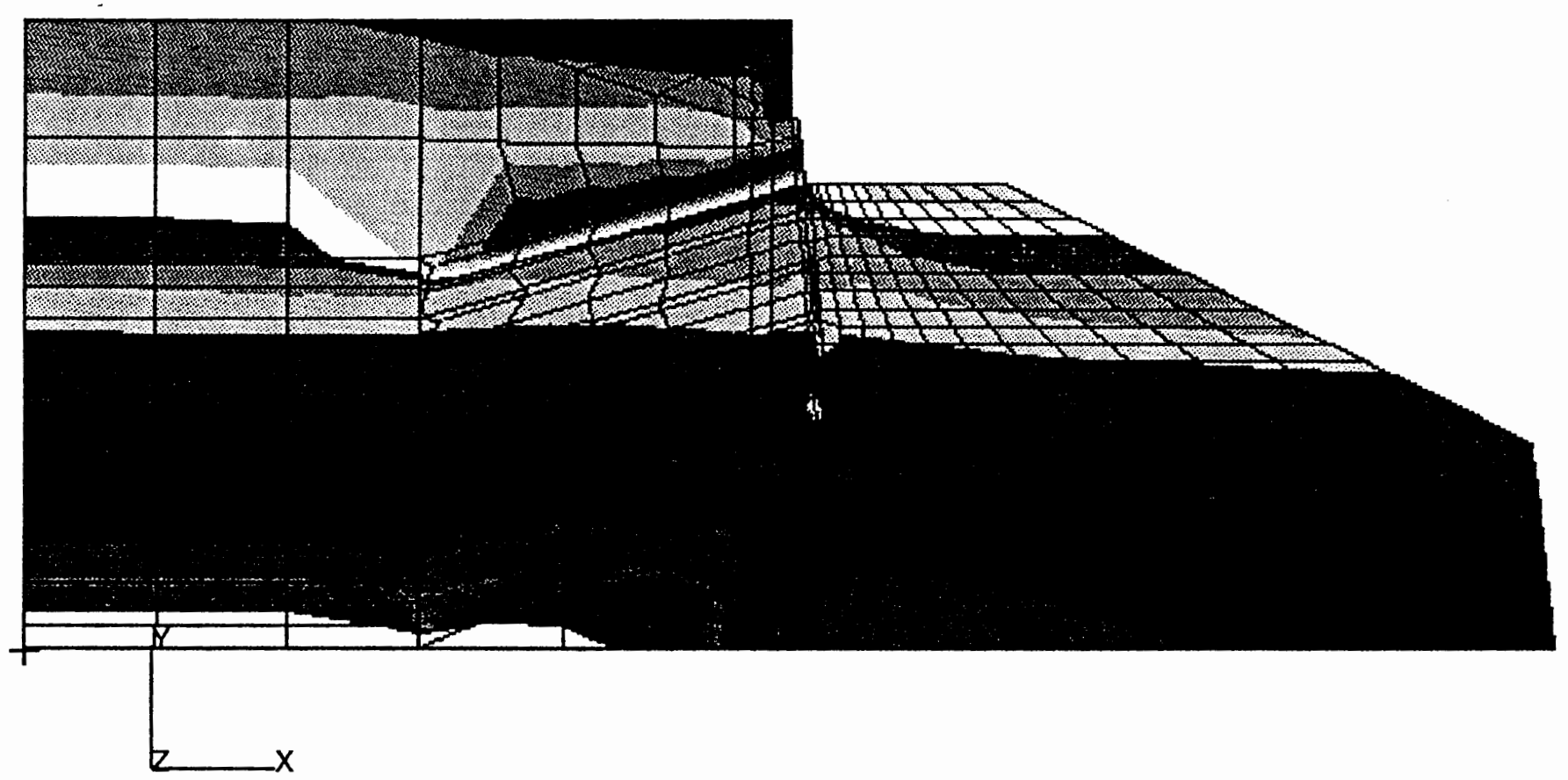

$-700.0$

$-933.3$

$-1167$

-1400 .

$-1633$.

$-1867$.

$-2100$

$-2333$

$-2567$.

-2800 .

$-3033$.

$-3267$

$-3500$ 
Fringe: $L C=3.4-R E S=1.1$-P3/PATRAN R.1-(Tensor-XX)-ABAQUS-31-Aug-94 11:02:18

SWIFT DELTA SOIL NAIL FEM RESULTS

MODEL NOLIN1N STATIC STEP 5

Horiz Stress

(psf)

0.

$-233.3$

$-466.7$

$-700.0$

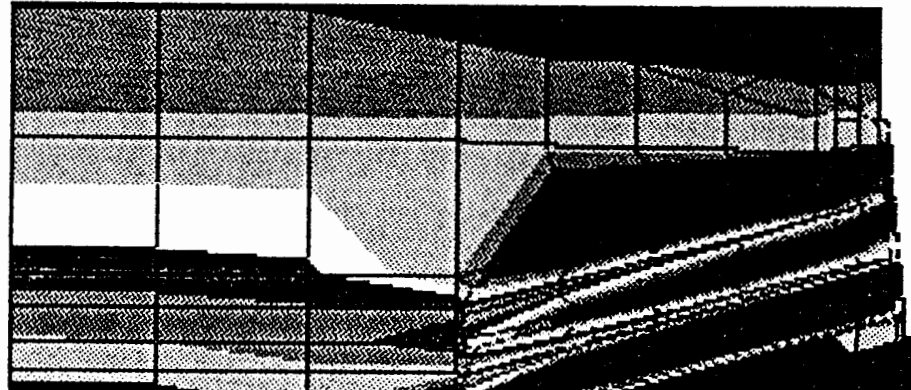

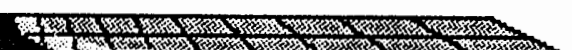
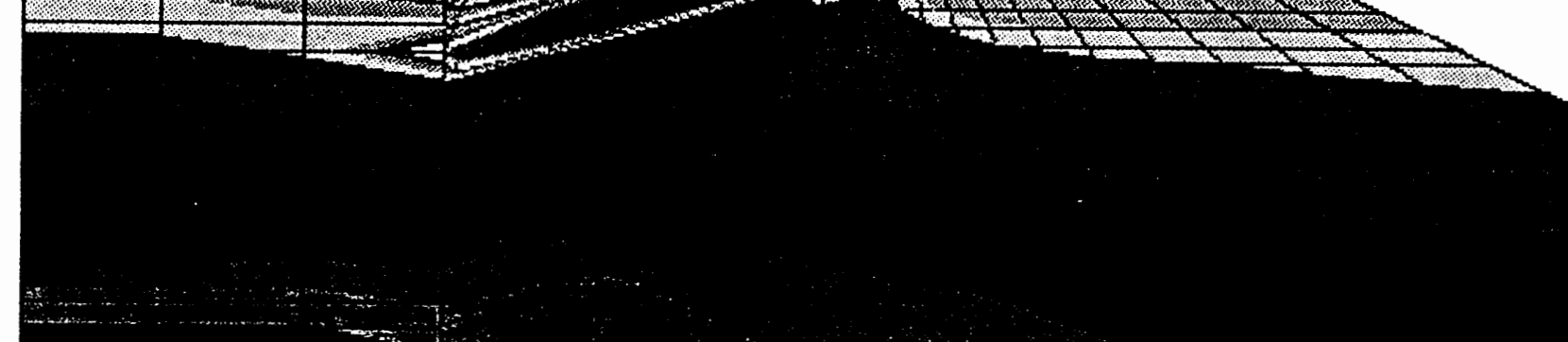

$+$
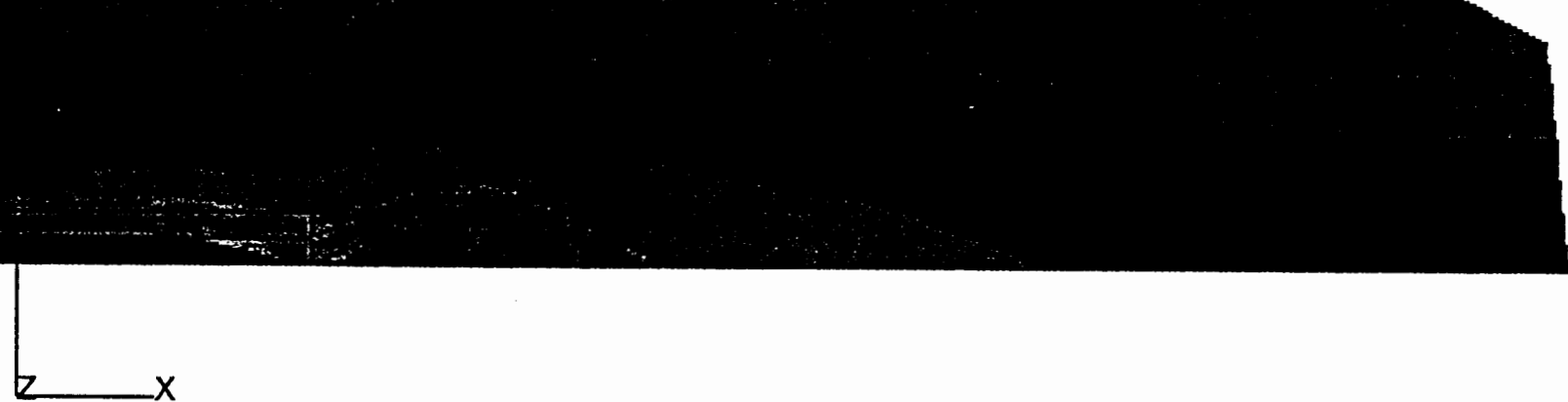

$-2100$

$-2333$

$-2567$.

$-2800$

$-3033$.

$-3267$

$-3500$ 
Fringe: $L C=3.5-R E S=1.1-P 3 / P A T R A N$ R.1-(Tensor-XX)-ABAQUS-13-Aug-94 13:52:16 SWIFT DELTA SOIL NAIL WALL FEM RESULTS

MODEL NOLIN1P STATIC STEP 6

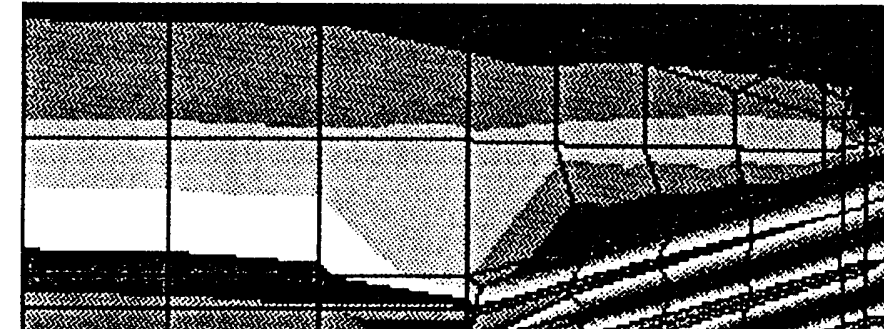

$-700.0$

$-933.3$

$-1167$

$-1400$

$-1633$
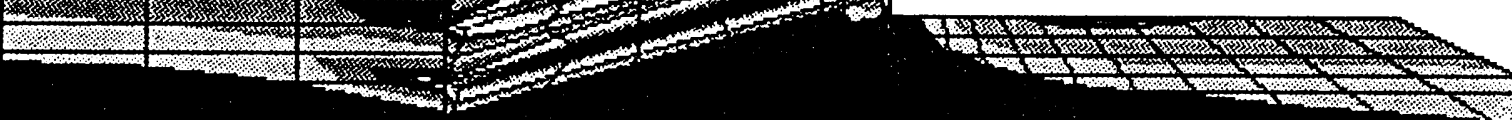

$-1867$

$-2100$

$-2333$

$-2567$.

$-2800$.

$-3033$

$-3267$

nolin1p3.fil 
Fringe: $L C=3.8-R E S=1.1-P 3 / P A T R A N$ R.1-(Tensor-XX)-ABAQUS-21-May-94 12:44:04

SWIFT DELTA SOIL NAIL WALL FEM RESULTS

\begin{tabular}{l} 
Horiz Stress \\
-233.3 \\
-466.7 \\
-700.0 \\
-933.3 \\
-1167. \\
-1400. \\
-1633. \\
-1867. \\
-2100. \\
-2333. \\
-2567. \\
-3033. \\
-32600 \\
\hline
\end{tabular}

nolin1p3.fil

FIGURE 47: Model NOLIN1P Static step 9 Horiz. Stress 


\section{SWIFT DELTA FINITE ELEMENT MESH}

\section{NOLIN1N MODEL STEP 8}

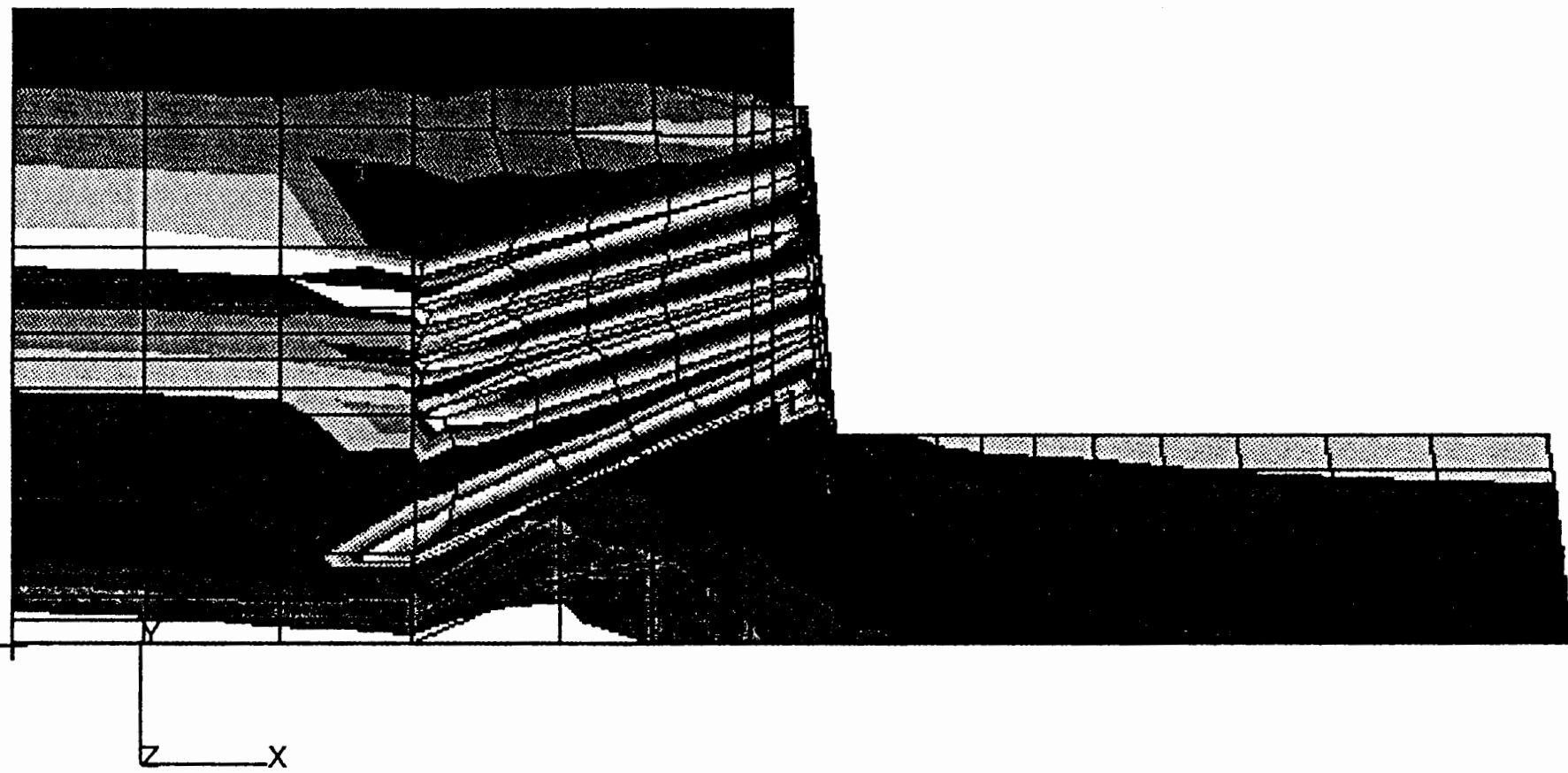

FIGURE 48: NOLIN1N Model static step 8 Horiz. stress: 
Fringe: LC=3.3-RES=1.1-P3/PATRAN R.1-(Tensor-YY)-ABAQUS-13-Aug-94 12:21:58

SWIFT DELTA SOIL NAIL WALL FEM RESULTS

\begin{tabular}{c} 
Vert Stress \\
(psf) 0. \\
-233.3 \\
-466.7 \\
$-700.0-$ \\
-933.3 \\
-1167. \\
-1400. \\
-1633. \\
-1867. \\
-2100. \\
-2333. \\
-2567. \\
-3033. \\
-3267. \\
\hline
\end{tabular}

nolin1p3.fil

FIGURE 49: Model NOLIN1P static step 8 vert. Stress 
Fringe: LC=3.4-RES=1.1-P3/PATRAN R.1-(Tensor-YY)-ABAQUS-13-Aug-94 13:13:16

SWIFT DELTA SOIL NAIL WALL FEM RESULTS

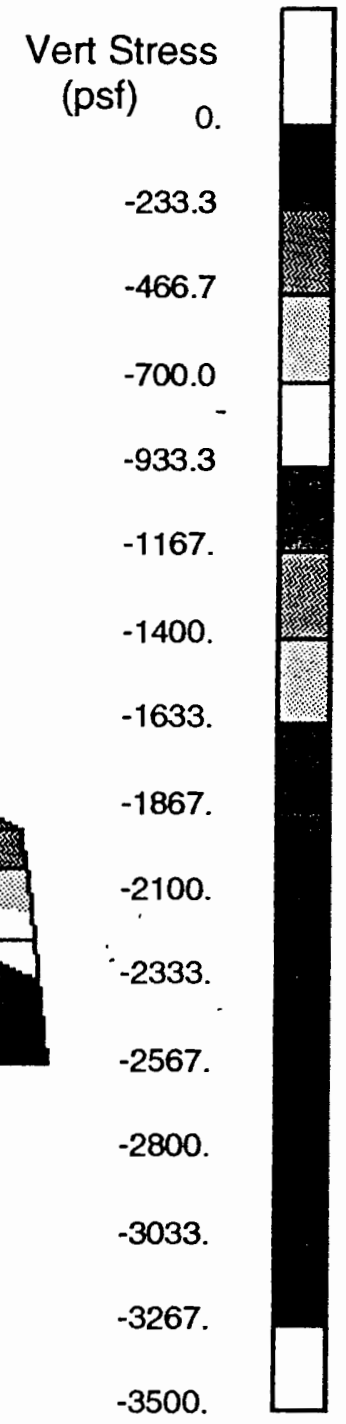

nolin1p3.fil 
Fringe: LC=3.5-RES=1.1-P3/PATRAN R.1-(Tensor-YY)-ABAQUS-13-Aug-94 13:57:46 SWIFT DELTA SOIL NAIL WALL FEM RESULTS

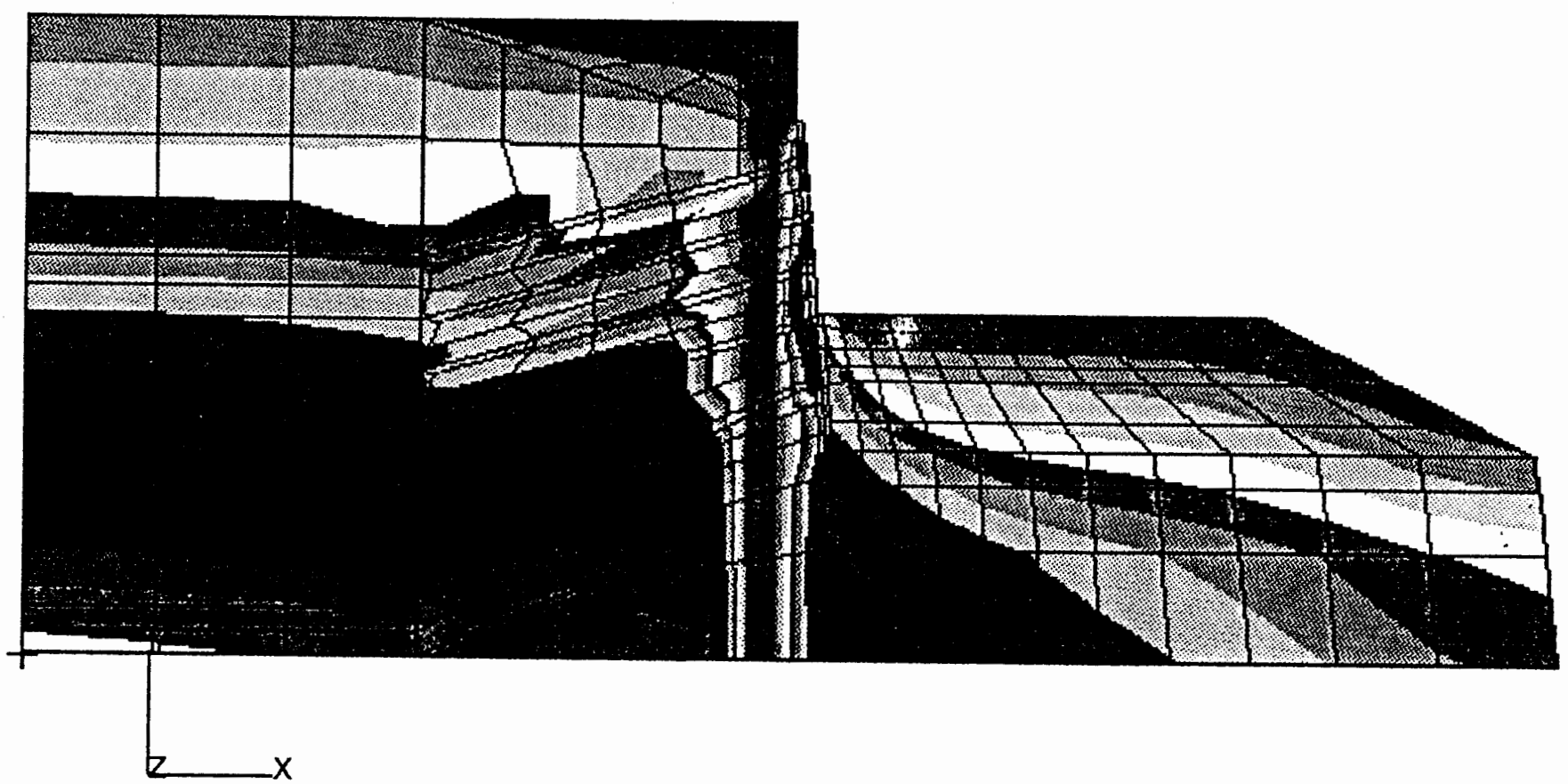

$--700.0$

$-933.3$

$-1167$.

-1400 .

$-1633$.

$-1867$.

$-2100$.

$-2333$.

$-2567$.

$-2800$

$-3033$

$-3267$.

nolin1p3.fil

FIGURE 51: Model NoLIN1P static step 6 Vert. Stress

-3500 . 
Fringe: $L C=3.6-R E S=1.1$-P3/PATRAN R.1-(Tensor-YY)-ABAQUS-03-Sep-94 14:56:44 SWIFT DELTA SOIL NAIL WALL FEM RESULTS MODEL NOLIN1P STATIC STEP 7 
MODEL NOLIN1N STATIC STEP 3

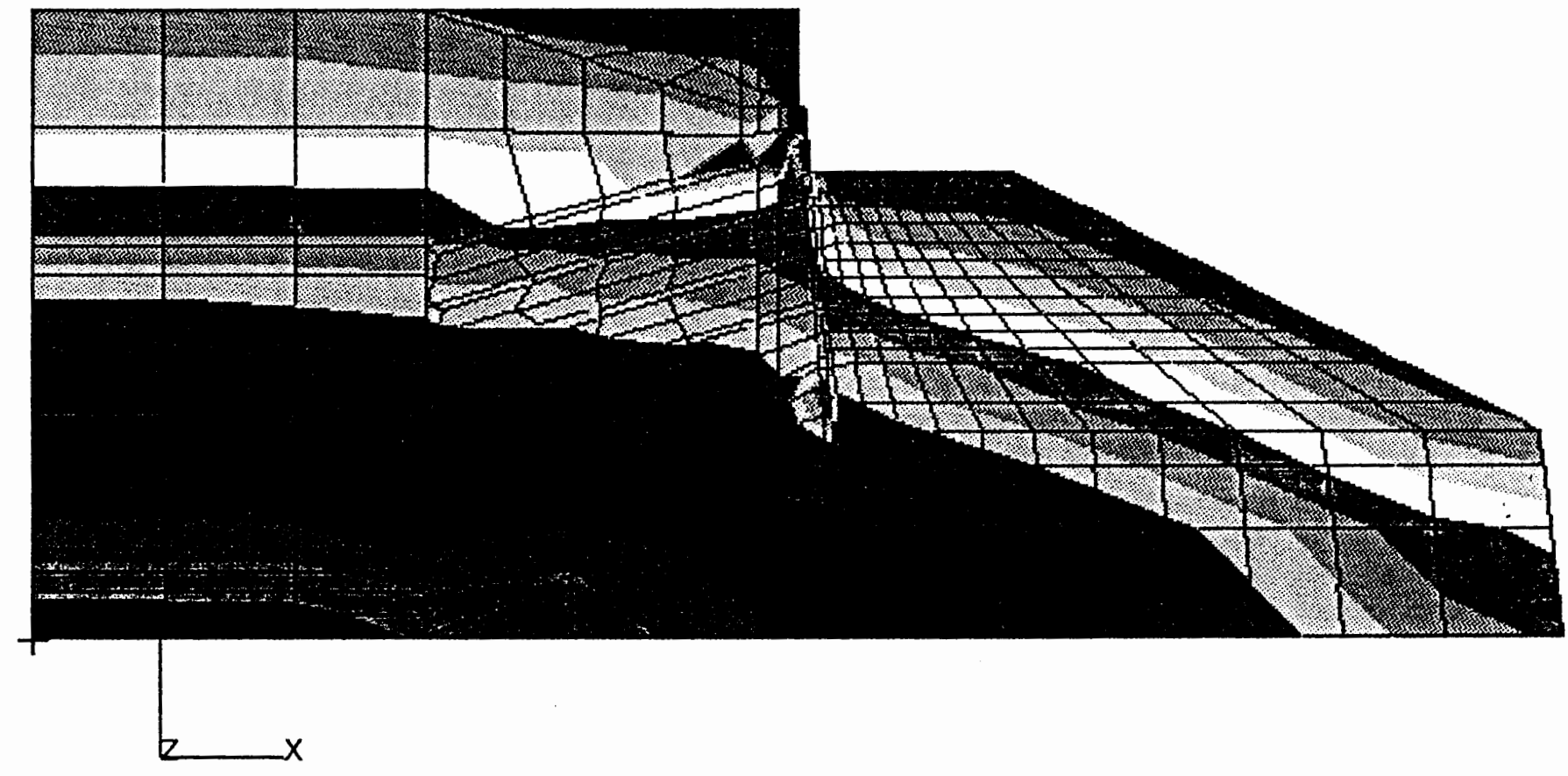

$-700.0$

$-933.3$

$-1167$.

$-1400$

$-1633$

$-1867$

$-2100$.

$-2333$.

$-2567$

$-2800$

$-3033$.

nolin1n3.fil

$-3267$.

$-3500$ 
Fringe: $L C=3.4-R E S=1.1-P 3 / P A T R A N$ R.1-(Tensor-YY)-ABAQUS-31-Aug-94 11:11:44 SWIFT DELTA SOIL NAIL FEM RESULTS MODEL NOLIN1N STATIC STEP 5

\section{Vert Stress}

(psf)

0.

$-233.3$

$-466.7$

$-700.0$

$-933.3$

$-1167$

$-1400$

$-1633$

$-1867$.

$-2100$

$-2333$

$-2567$.

$-2800$

$-3033$

$-3267$

$-3500$ 
Fringe: LC=3.7-RES=1.1-P3/PATRAN R.1-(Tensor-YY)-ABAQUS-18-Mar-94 15:56:22

\section{SWIFT DELTA FINITE ELEMENT MESH}

NOLIN1N MODEL STEP 8

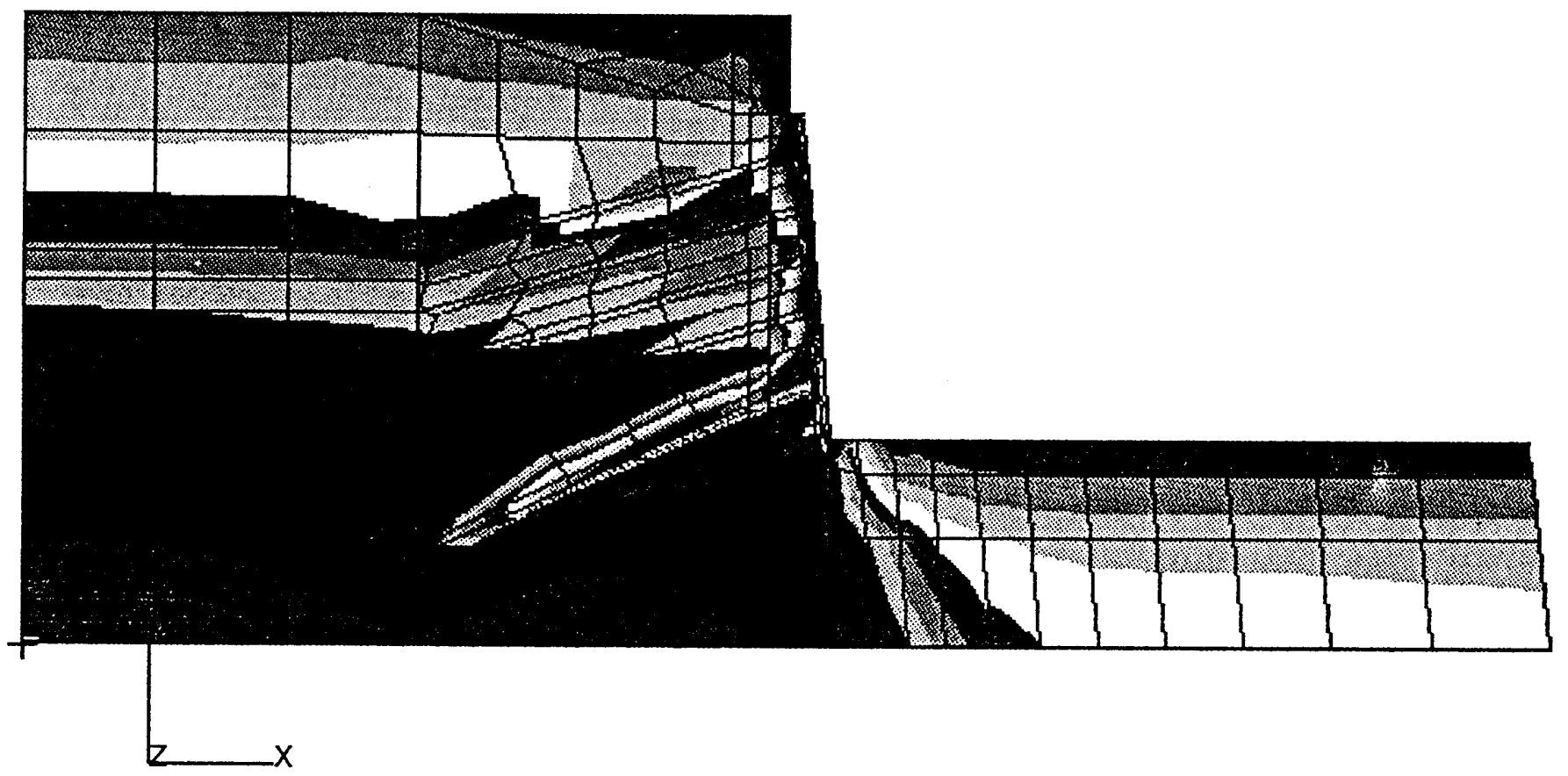

$-700.0$

$-933.3$

$-1167$.

$-1400$

$-1633$

$-1867$.

-2100 .

$-2333$

$-2567$

$-2800$

$-3033$.

$-3267$.

FIGURE 56: NONLIN1N Model Step 8 Vert stress 
Fringe: LC=3.2-RES=1.1-P3/PATRAN R.1-(Major)-ABAQUS-31-Aug-94 10:01:13

SWIFT DELTA SOIL NAIL FEM RESULTS

Major Stress

(pst)

MODEL NOLIN1N STATIC STEP 3

10000.

9333

8667

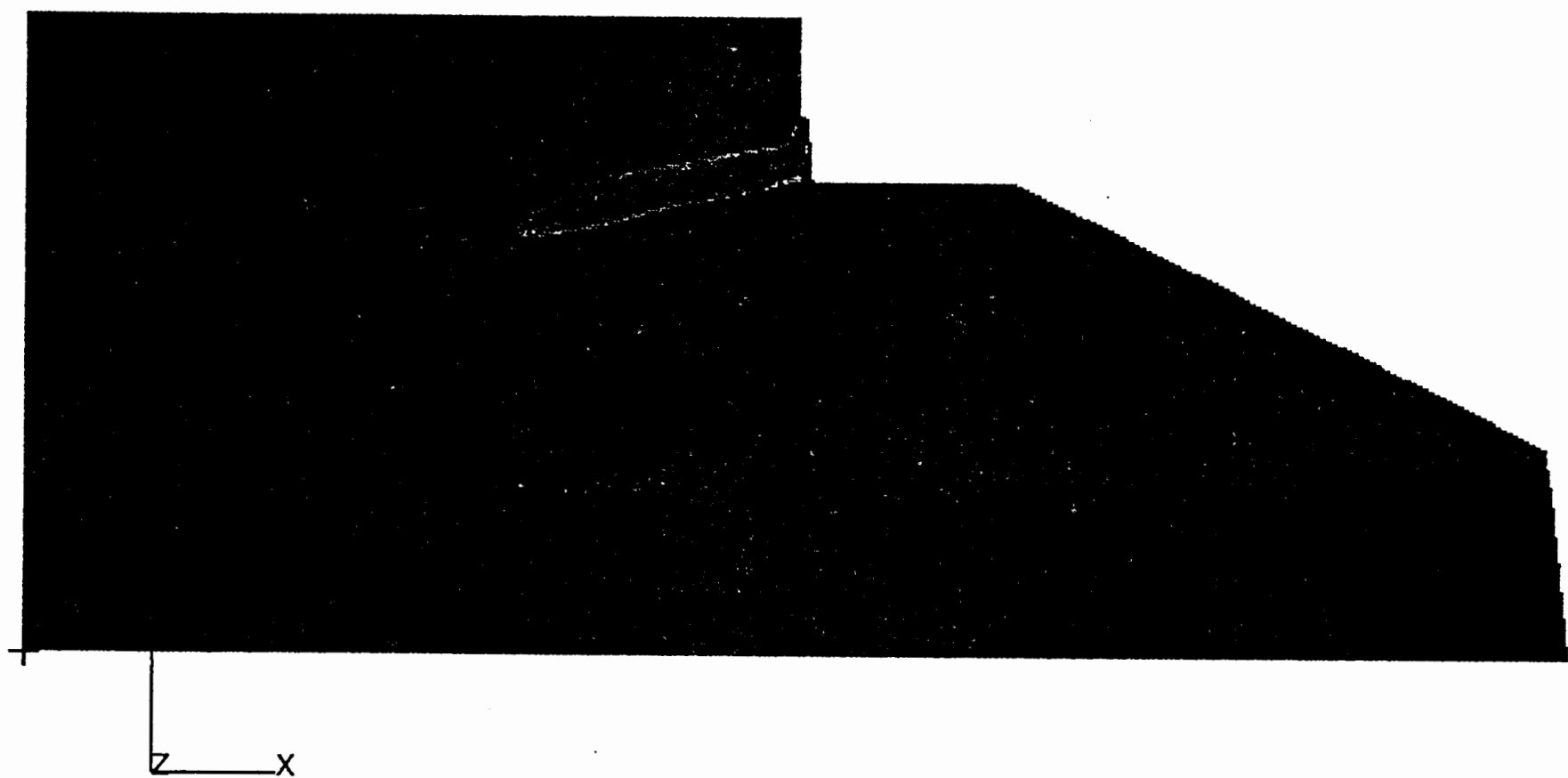

$-8000$

7333.

6667.

6000.

5333.

4667.

4000 .

3333.

2667.

2000.

1333.

nolin 1 n3.fil

666.7

FIGURE 57: Model NONLIN1N static step 3 Major stress 
8667.

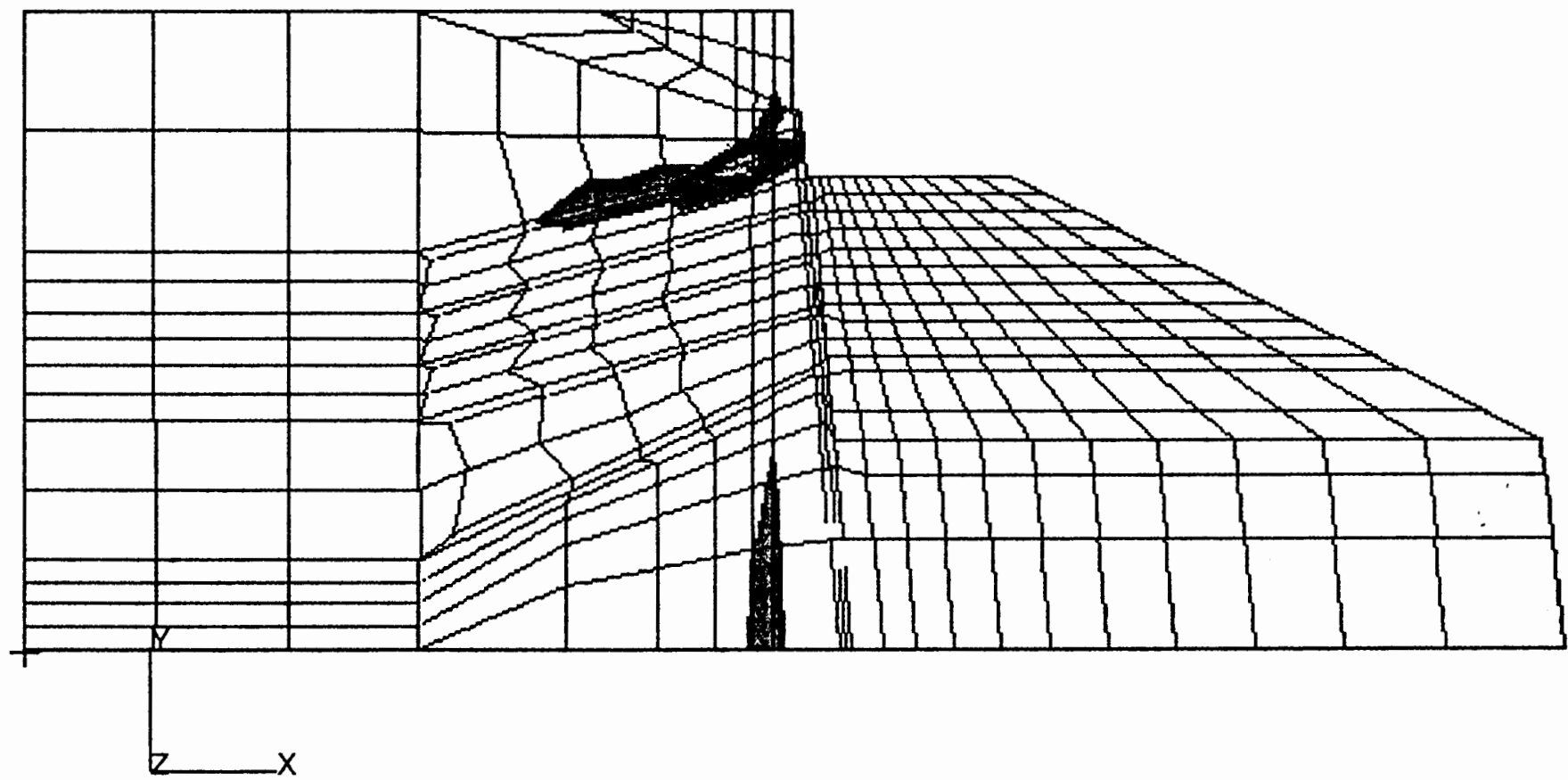

8000.

7333.

6667.

6000.

5333.

4667.

4000.

3333.

2667.

2000.

1333.

666.7

nolin1p3.fil

FIGURE 58: Model NONLIN1P static Step 4 Major stress

$-.0001221$ 


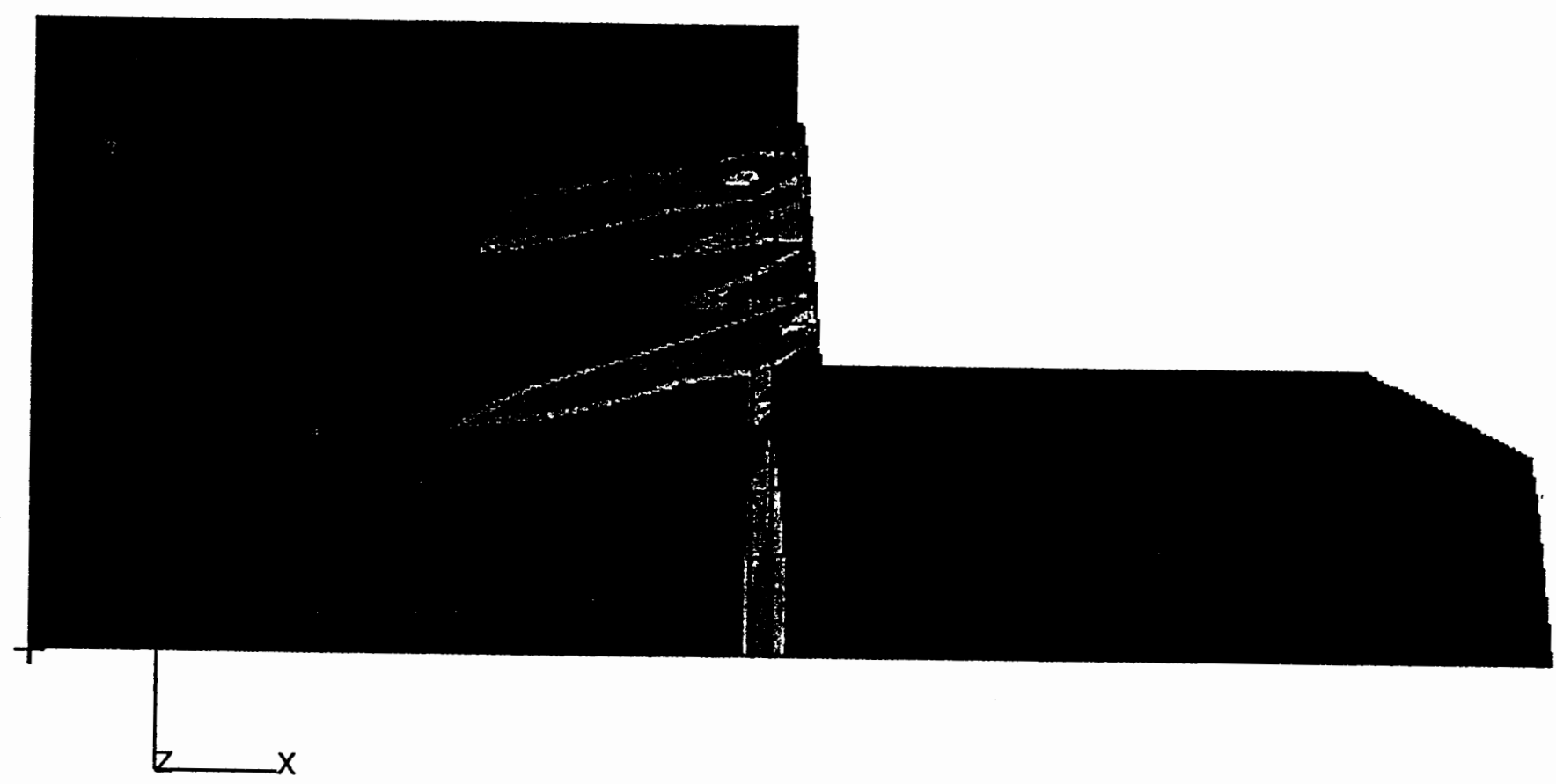


MODEL NOLIN1N STATIC STEP 6

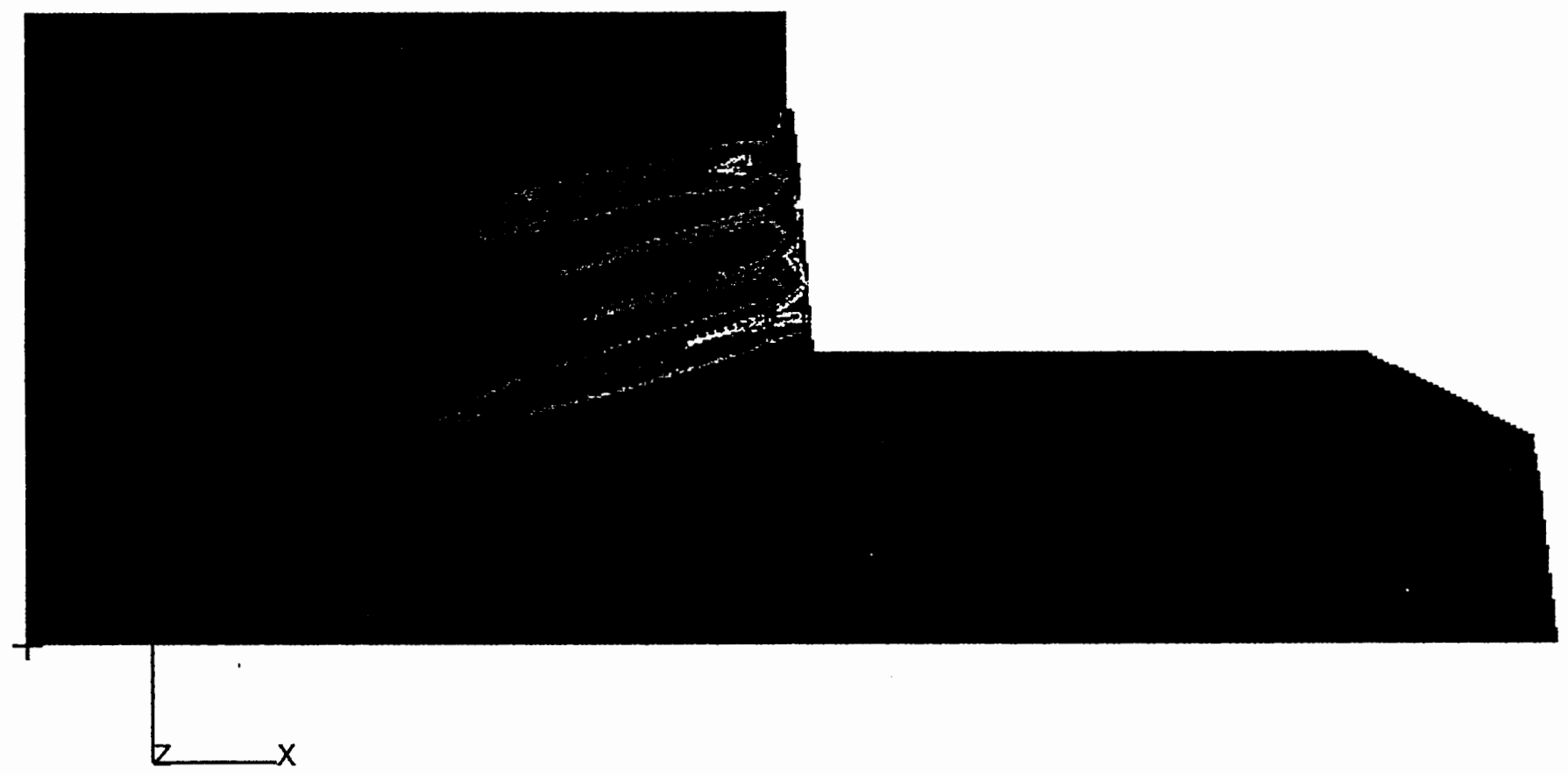


Fringe: LC=3.7-RES=1.1-P3/PATRAN R: 1-(Major)-ABAQUS-09-Oct-94 16:31:49 SWIFT DELTA SOIL NAIL FEM RESULTS

Major Stress (psf)

MODEL NOLIN1N STATIC STEP 8

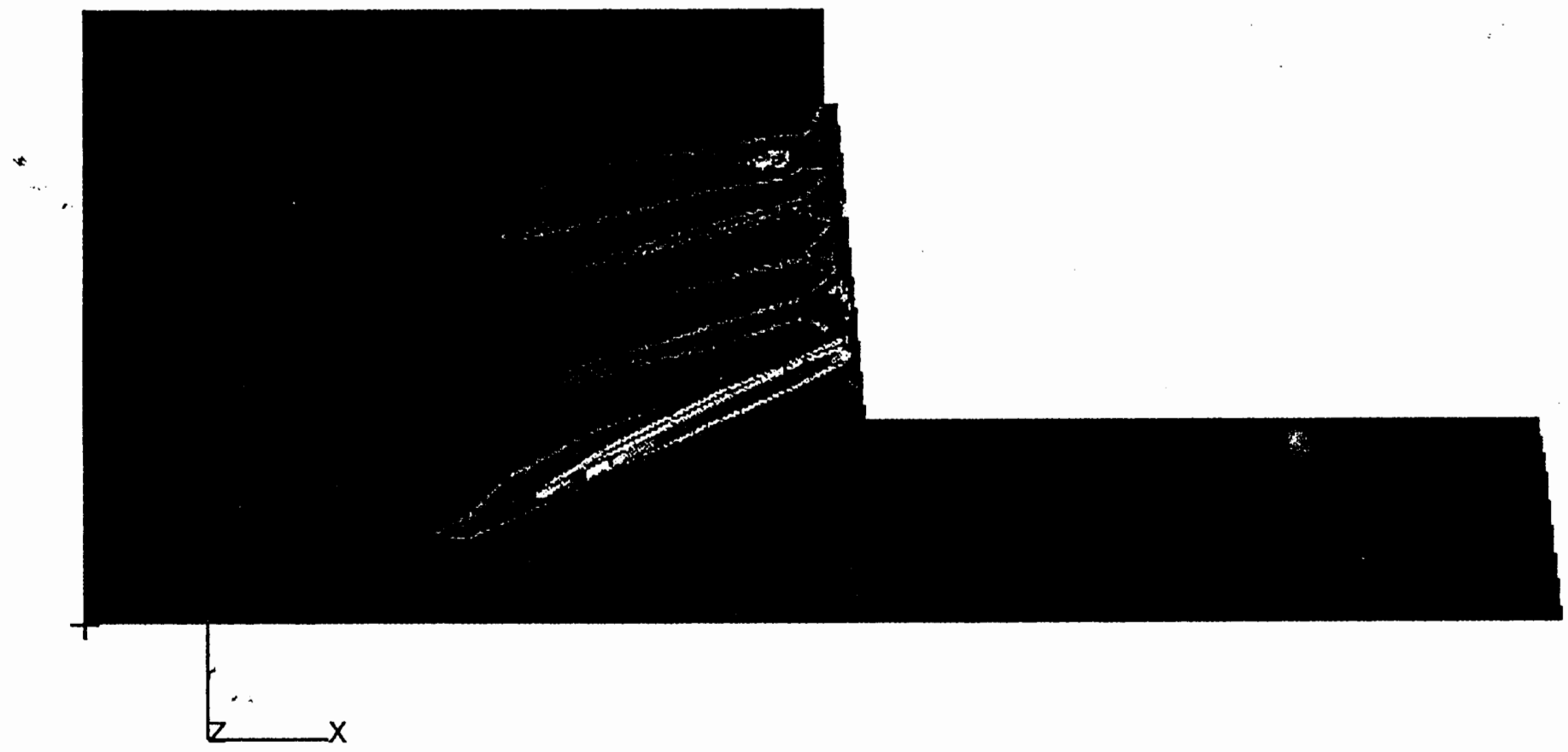

nolin1n3.fil

FIGURE 62: Model NONLIN1P static step 8 Major stress
10000.

9333

8667

8000

7333

6667.

6000.

5333.

4667

4000

3333.

2667

2000

1333.

666.7

$-.0001221$ 
Fringe: LC=3.2-RES=1.1-P3/PATRAN R.1-(Major)-ABAQUS-13-May-94 16:39:03

SWIFT DELTA SOIL NAIL WALL FEM RESULTS

Major Stress
(psf) 0.
-.6667
-1.333
-2.000
-2.667
-3.333
-4.000
-4.667
-5.333
-6.000
-6.667
-7.333
-8.000
-8.667
-9.333
-10.00


Fringe: $L C=3.3-R E S=1.1$-P3/PATRAN R.1-(Major)-ABAQUS-13-Aug-94 12:58:26

Major Stress

SWIFT DELTA SOIL NAIL WALL FEM RESULTS

(psf) 1500

MODEL NOLIN1P STATIC STEP 4

1400

1300.

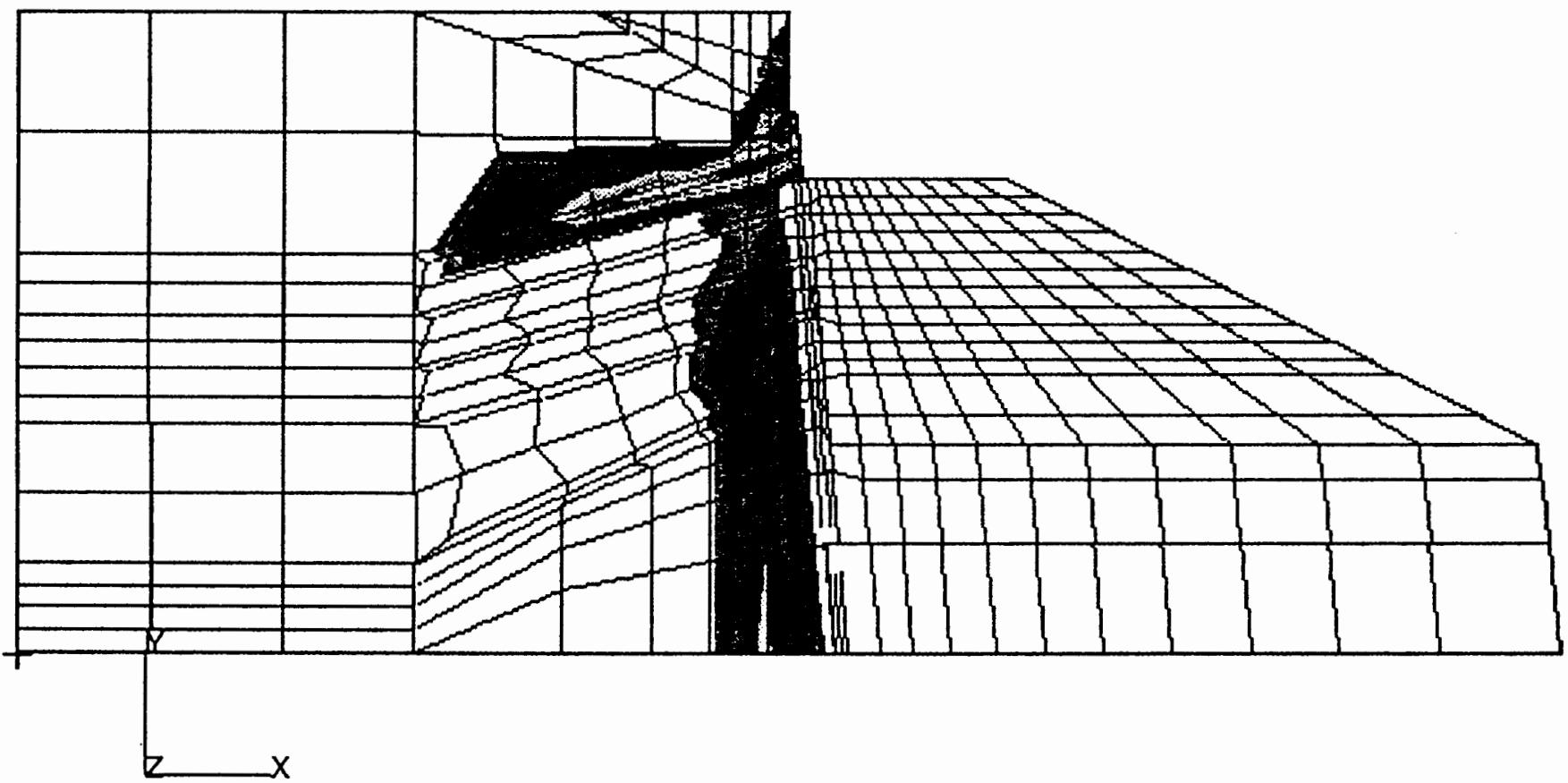

1200.

1100.

1000

900.0

800.0

700.0

600.0

500.0

400.0

300.0

200.0

100.0

nolin1p3.fil

FIGURE 64: Model NONLIN1P static step 4 Major Stress

0 
Fringe: $L C=3.5-R E S=1.1$-P3/PATRAN R.1-(Major)-ABAQUS-13-Aug-94 14:04:20

Major Stress

SWIFT DELTA SOIL NAIL WALL FEM RESULTS

1500.

MODEL NOLIN1P STATIC STEP 6

1400.

1300.

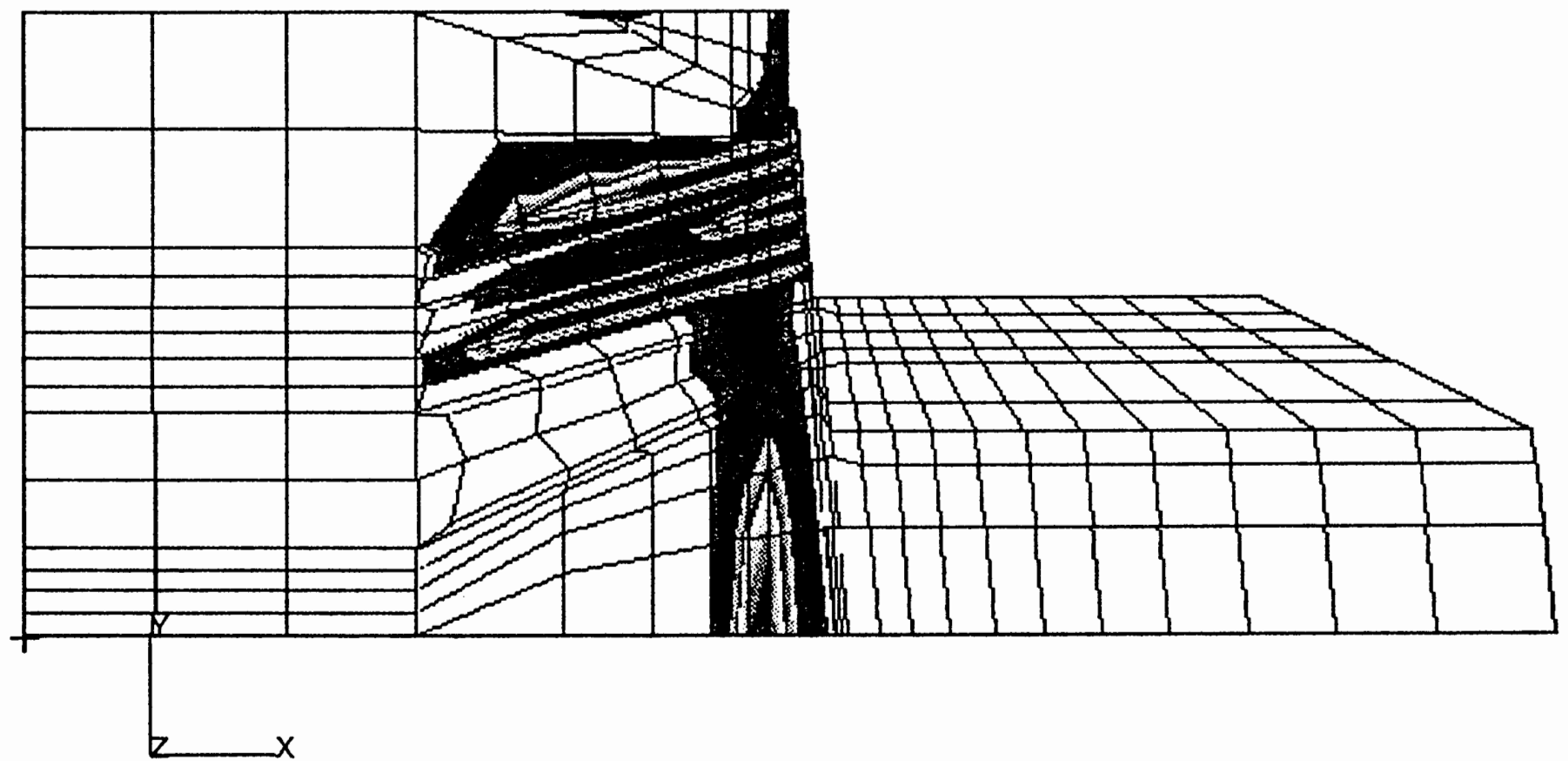

1200

1100.

1000.

900.0

800.0

700.0

600.0

500.0

400.0

300.0

200.0

100.0

nolin1p3.fil

FIGURE 65: Model NONLIN1P static step 6 Major stress

0 


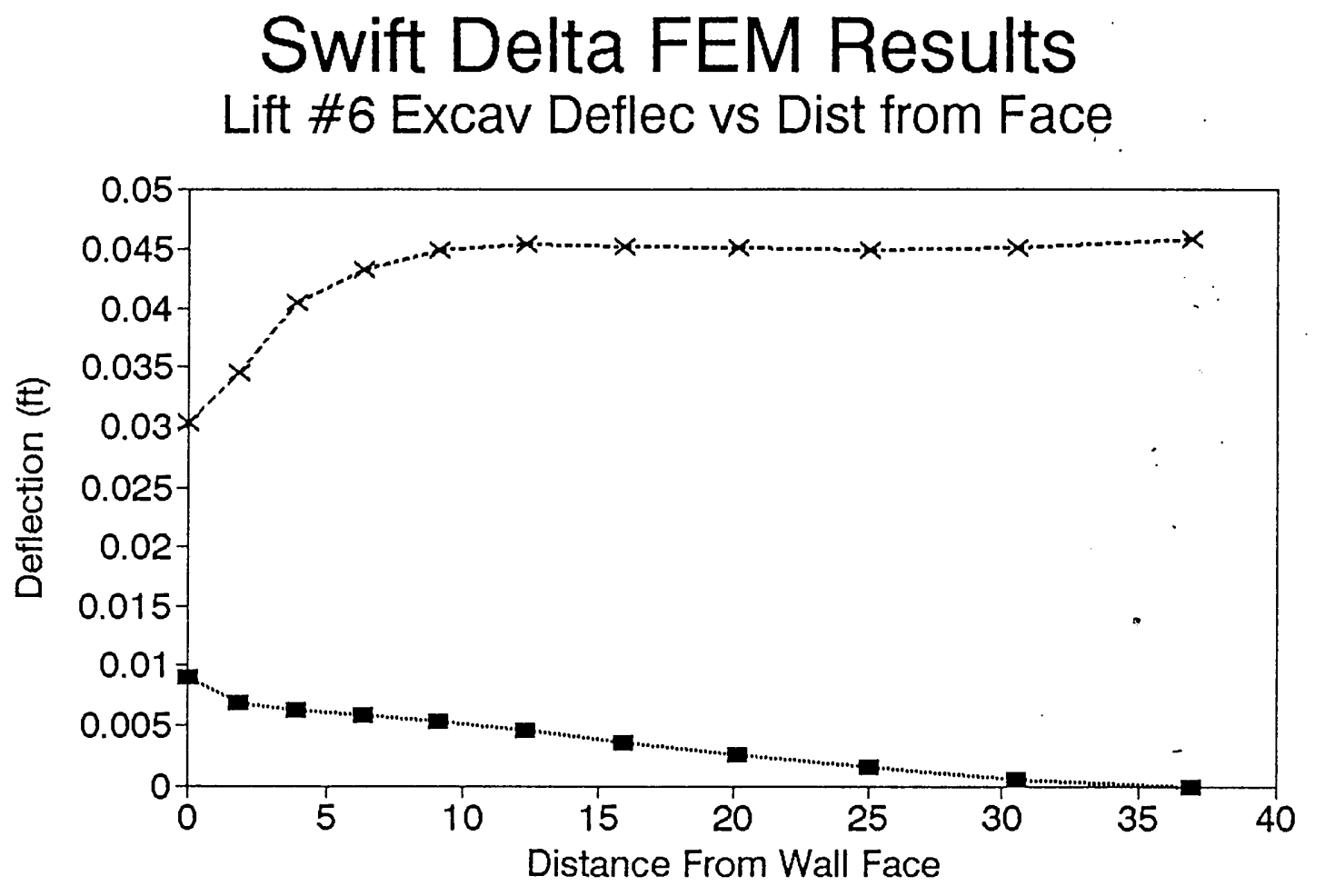

$\cdots \cdots \cdots \cdot$ Horiz Disp $\cdots-\ngtr \cdots$ Vert Disp

FIGURE 66: Soil Excavation Lift Displacement 


\section{Swift Delta FEM Results Shotcrete Face Deflection vs Height}

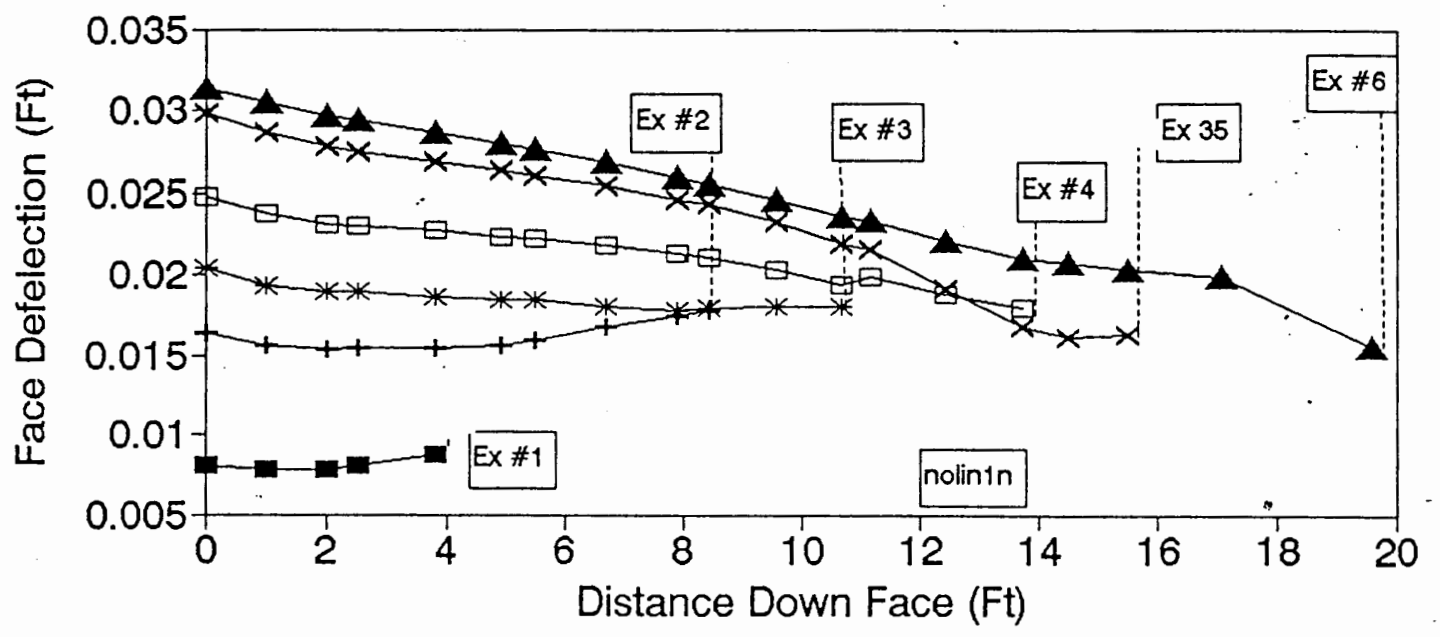

$$
\begin{aligned}
& \rightarrow-\text { Lift \#1 } \rightarrow \text { Lift \#2 } \rightarrow-\text { Lift \#3 } \\
& \square-\text { Lift \#4 } \rightarrow-\text { Lift \#5 } \rightarrow \text { Lift \#6 }
\end{aligned}
$$

FIGÜRE 67: NONLIN1 Wall Face Deflection 


\section{Swift Delta FEM Results Shotcrete Face Deflection vs Height.}

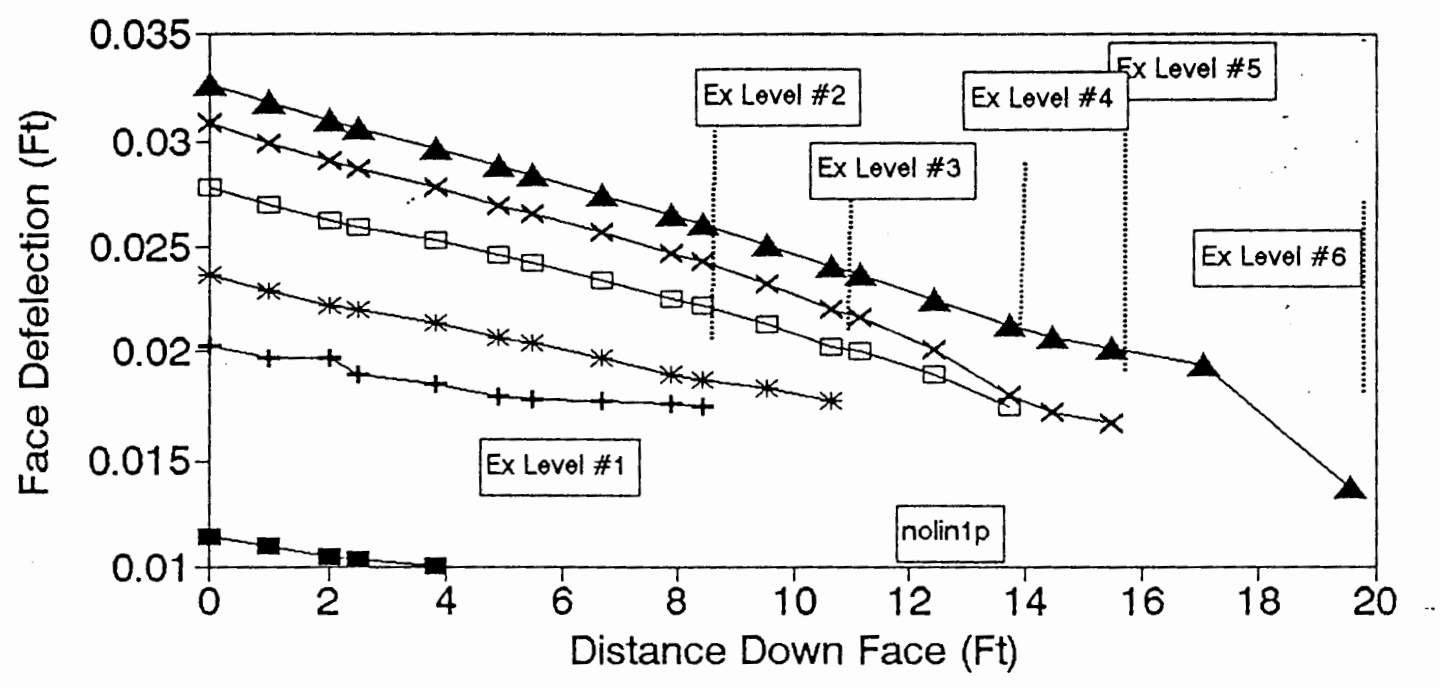

FIGURE 68: NONLIN1P Wall Face Deflection 
MODEL NOLINIP STATIC

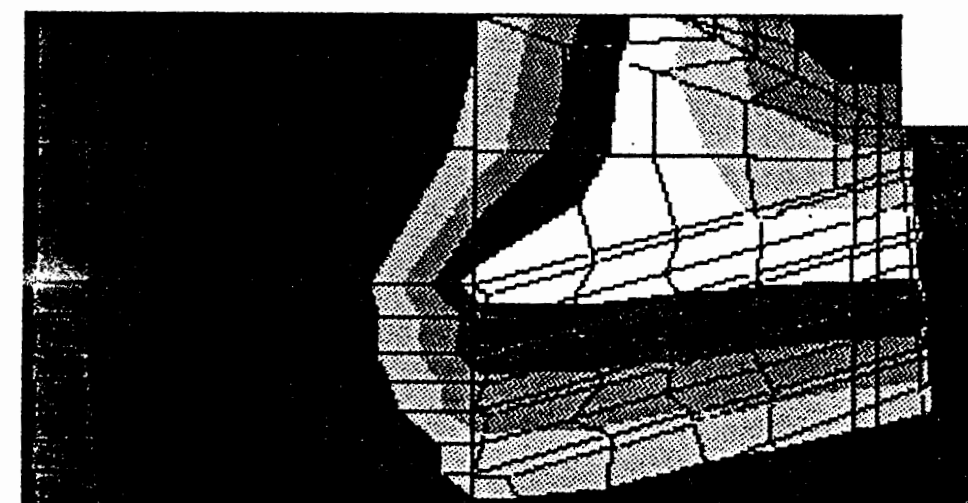




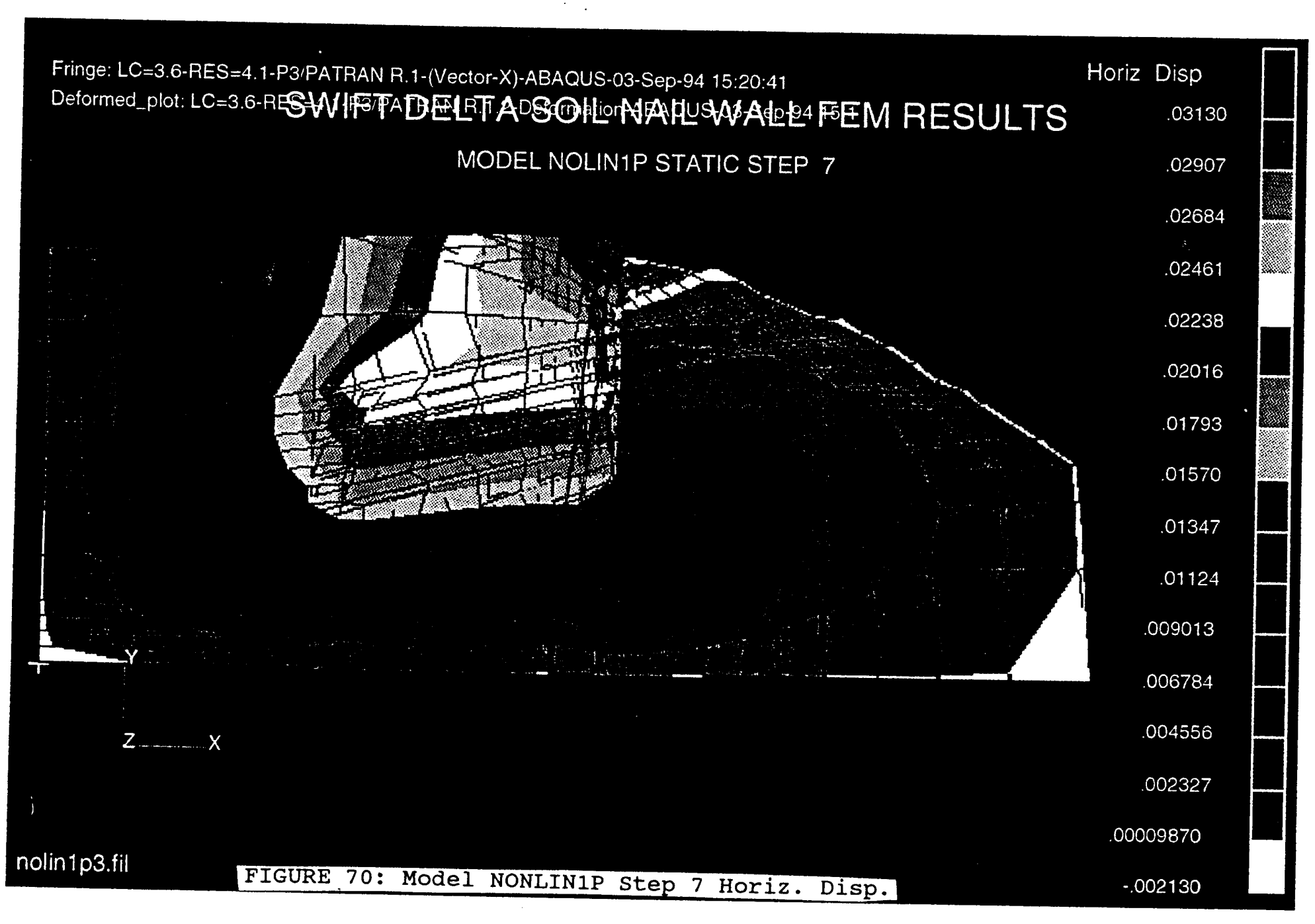



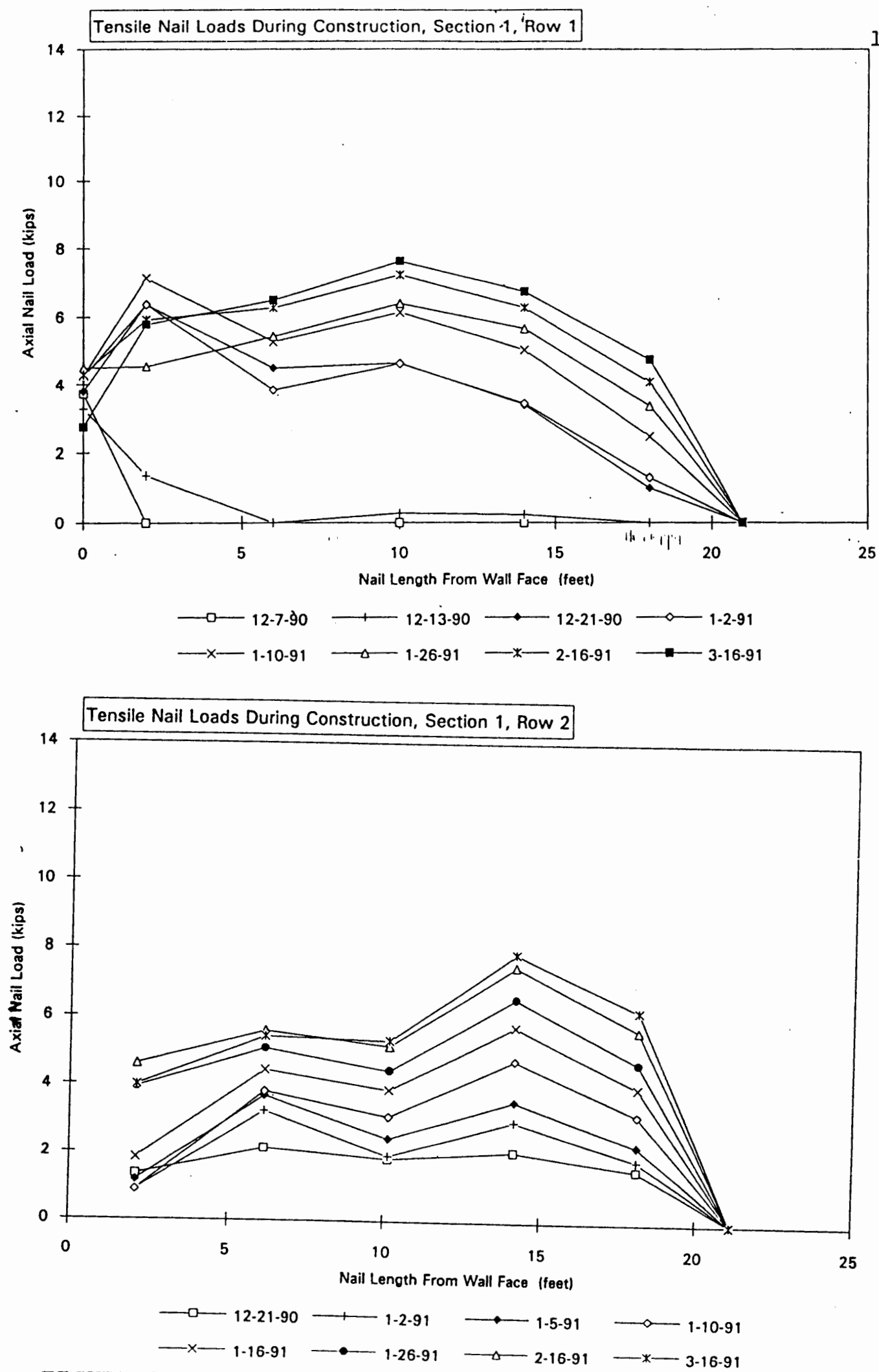

FIGURE 71: Instrument section 1 Row 1 and 2 Nail Load's 

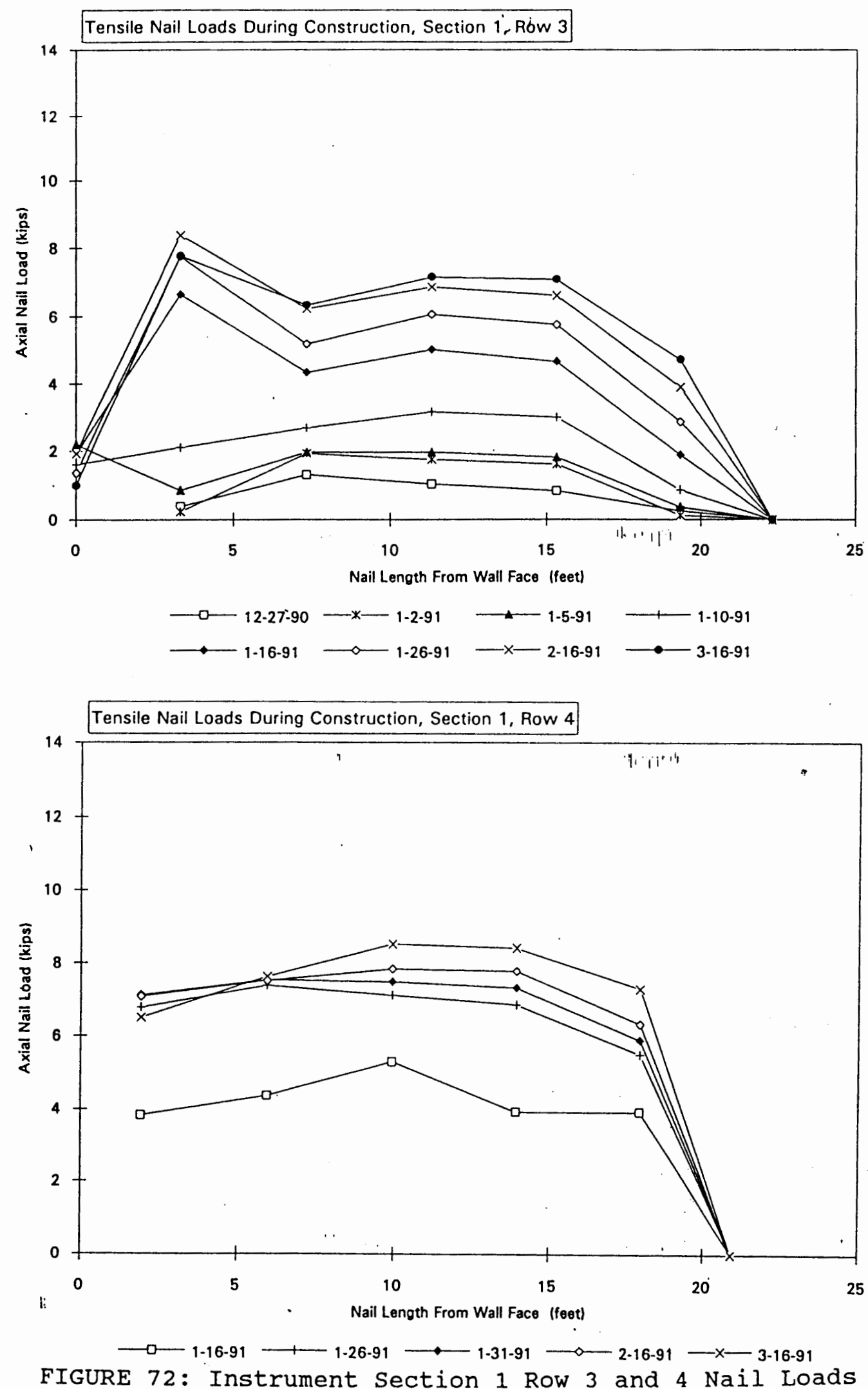


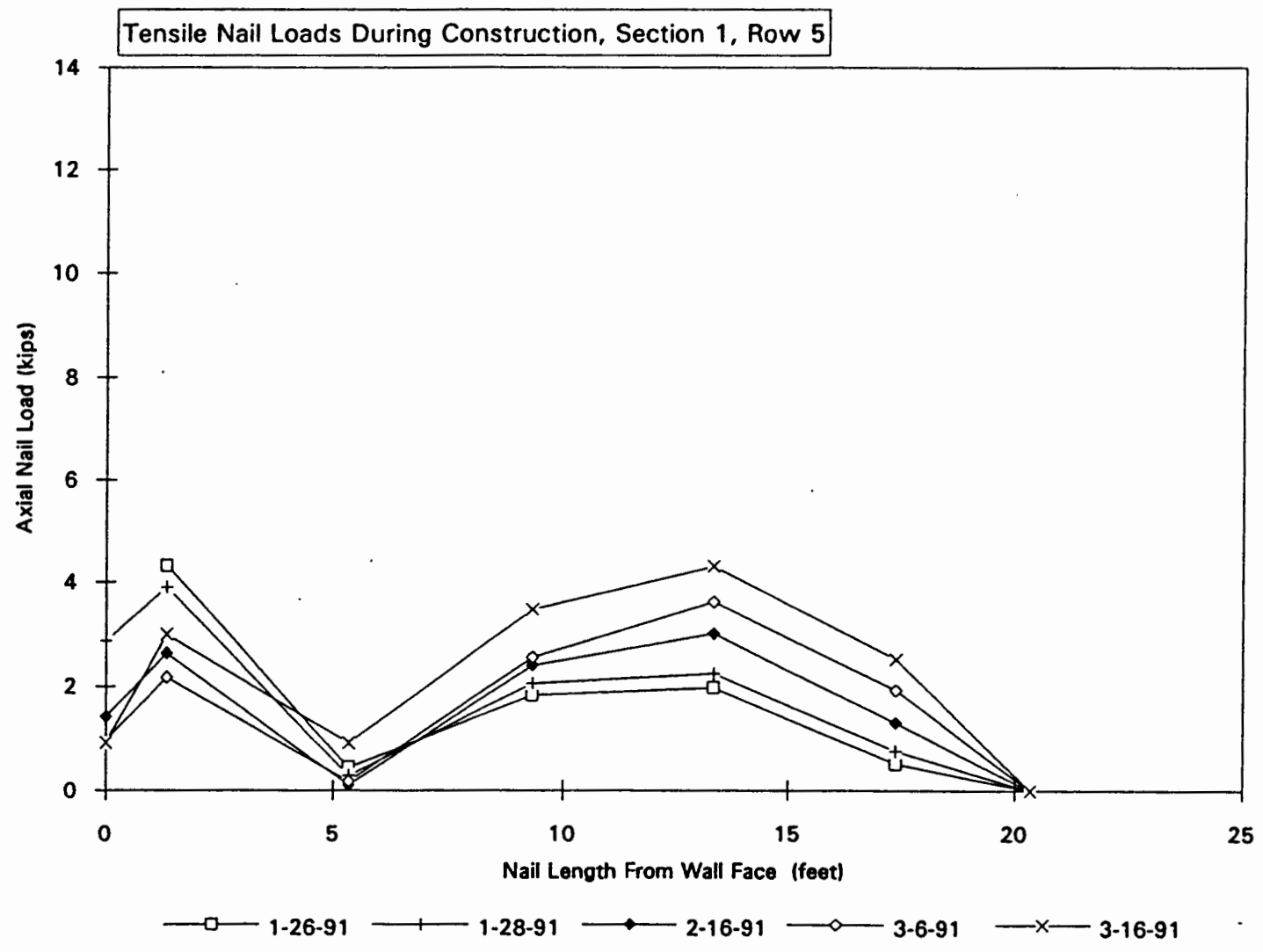

FIGURE 73: Instrument section 1 Row 5 Nail Loads 

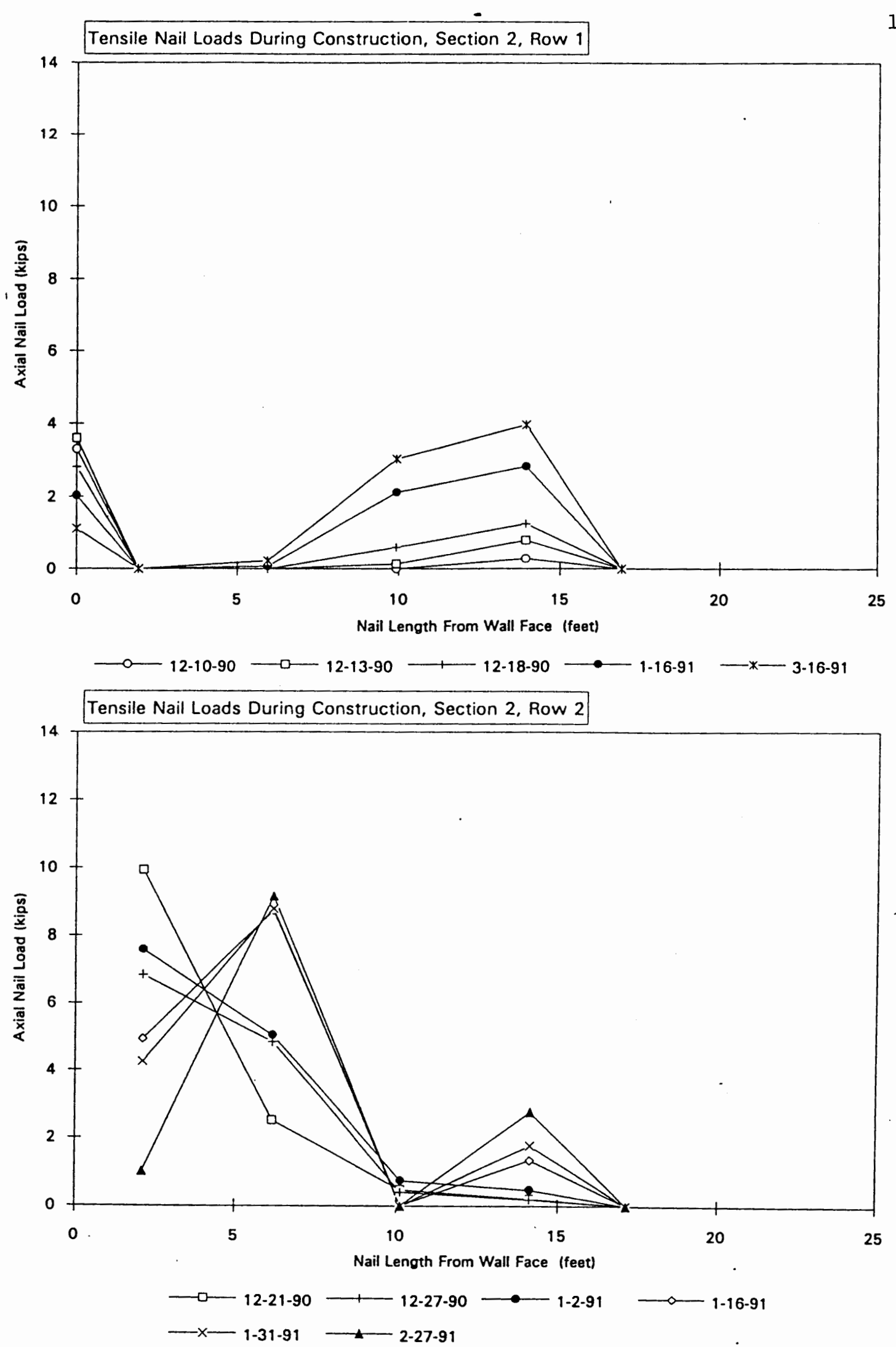

FIGURE 74: Instrument section 2 Row 1 And 2 Nail Loads 

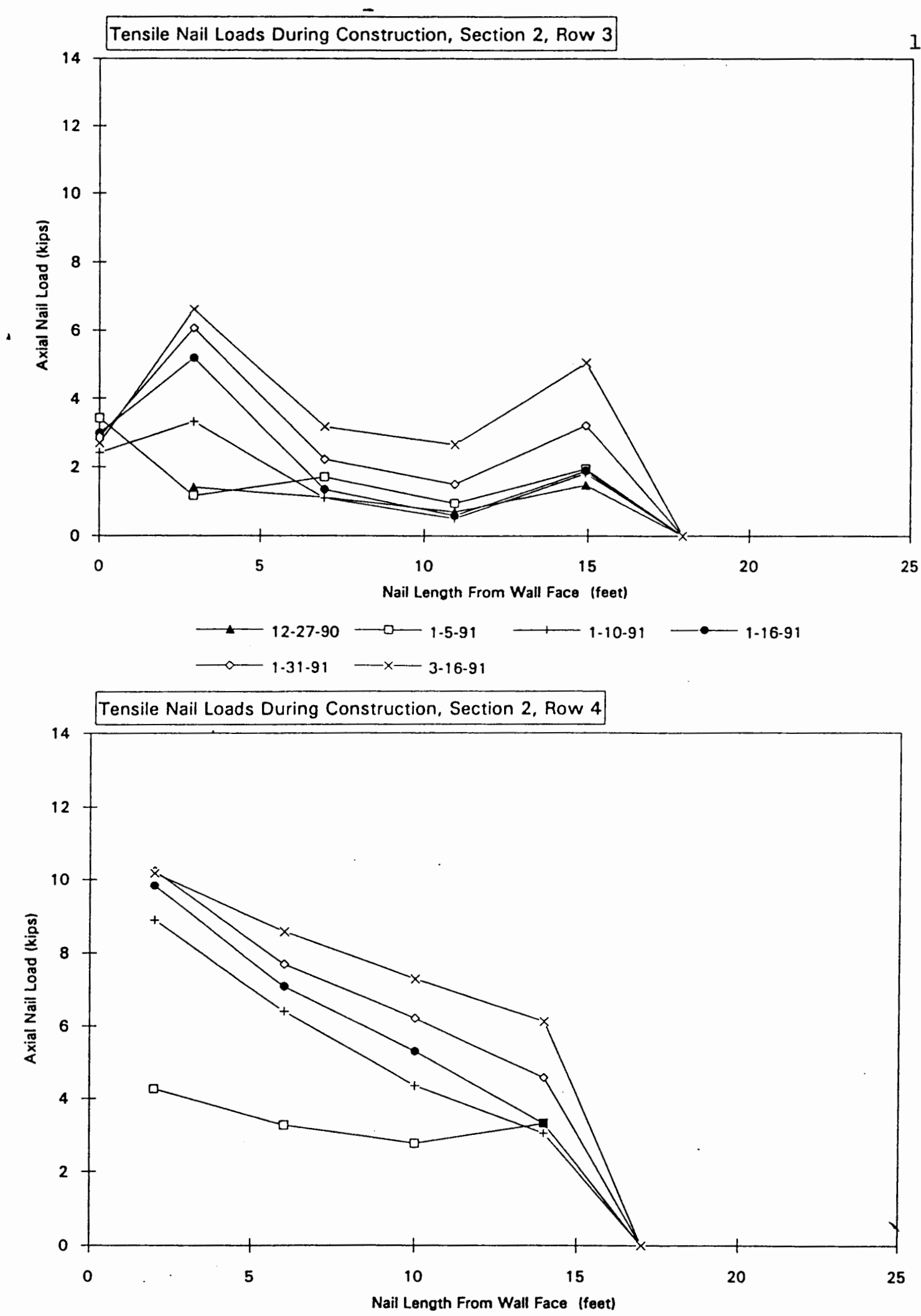

$\longrightarrow$ 1-16-91 1-26-91 - $\longrightarrow$ 1-31-91 3-16-91

FIGURE 75: Instrument section 2 Row 3 And 4 Nail Loads 


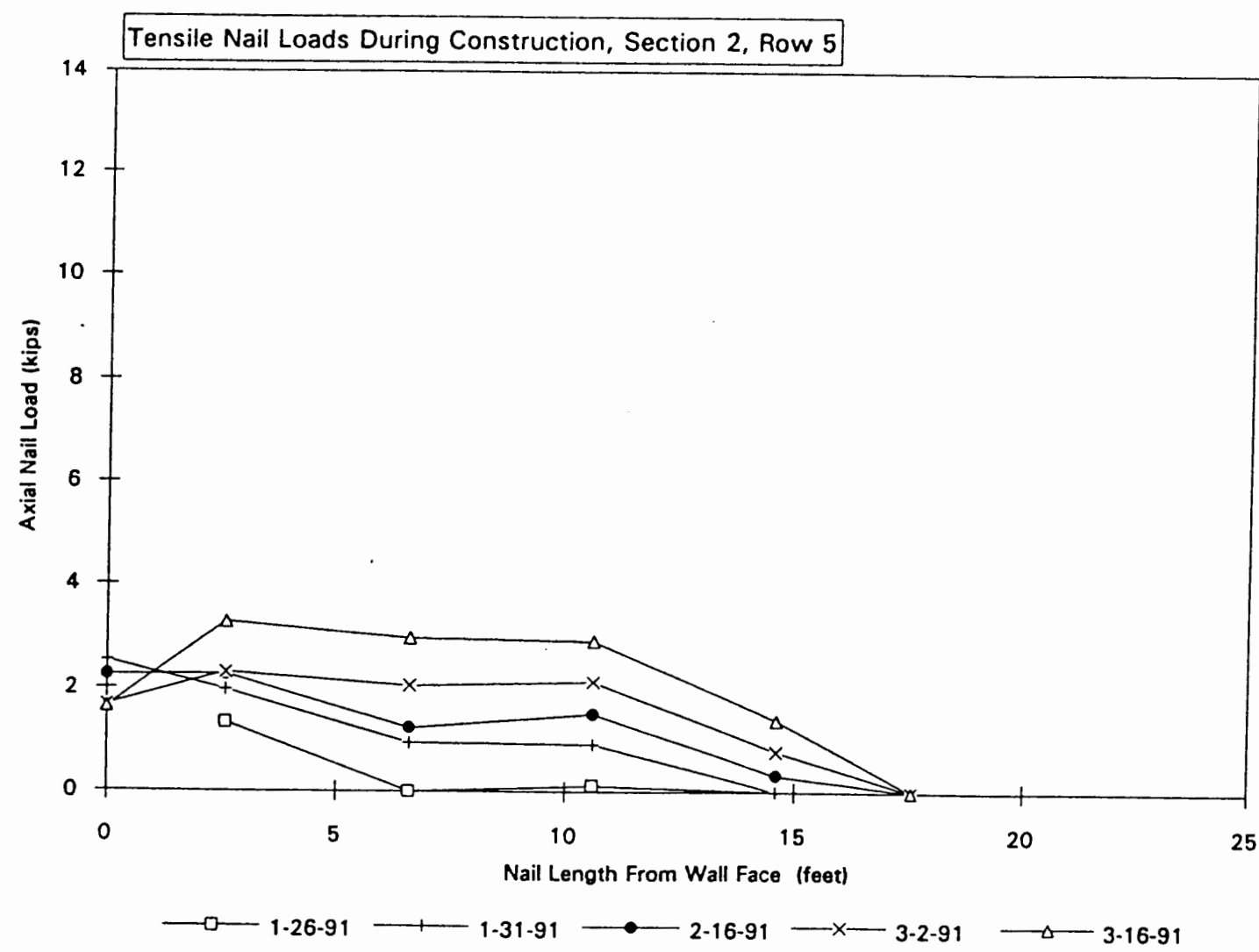

FIGURE 76: Instrument Section 2 Row 5 Nail Loads 


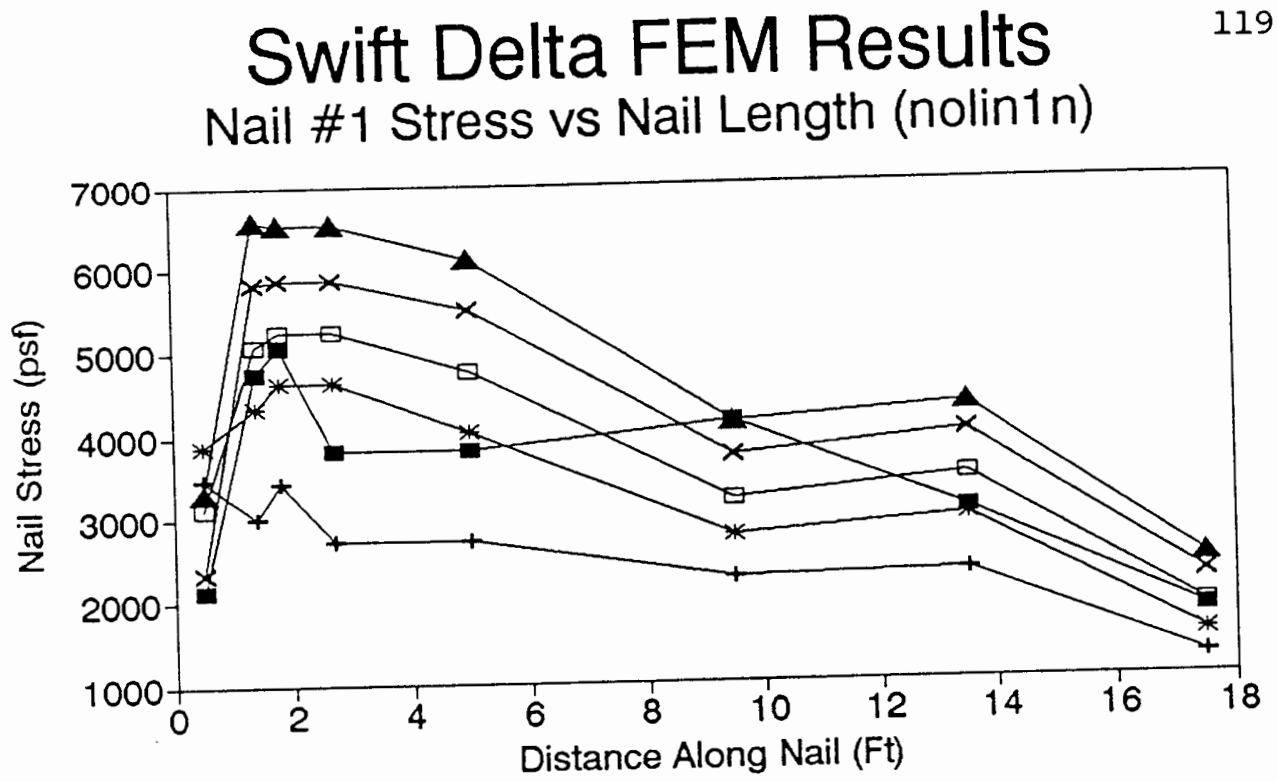

$\rightarrow-$ Lift \#1 $\rightarrow$ Lift \#2 $*-$ Lift \#3
$\rightarrow$ Lift \#4 $\rightarrow$ Lift \#5 $\rightarrow$ Lift \#6

Nail \#2 Stress vs Nail Length (nolin1n)

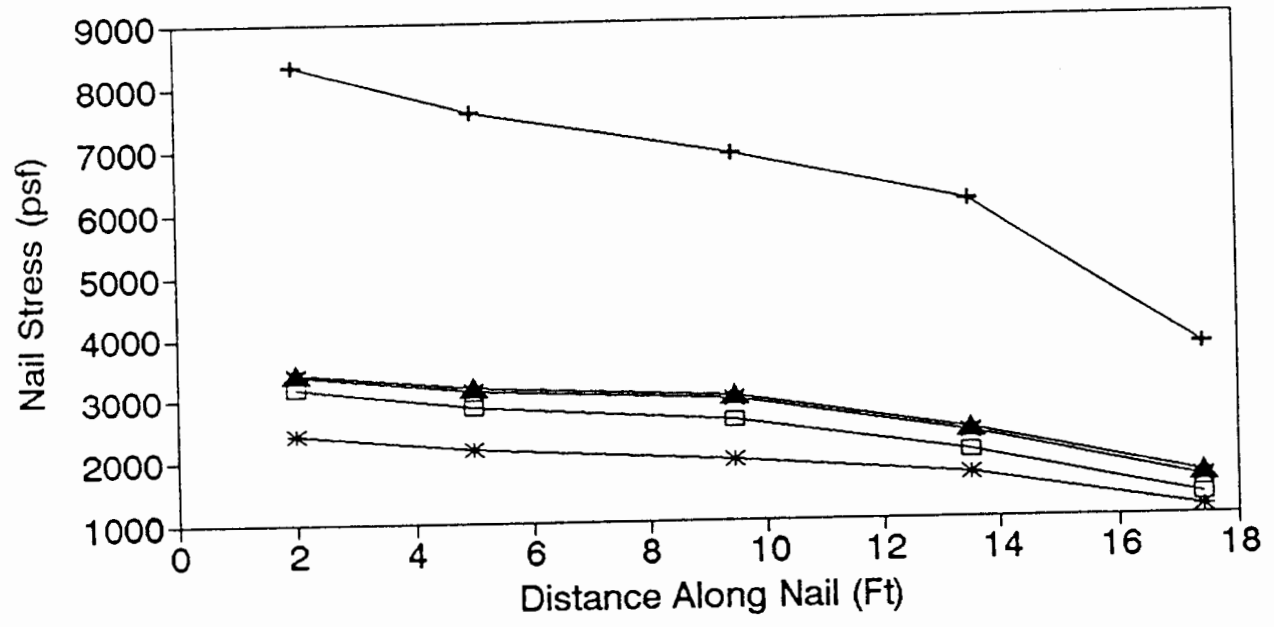

+ Lift \#2 $\rightarrow-$ Lift \#3 $\because-$ Lift \#4
$\rightarrow$ Lift \#5 $\rightarrow-$ Lift \#6

FIGURE 77: NONLIN1N Nail 1 and 2 stresses 


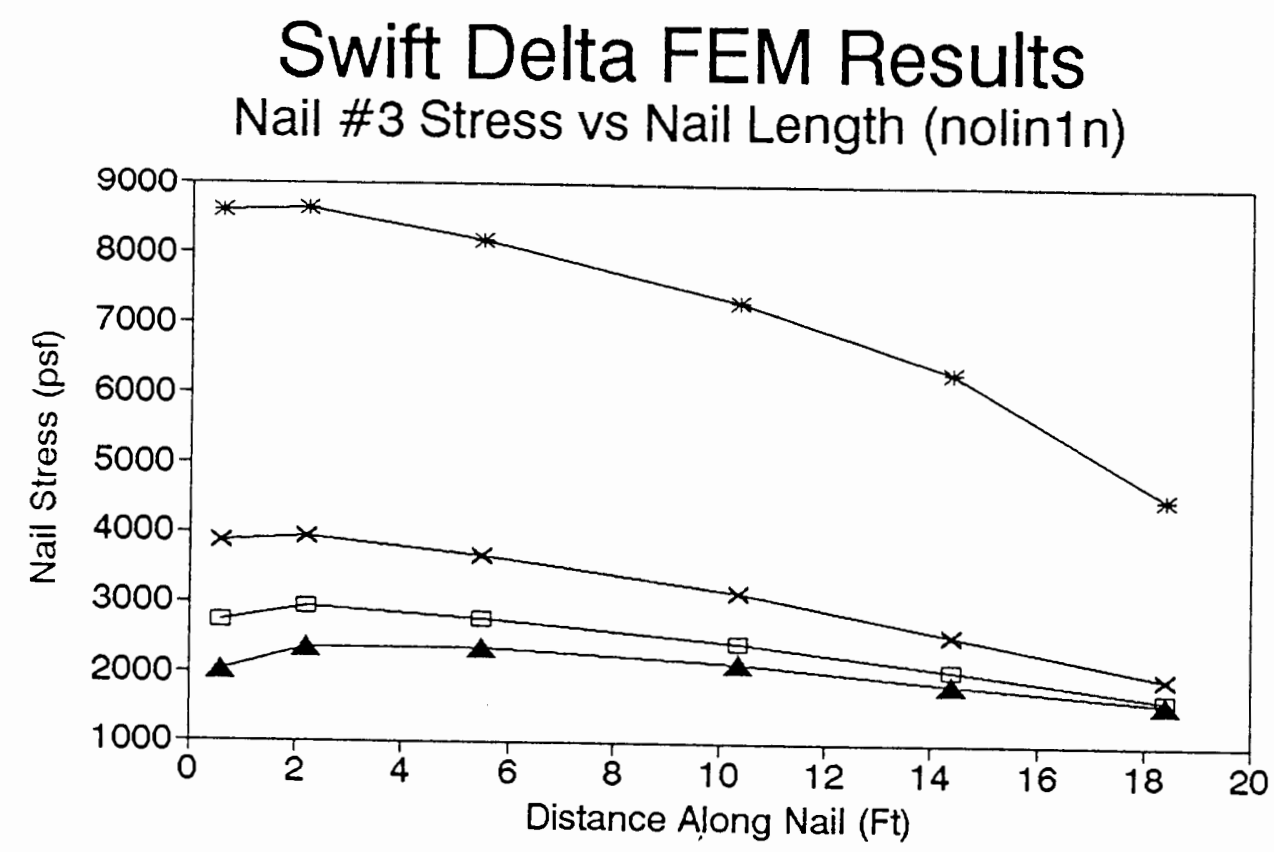

Nail \#3 Stress vs Nail Length (nolin1n)

$\rightarrow-$ Lift \#3- $\square$ Lift \#4 $\rightarrow$ Lift \#5 - Lift \#6

Nail \#4 Stress vs Nail Length (nolin1n)

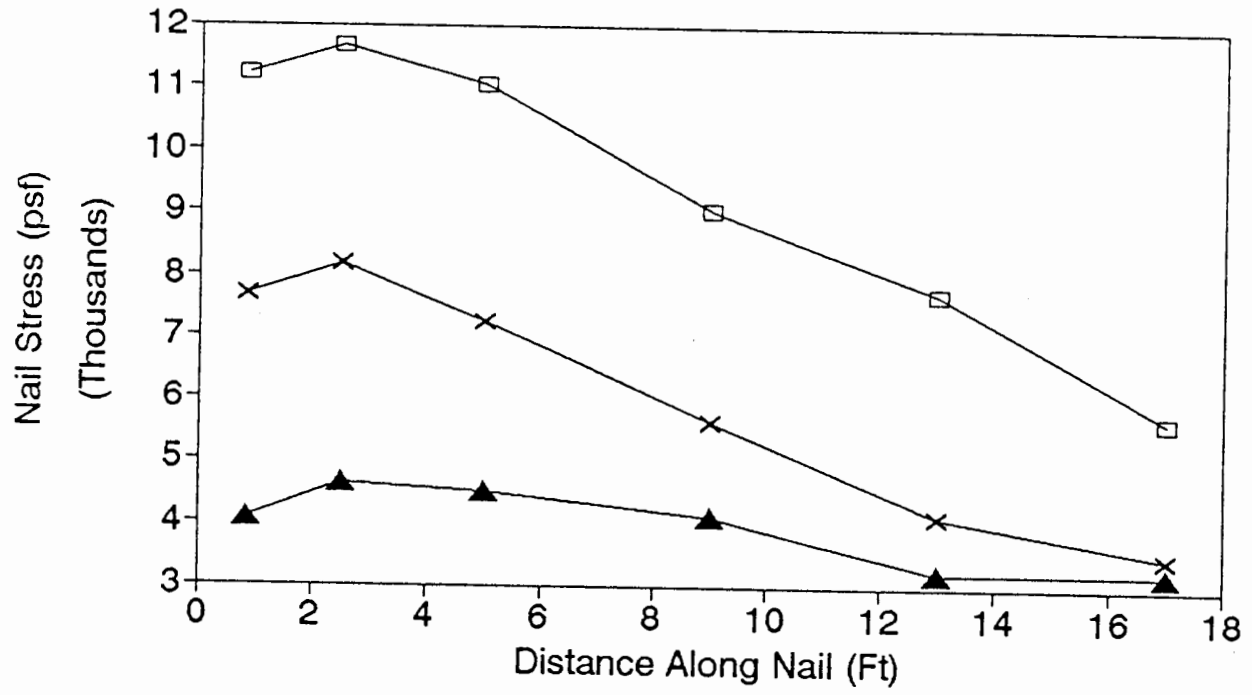

$\square-$ Lift \#4 $\rightarrow$ Lift \#5 - Lift \#6

FIGURE 78: NONLININ Nail 3 and 4 stresses 


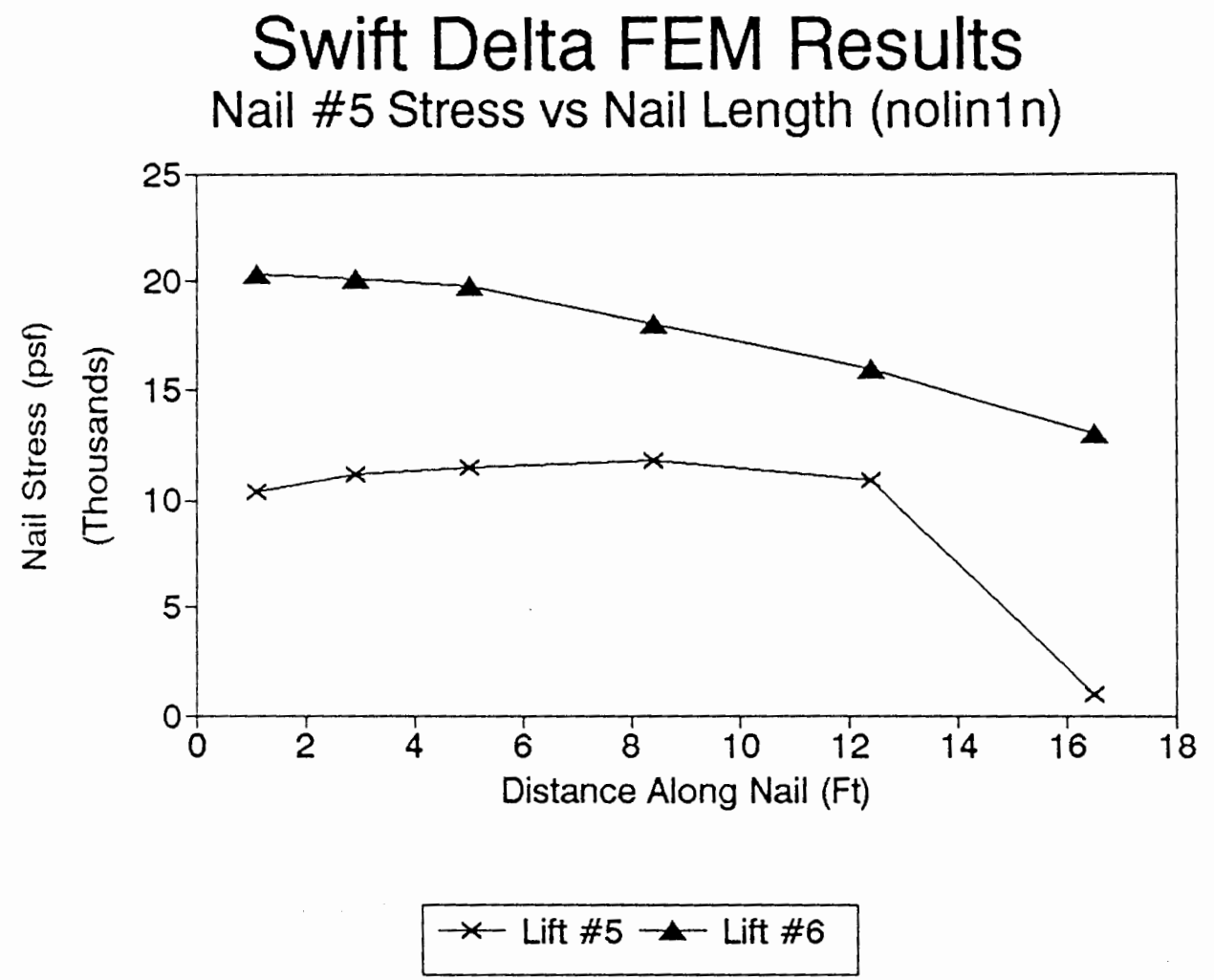

FIGURE 79: NONLIN1N Nail 5 stress 


\section{Swift Delta FEM Results}

Nail \#1 Stress vs Nail Length (nolin1p)

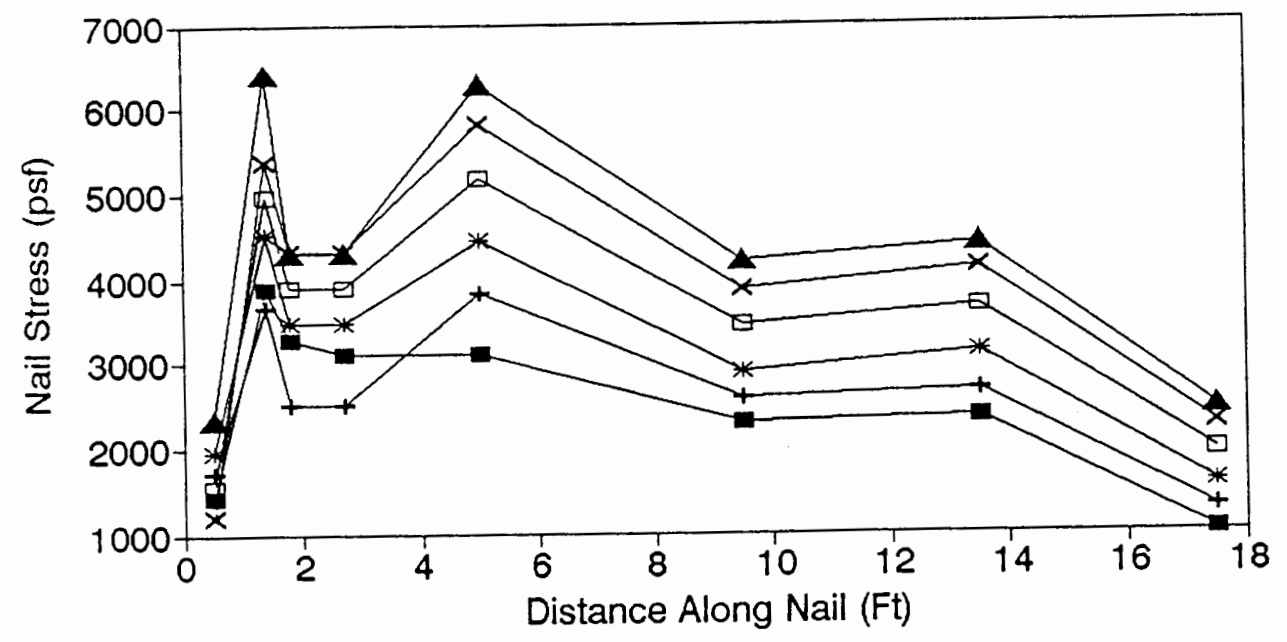

$$
\begin{aligned}
& \rightarrow-\text { Lift \#1- }+ \text { Lift \#2 } \rightarrow \text { - Lift \#3 } \\
& -- \text { Lift \#4 } \rightarrow-\text { Lift \#5 }- \text { Lift \#6 }
\end{aligned}
$$

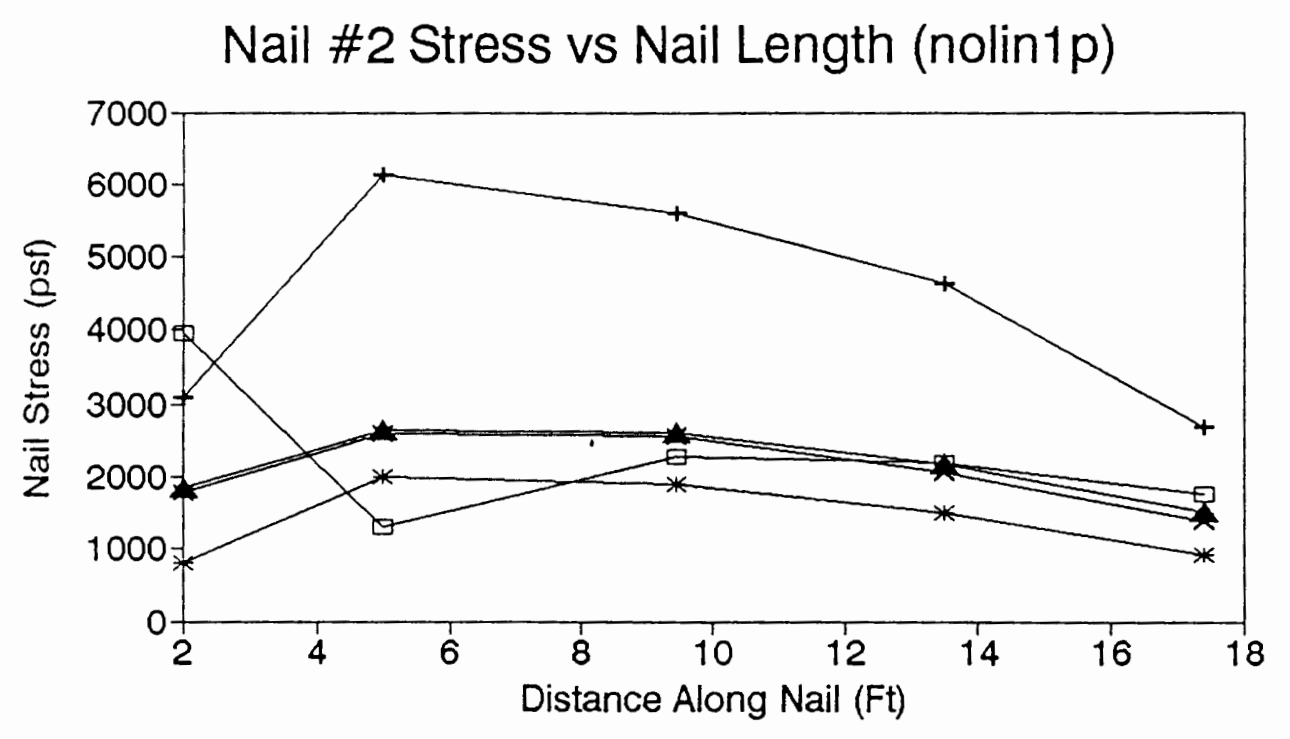

FIGURE 80: NONLIN1P Nail 1 And 2 stresses 


\section{Swift Delta FEM Results}

Nail \#3 Stress vs Nail Length (nolin1p)

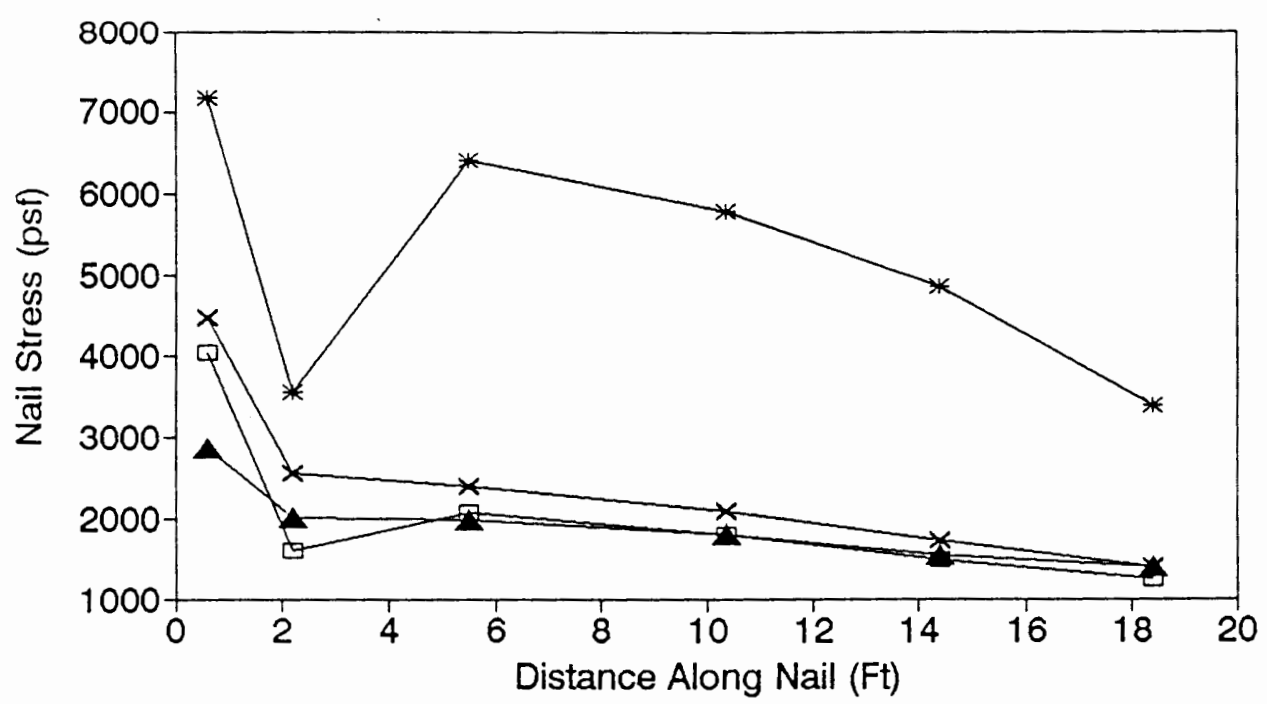

$\rightarrow-$ Lift \#3 ש- Lift \#4 $\rightarrow-$ Lift \#5 $\rightarrow-$ Lift \#6

Nail \#4 Stress vs Nail Length (nolin1p)

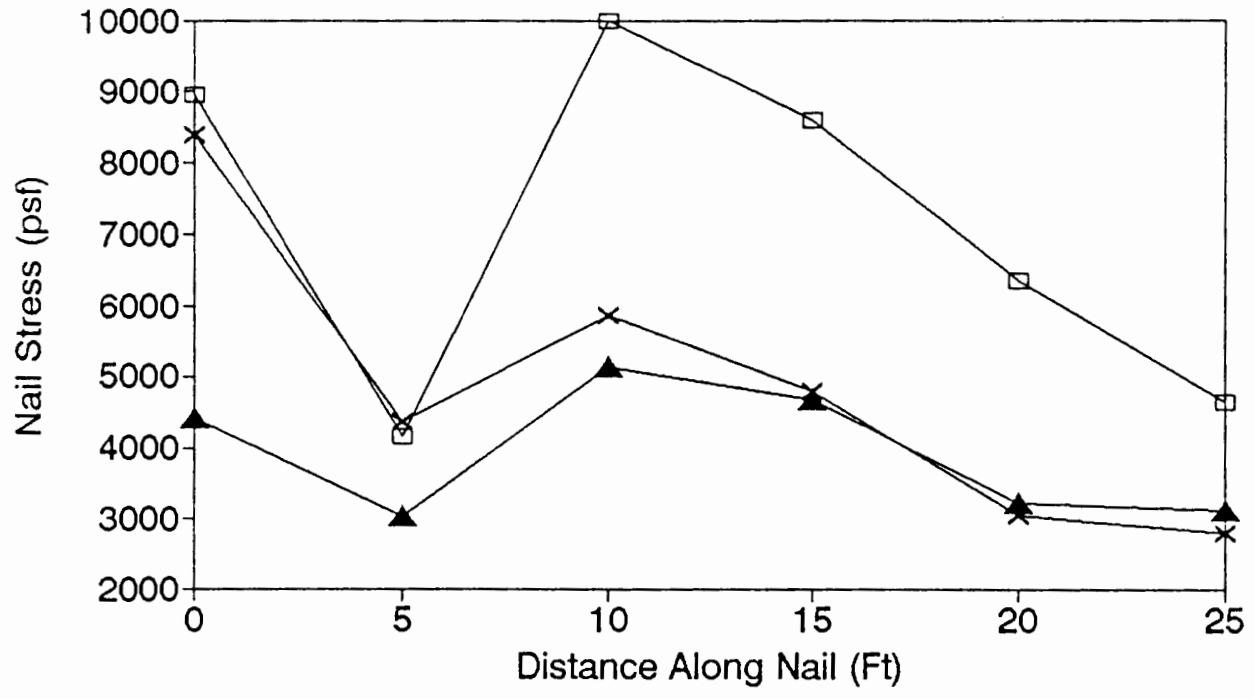

- Lift \#4- Lift \#5-1- Lift \#6

FIGURE 81: NONLIN1P Nail 3 And 4 stresses 


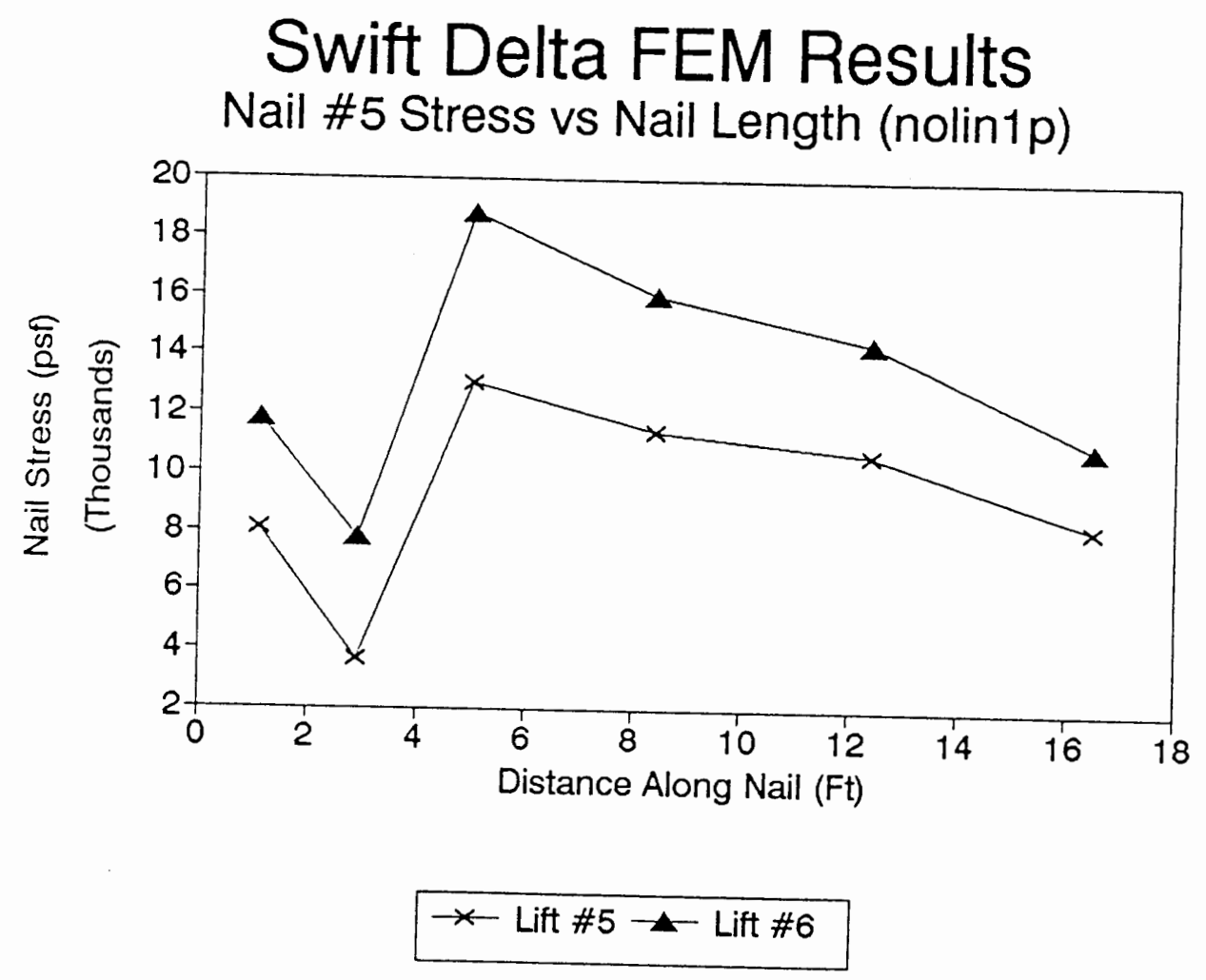

FIGURE 82: NONLINIP Nail 5 And 4 stresses 


\section{Swift Delta FEM Results}

Nail \#1 Stress vs Nail Length (nolin2n)

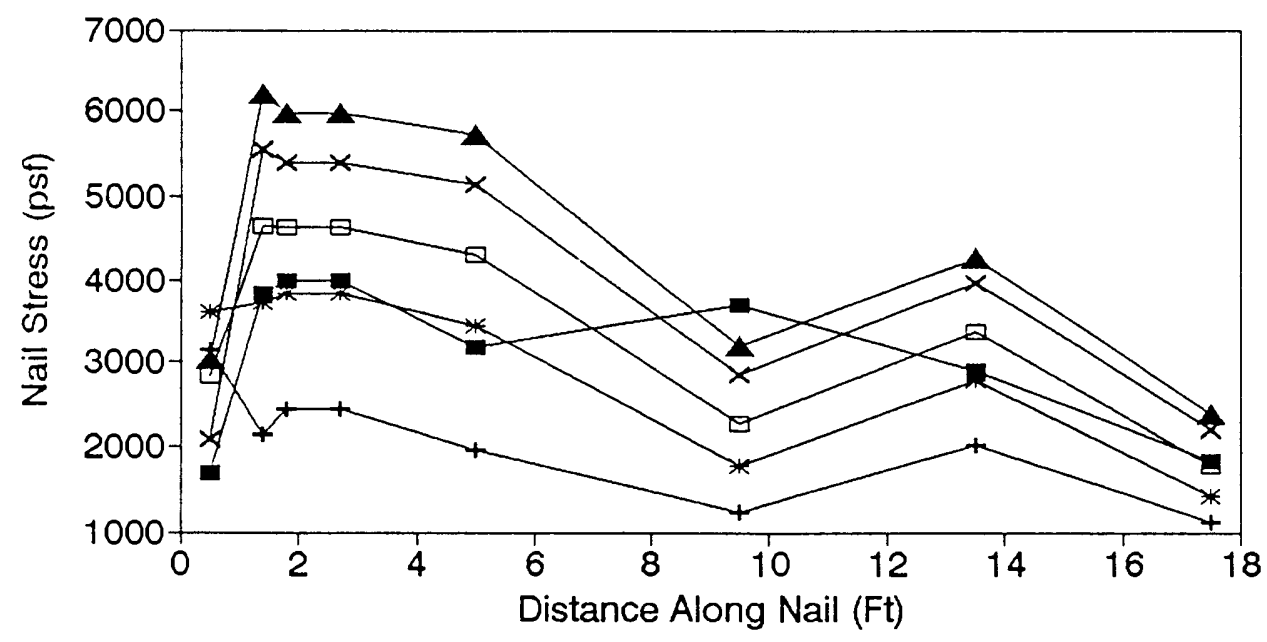

$$
\begin{aligned}
& \rightarrow-\text { Lift \#1 } \rightarrow \text { Lift \#2 } \rightarrow \text { Lift \#3 } \\
& \square-\text { Lift \#4 } * \text { Lift \#5 }- \text { Lift \#6 }
\end{aligned}
$$

Nail \#2 Stress vs Nail Length (nolin2n)

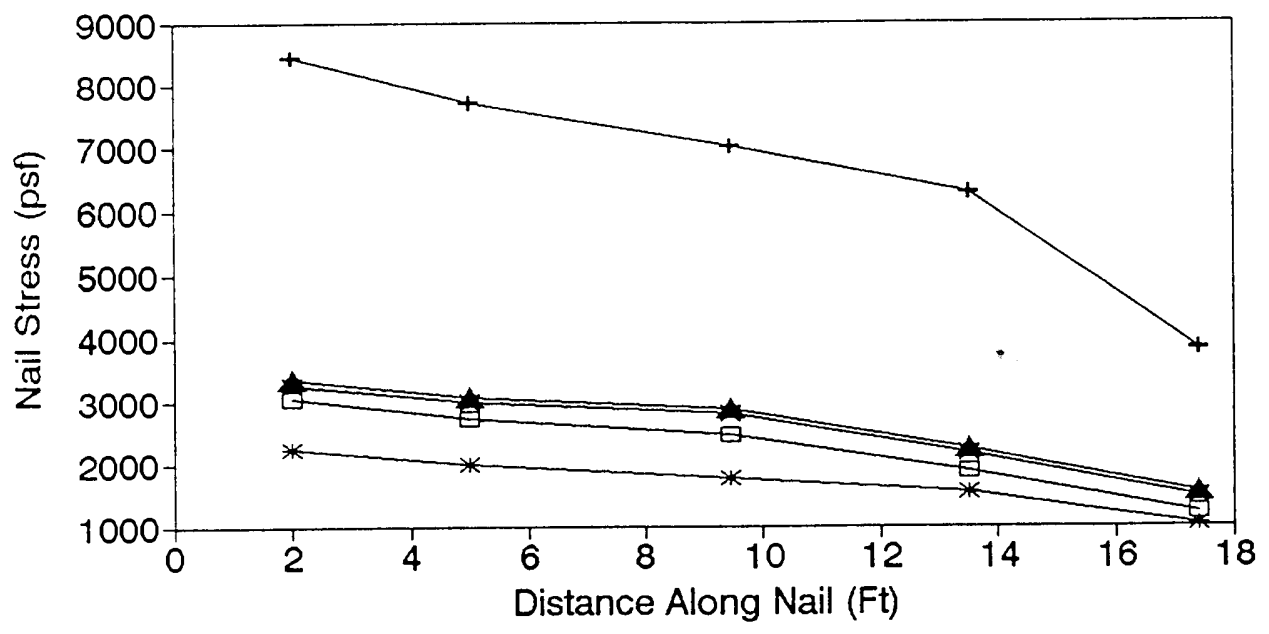

$$
\begin{aligned}
& + \text { Lift \#2 } \rightarrow-\text { Lift \#3-口 Lift \#4 } \\
& \times- \text { Lift \#5 } \rightarrow-\text { Lift \#6 }
\end{aligned}
$$

FIGURE 83: NONLIN2N Nail 1 And 2 stresses 


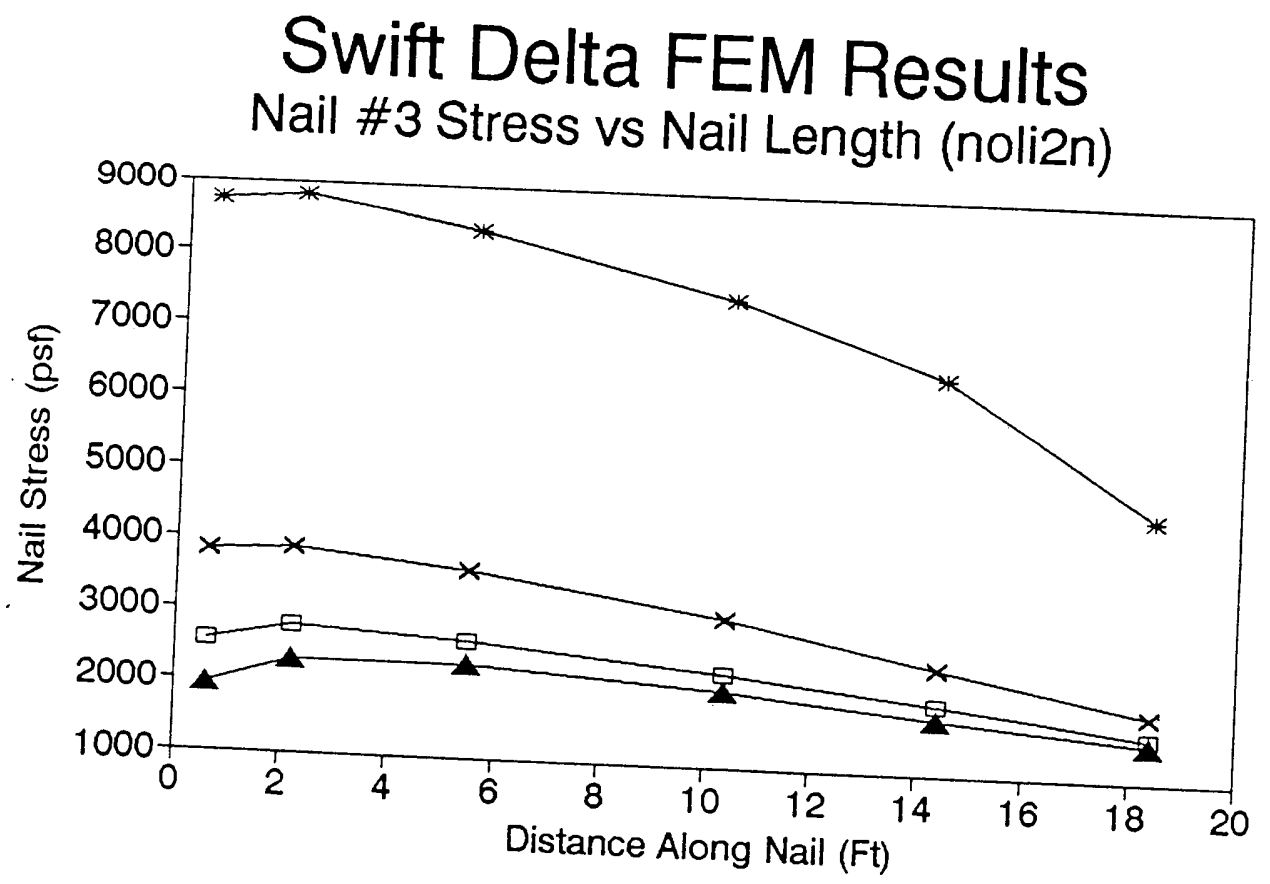

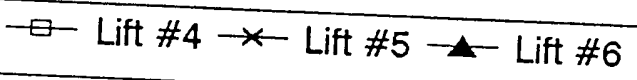

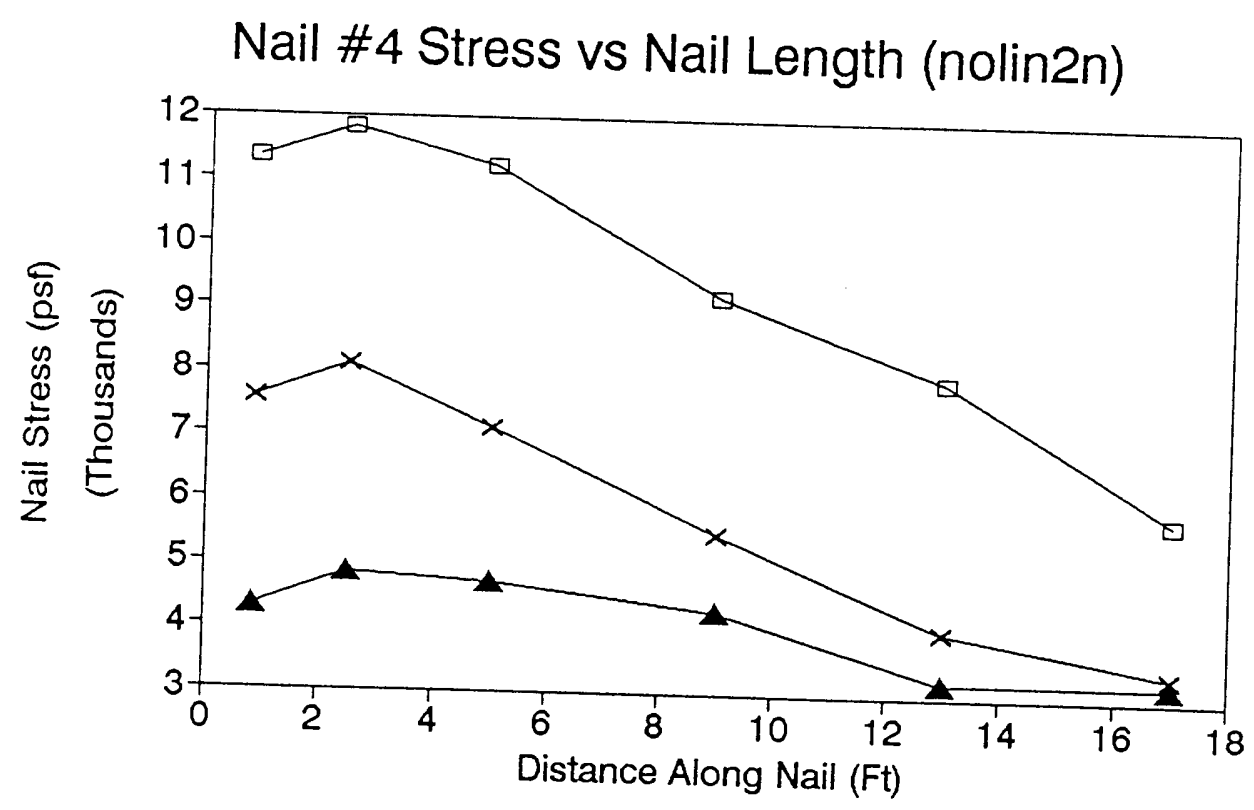

FIGURE 84: NONLIN2N Nail 3 And 4 stresses 


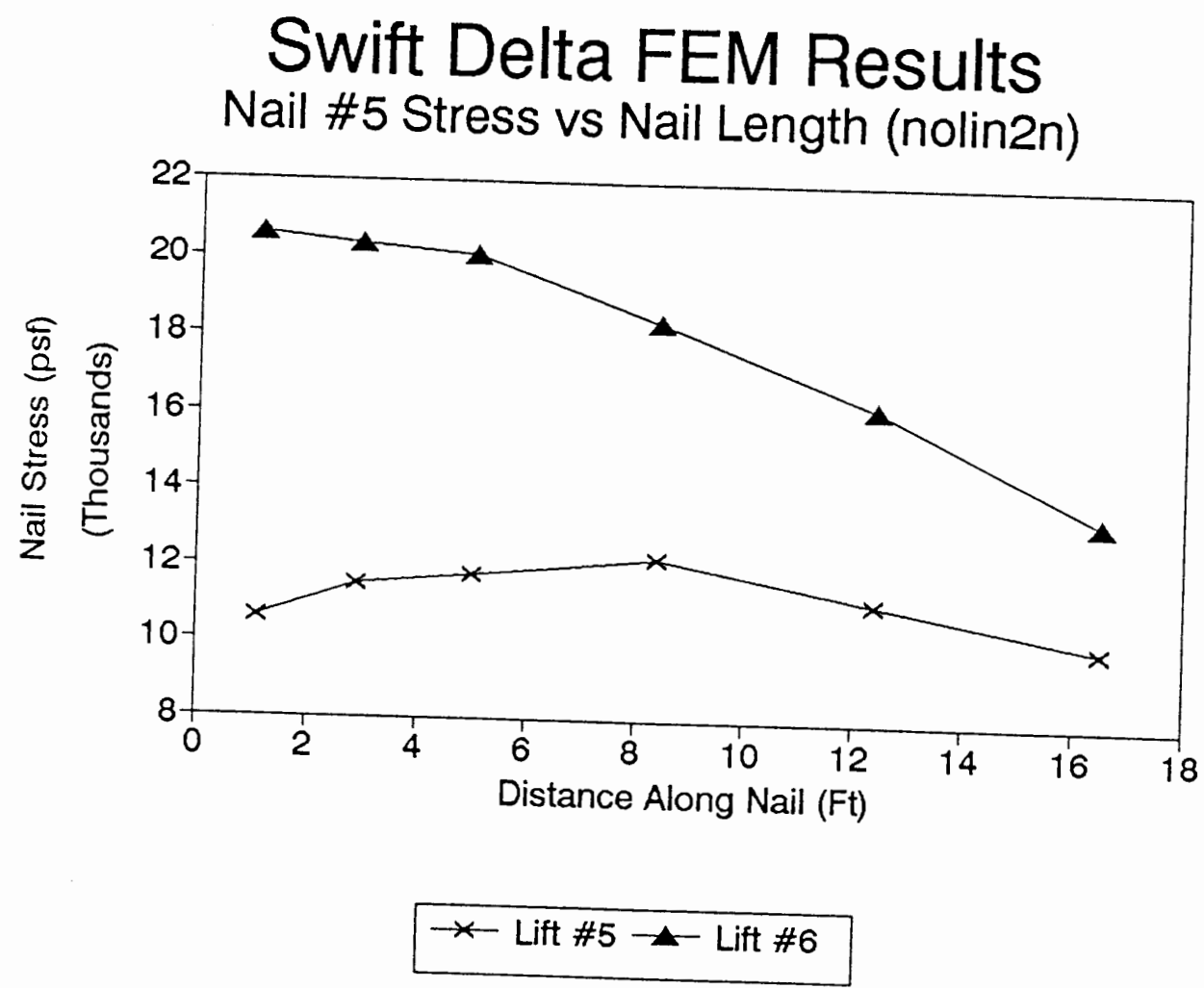

FIGURE 85: NONLIN2N Nail 5 


\section{CONCLUSIONS AND FURTHER STUDY}

At the time that this project was started no other FE codes written specifically for soil nail walls was available. The application of ABAQUS was not routine and the general purpose FE code was not soil nail frejndly. Even with this good comparison of modeled deflections to measured data (figure 86) give some support to the validity of the ABAQUS models. However, comparison of predicted nail stresses to measured did not show particularly good agreement. This is in part due to the difficulty in modeling soil nails which mainly lies with the variability in grouting and nail/soil modulus incompatibility. The results of this report indicate that the presence of the pile within the nail zone results in lower over all nail stresses. This is possibly due to soil arching between piling. The nail zone was found to form a gravity block. Within this block horizontal displacements were found to be relatively uniform. This type of movement confirms what has been suggested by others, and that is that soil nail walls behave in a gravity block fashion. With this type of behavior and considering the piling. The piling has to be deflecting with the soil mass and under going new bending stresses. 
Further study in this area could include continued FEM work with nails that more correctly model the initial stress state. A time function should be considered to simulate actual construction time. In addition more full scale studies of pile supported bridge abutment/nail walls should be performed. These studies should incorporate piling instrumentation to accurately measure any nail wall induced bending. The future modeling results and measurements should be combined and used to form a design procedure for pile supported abutments with nail walls in front of them. 


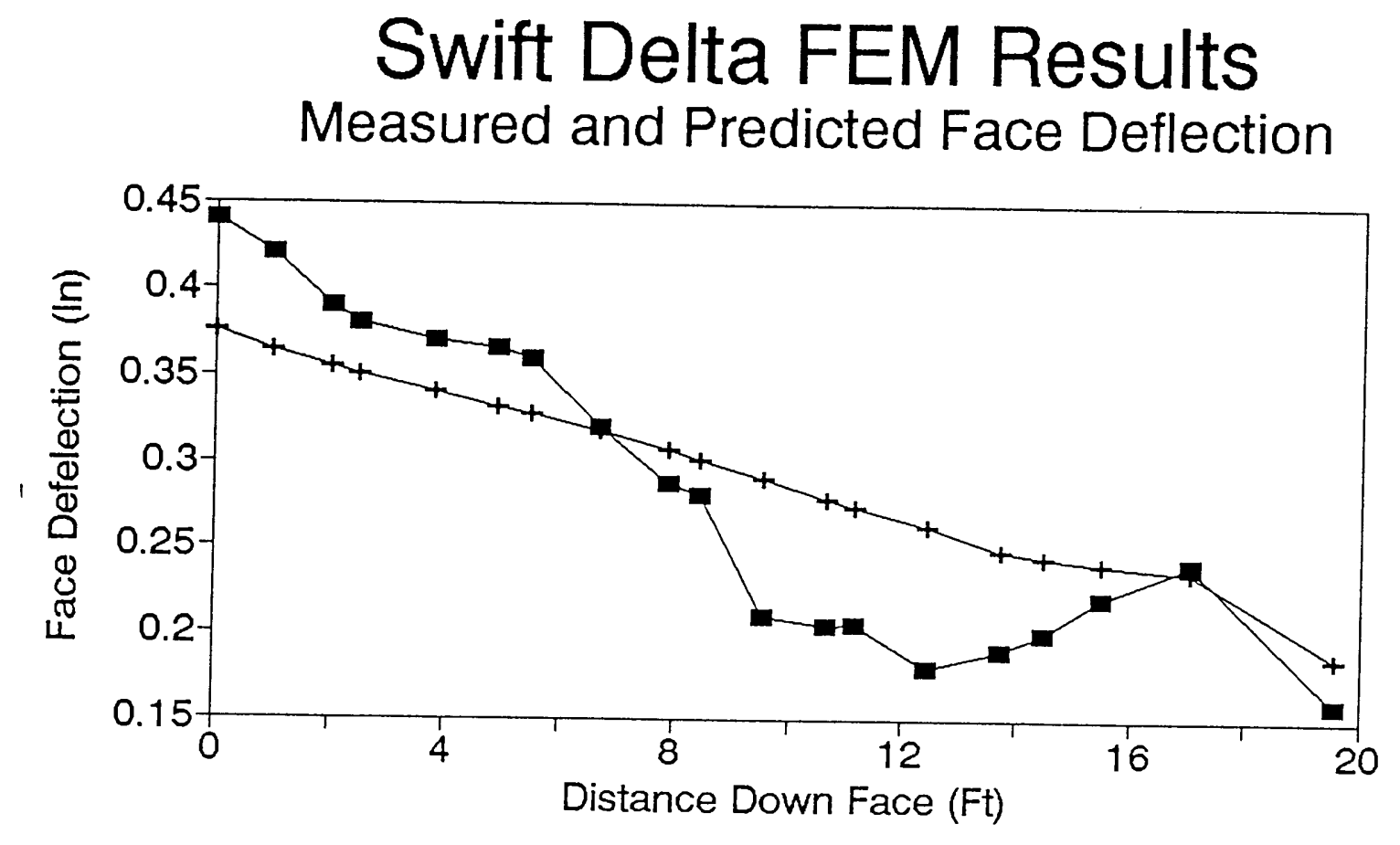

$\rightarrow$ Measured SI-130 + Predicted nolin2n

FIGURE 86: Measured and Predicted Wall Face Deflection 
131

APPENDICES 
Appendix A 


\begin{tabular}{|c|c|c|c|c|c|}
\hline \multicolumn{6}{|c|}{$\begin{array}{l}\text { TABLE A-I } \\
\text { Swift Delta Instrumentation }\end{array}$} \\
\hline Instrument Type & Manufacturer & Model & Readout & Accuracy & Qty \\
\hline $\begin{array}{l}\text { Vibrating wire } \\
\text { Strain Gages }\end{array}$ & Geokon/RST & VK4 100 & Micro Strain & $\begin{array}{l}+/-1 \\
\text { Micro E }\end{array}$ & 58 \\
\hline Load Cell & Carlson/RST & $\begin{array}{r}S C A-100- \\
1.5 \times 4.00 \\
\end{array}$ & Micro strain & & 6 \\
\hline $\begin{array}{l}\text { Pneumatic Earth } \\
\text { Cell }\end{array}$ & SINCO & 51408200 & psi & $.25 \%$ & 2 \\
\hline Tiltmeter/Plates & SINCO & $\begin{array}{l}50304400 / 503 \\
2300\end{array}$ & $2(\sin )$ theta & & 3 \\
\hline $\begin{array}{l}\text { Single Point } \\
\text { Extesometer }\end{array}$ & RST & $\mathrm{EX}-1$ & In & $\begin{array}{l}1 \text { in } \\
10,000\end{array}$ & 1 \\
\hline Survey Tag Line & Wild EDM & $\mathrm{T}-16$ & Feet & $.05 \mathrm{Ft}$ & 2 \\
\hline $\begin{array}{l}\text { Load Cell } \\
\text { Read Out }\end{array}$ & RST & Micro E 350 & $\begin{array}{l}\text { Micro } \\
\text { Strain }\end{array}$ & $+/-1$ & 1 \\
\hline $\begin{array}{l}\text { Strain Gage } \\
\text { Readout }\end{array}$ & Geokon/RST & $G K-401$ & $\begin{array}{l}\text { Micro } \\
\text { Strain } \\
\end{array}$ & $\begin{array}{l}+/- \\
1 \mathrm{psi}\end{array}$ & 1 \\
\hline $\begin{array}{l}\text { Earth Pressure } \\
\text { Cell Readout }\end{array}$ & SINCO & & & $\begin{array}{l}+/- \\
1 \mathrm{psi}\end{array}$ & 1 \\
\hline $\begin{array}{l}\text { LVDT } \\
\text { Extensometers }\end{array}$ & RST & $\mathrm{EX}-1$ & In & $\begin{array}{l}1 \text { in } \\
100\end{array}$ & 2 \\
\hline
\end{tabular}


134

APPENDIX B

NOLIN1NP INPUT FILE 
*INITIAL CONDITIONS, TYPE=STRESS, GEOSTATIC

SOIL $, 0.0,35,-3500.0,0.0,1.0$

$\star \star$

**-.-- REMOVAL OF ELEMENTS TO BE INSTALLED DURRING CONSTRUCTION

*STEP, AMPLITUDE $=$ RAMP

$\star \star$

LOAD 1 REMOVAL OF ELEMENTS TO BE ADDED LATER.

*MODEI, CHANGE, REMOVE

PILE

^MODEL CHANGE, REMOVE

AP1SC

^MODEL CHANGE, REMOVE

AP2SC

^MODEL CHANGE, REMOVE

AP3SC

*MODEL CHANGE, REMOVE

AP4 SC

*MODEL CHANGE, REMOVE

AP5SC

^MODEL CHANGE, REMOVE

AP6SC

*MODEL CHANGE, REMOVE

NAIL1

^MODEL CHANGE, REMOVE

NAIL2

* MODEL CHANGE, REMOVE

NAIL3

*MODEL CHANGE, REMOVE

NAIL4

* MODEL CHANGE, REMOVE

NAIL5

$\star \star$

*END STEP

$\star \star$

$\star \star$

* STEP, AMPLITUDE=RAMP

**-

**-1-0-0-0.-

$\star \star$

$\star \star$

** $*$

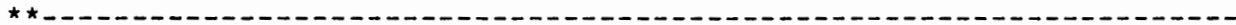

$\star \star$

LOAD 2 APPLICATION OF GEOSTATIC STRSS

*GEOSTATIC

$\star D L O A D, O P=N E W$

SOIL, BY, -102.0

$\star \star$

$\star \star$

$\star \star$

**

$\star \star$

*BOUNDARY, OP=NEW

$\begin{array}{rrr}1, & 1,, & 0.0 \\ 2, & 1, & 0.0 \\ 4, & 1, & 0.0 \\ 6, & 1, & 0.0 \\ 8, & 1, & 0.0 \\ 10, & 1, & 0.0 \\ 12, & 1, & 0.0\end{array}$




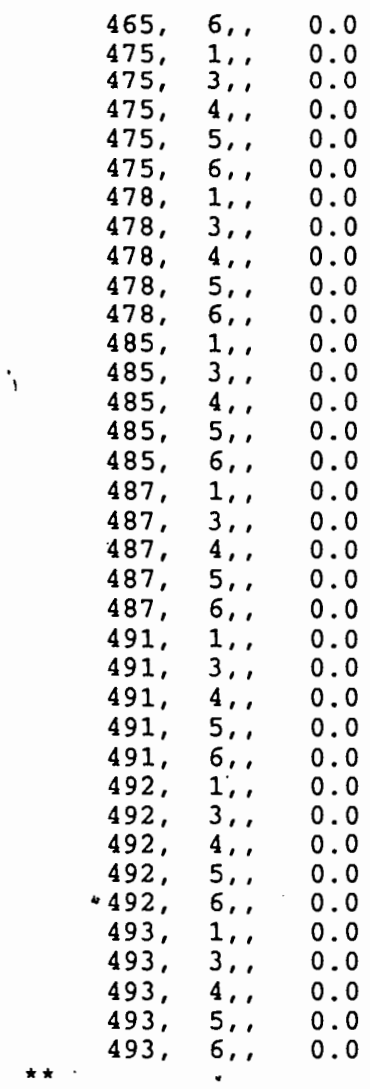

*EL FILE, POSITION=CENTROIDAL

SINV

E

EE

*NODE FILE, GLOBAL=YES

^EL PRINT, ELSET=NAIL1, POSITION=CENTRODIAL

SINV

E

EE

*EL PRINT, ELSET=NAIL2， POSITION=CENTRODIAL

SINV

E

EE

${ }^{\star}$ END STEP

$\star \star \star$

*STEP, AMPLITUDE $=$ RAMP

* STATIC

$\star$ DLOAD

**

* MODEL CHANGE, REMOVE

PILEX 


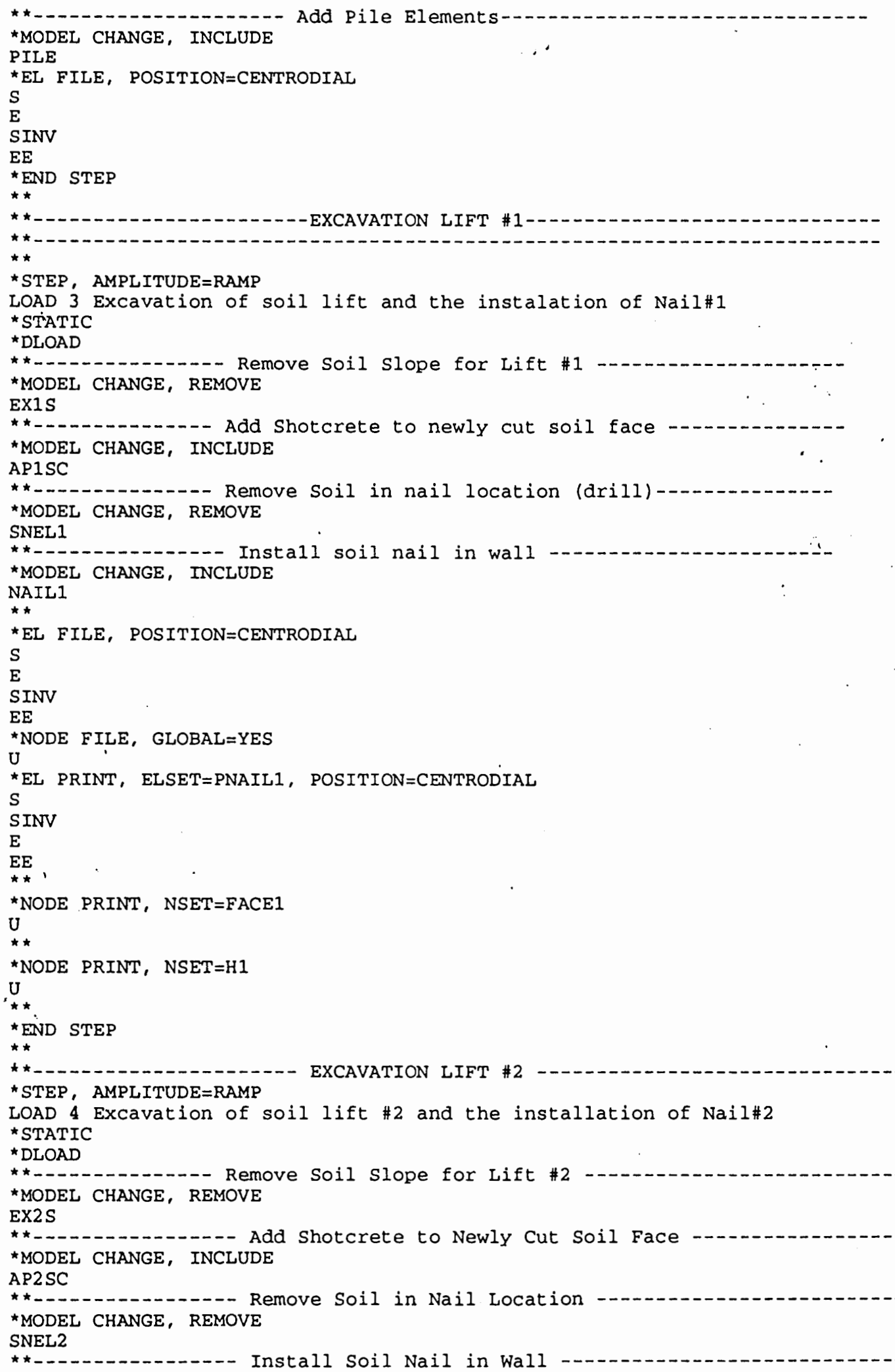


*MODEL CHANGE, INCLUDE

NAIL2

$\star \star$

^EL FILE, POSITION=CENTRODIAL

$S$

$\boldsymbol{E}$

SINV

EE

$\star \star$

^NODE FILE, GLOBAL=YES

$\mathrm{U}$

**

*EL PRINT, ELSET=PNAIL2, POSITION=CENTRODIAL

S

E

*NODE PRINT, NSET=FACE1

U

$\star \star$

${ }^{\star}$ NODE PRINT, NSET $=\mathrm{H} 2$

$\mathrm{U}$

* *

$\star$ END STEP

$\star \star$

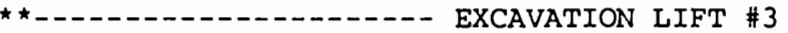

^STEP, AMPLITUDE=RAMP

LOAD 5 Excavation of soil lift \#3 and the installation of Nail\#3

*STATIC

$\star$ DLOAD

**-.--

^MODEL CHANGE, REMOVE

EX3S

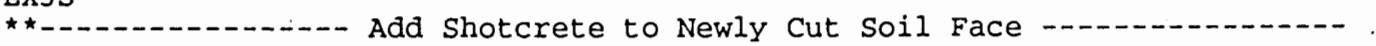

*MODEL CHANGE, INCLUDE

AP3SC

**... Remove Soil in Nail Location

* MODEL CHANGE, REMOVE

SNEL3

**...- Install soil Nail in Wall

*MODEL CHANGE, INCLUDE

NAIL3

$\star \star$

^EL FILE, POSITION=CENTRODIAL

S

E

SINV

EE

*NODE FILE, GLOBAL=YES

$\mathrm{U}$

*EL PRINT, ELSET=PNAIL3， POSITION=CENTRODIAL

$S$

E

^NODE PRINT, NSET $=\mathrm{H} 3$

$\mathrm{U}$

^NODE PRINT, NSET $=$ FACE1

$\mathrm{U}$

$\star$ END STEP

$\star \star$

**

*STEP, AMPLITUDE=RAMP

LOAD 6 Excavation of soil lift \#4 and the installation of Nail\#4 * STATIC

*DLOAD 


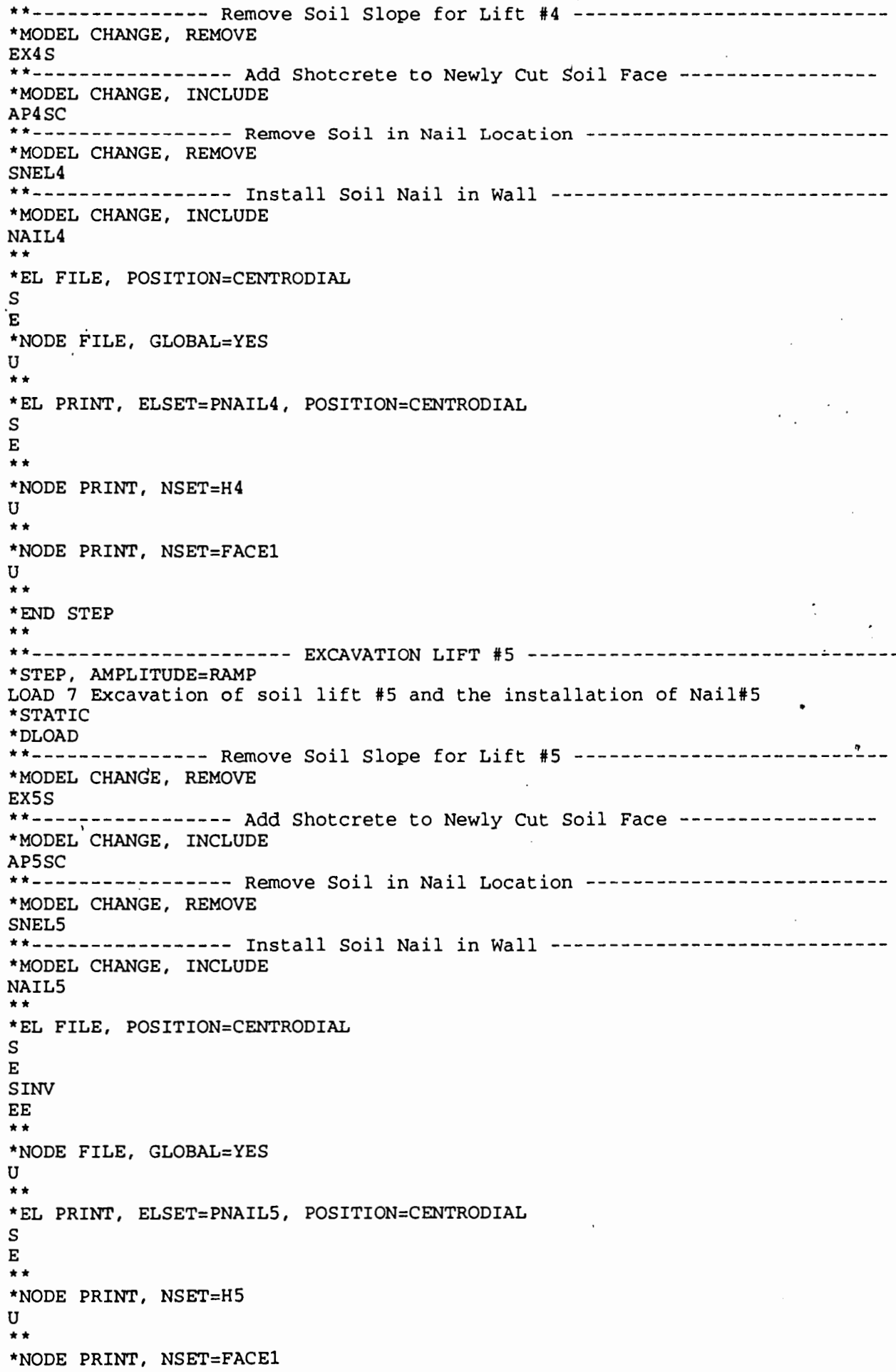


$\star$ END STEP

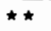

**

*STEP, AMPLITUDE=RAMP

LOAD 8 Excavation of soil lift \#6 and the installation of Nail\# 6

*STATIC

*DLOAD

**-..-...-.-- Remove Soil Slope for Lift \#6

* MODEL CHANGE, REMOVE

EX6S

-.. Add Shotcrete to Newly Cut Soil Face

*MODEL CHANGE, INCLUDE

APGSC

$\star \star$

*EL FILE, POSITION=CENTRODIAL

$S$

E

${ }^{\star}$ NODE FILE, GLOBAL=YES

$\mathrm{U}$

*EL PRINT, ELSET $=$ PNAIL5, POSITION=CENTRODIAL

$S$

^NODE PRINT, NSET $=\mathrm{H} 6$

$\mathrm{U}$

${ }^{\star}$ NODE PRINT, NSET $=$ FACE1

$\mathrm{U}$

**

$\star$ END STEP

$\star \star$

*STEP, AMPLITUDE $=$ RAMP

**-..- Activate shootcrete WEIGHT

* GEOSTATIC

*DLOAD

SHOT, BY, -145.0

**

*EL FILE, POSITION=CENTRODIAL

$S$

E

*NODE FILE，GLOBAL=YES

, U

*EL PRINT, ELSET=PNAIL5， POSITION=CENTRODIAL

$S$

$E$

*NODE PRINT, NSET $=\mathrm{H} 6$

$\mathrm{U}$

$\star \star$

*NODE PRINT, NSET $=$ FACE1

U

* FILE FORMAT, ASCII

* END STEP 
APPENDIX C

LINEAR ELASTIC PATRAN PLOTS 


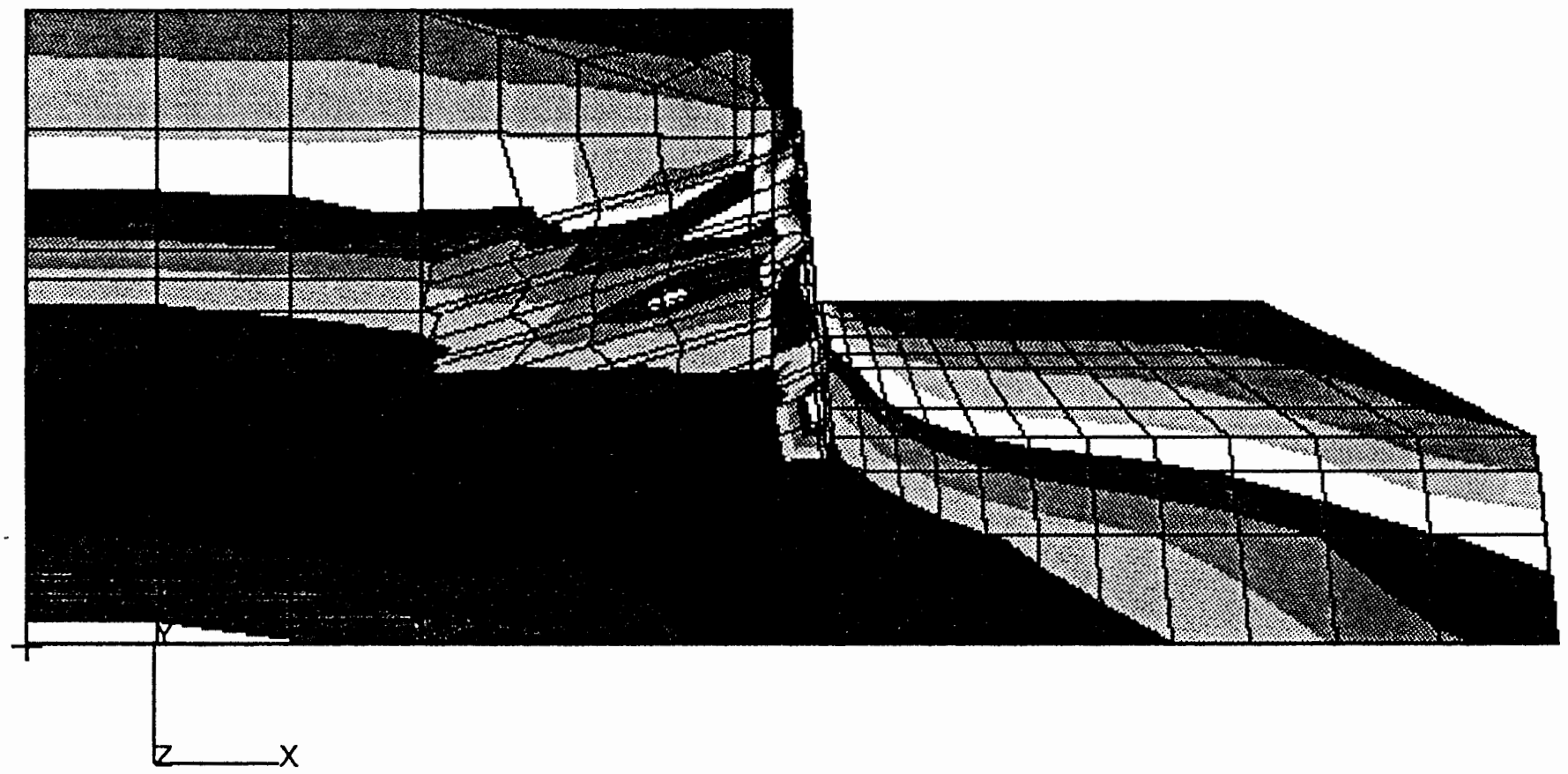

$-700.0$

$-933.3$

$-1167$.

$-1400$

$-1633$

$-1867$.

$-2100$

$-2333$

$-2567$

$-2800$

$-3033$

$-3267$

$-3500$ 


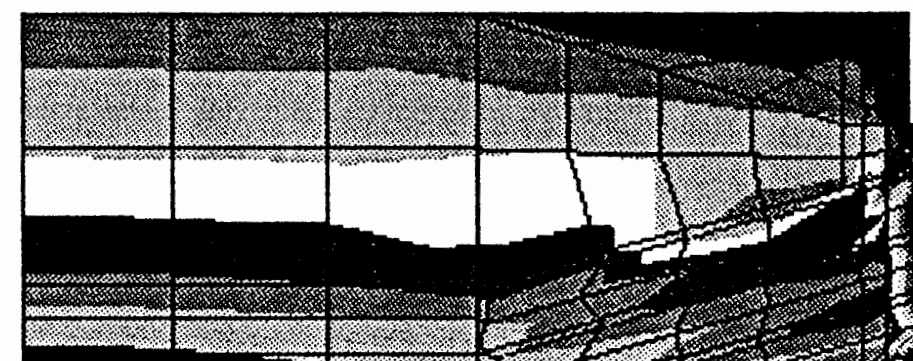




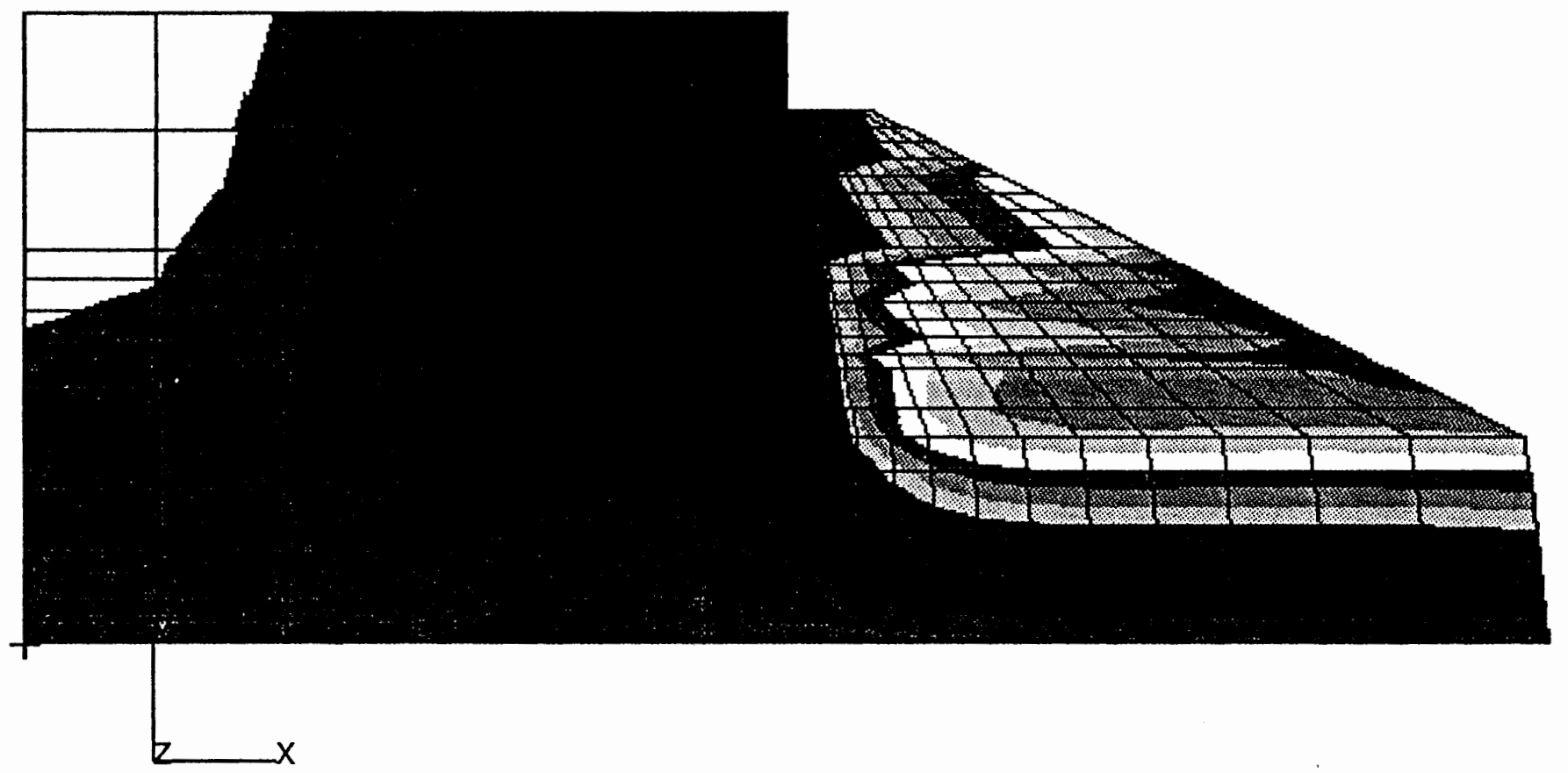


APPENDIX D

NON-LINEAR PATRAN PLOTS 
Fringe: LC=2.1-RES=1.1-P3/PATRAN R.1-(Tensor-YY)-ABAQUS-31-Aug-94 09:42:57 SWIFT DELTA SOIL NAIL FEM RESUL TS

MODEL NOLININ GEOSTATIC STEP 2

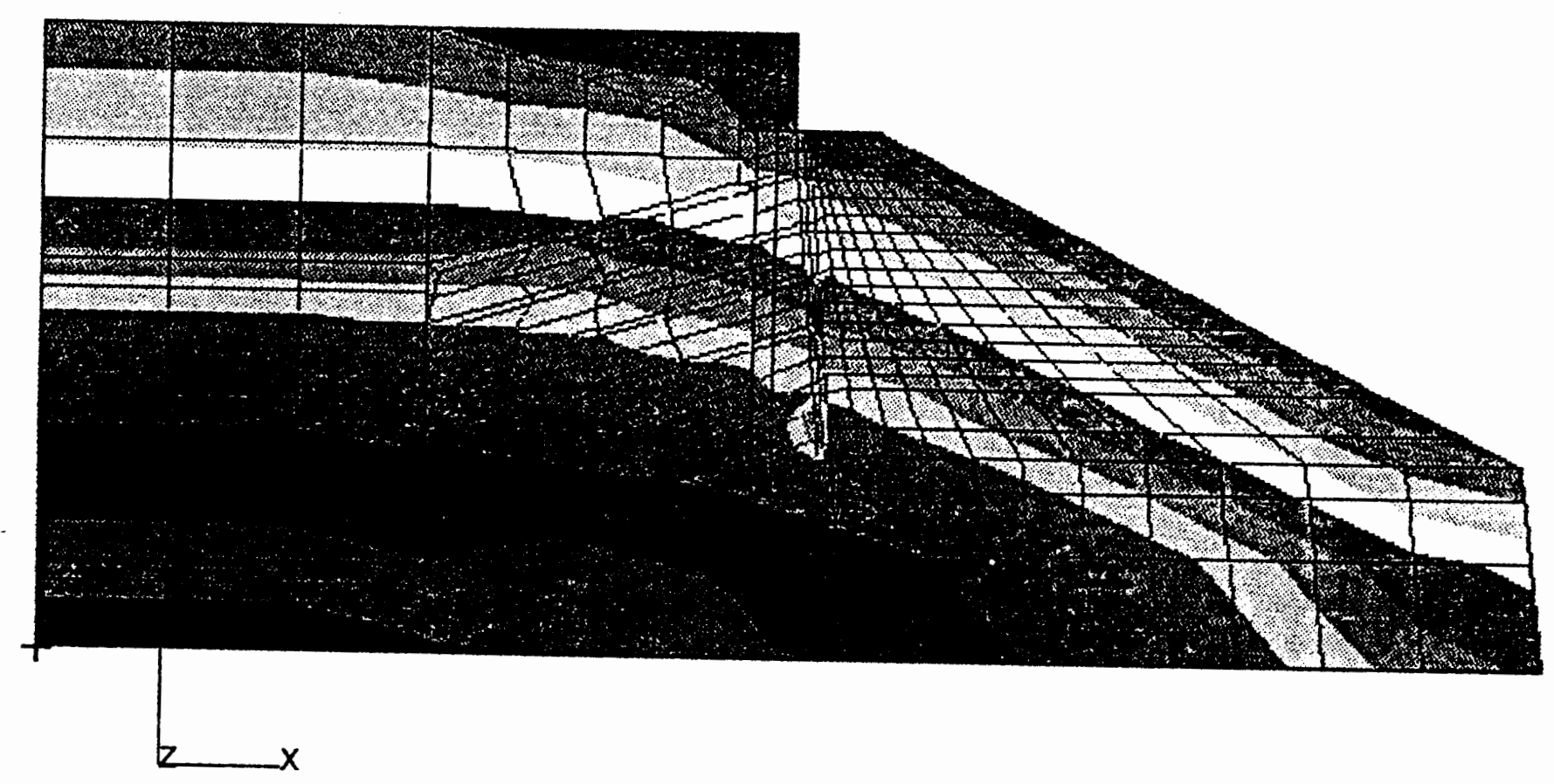

Vert Stress

(psf)

0.

$-233.3$

$-466.7$

$-700.0$

$-933.3$

$-1167$.

-1400 .

$-1633$.

$-1867$.

-2100 .

$-2333$.

$-2567$.

$-2800$

$-3033$.

$-3267$.

-3500 . 
Fringe: $L C=3.3-R E S=1.1$-P3/PATAAN R.1-(Tensor-XX)-ABAQUS-31-Aug-94 10:22:40 SWIFT DELTA SOIL NAIL FEM RESULTS

MODEL NOLIN1N STATIC STEP 4

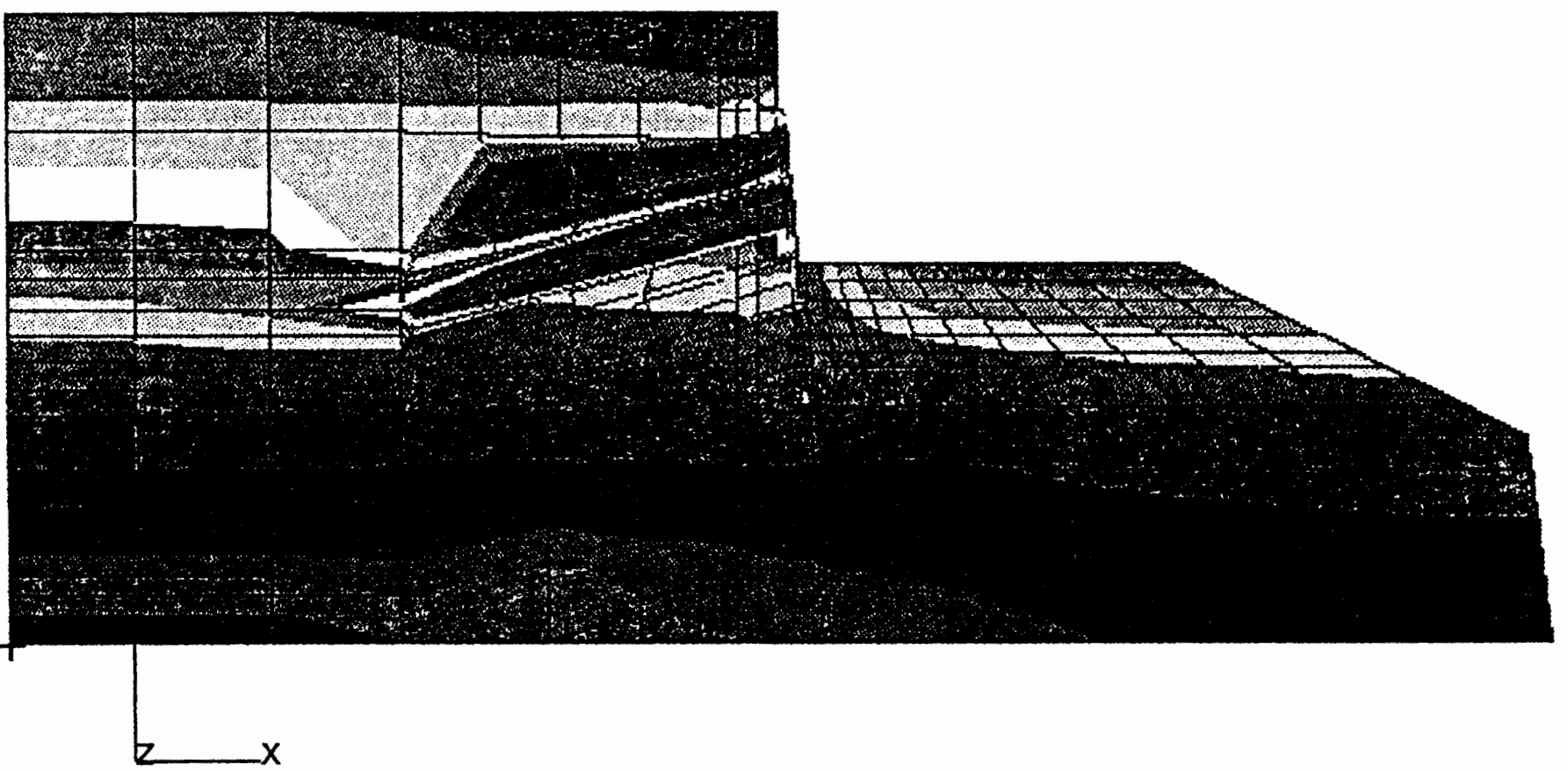

nolin1n3.fil
$-233.3$

$-466.7$

Horiz Stress

(psf)

0.

$\square$

$-700.0$

$-933.3$

$-1167$.

$-1400$

$-1633$.

$-1867$.

$-2100$.

$-2333$

$-2567$.

-2800 .

$-3033$.

$-3267$.

$-3500$ 
Fringe: $L C=3.5-R E S=1.1$-P3/PATRAN R.1-(Tensor-XX)-ABAQUS-31-Aug-94 11:23:11 SWIFT DELTA SOIL NAIL FEM RESULTS

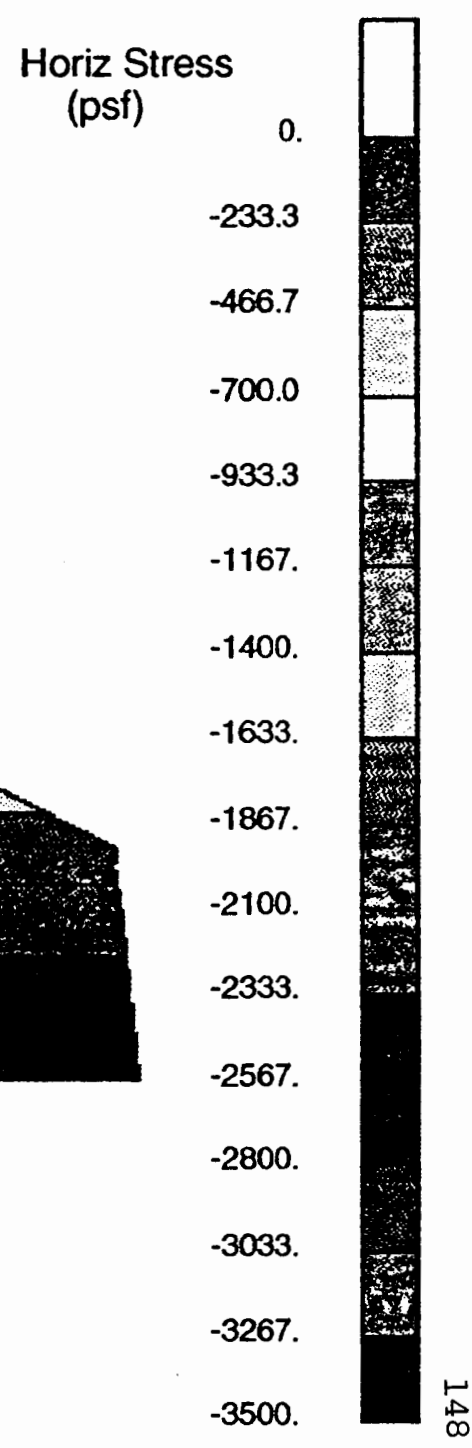


Fringe: $L C=3.2-R E S=3.1$-P3/PATRAN R.1-(Tensor-YY)-ABAQUS-13-May-94 16:58:23 SWIFT DELTA SOIL NAIL WALL FEM RESULTS MODEL NOLIN1P STATIC STEP 3

\begin{tabular}{c} 
Vert Strain \\
.001649 \\
.001304 \\
.0009592 \\
.0006144 \\
.0002696 \\
-.00007518 \\
-.0004200 \\
-.0007647 \\
-.001110 \\
-.001454 \\
-.001799 \\
-.002144 \\
-.002489 \\
-.002833 \\
\hline
\end{tabular}

nolin1p3.fil 
Fringe: $L C=3.2-R E S=4.1-$ P3/PATRAN R. 1-(Nector-X)-ABAQUS-21-May-94 13:54:32

SWIFT DELTA SOIL NAIL WALL FEM RESULTS

Horiz Disp MODEL NOLIN1P STATIC STEP 4

.008571

.007918

.007265

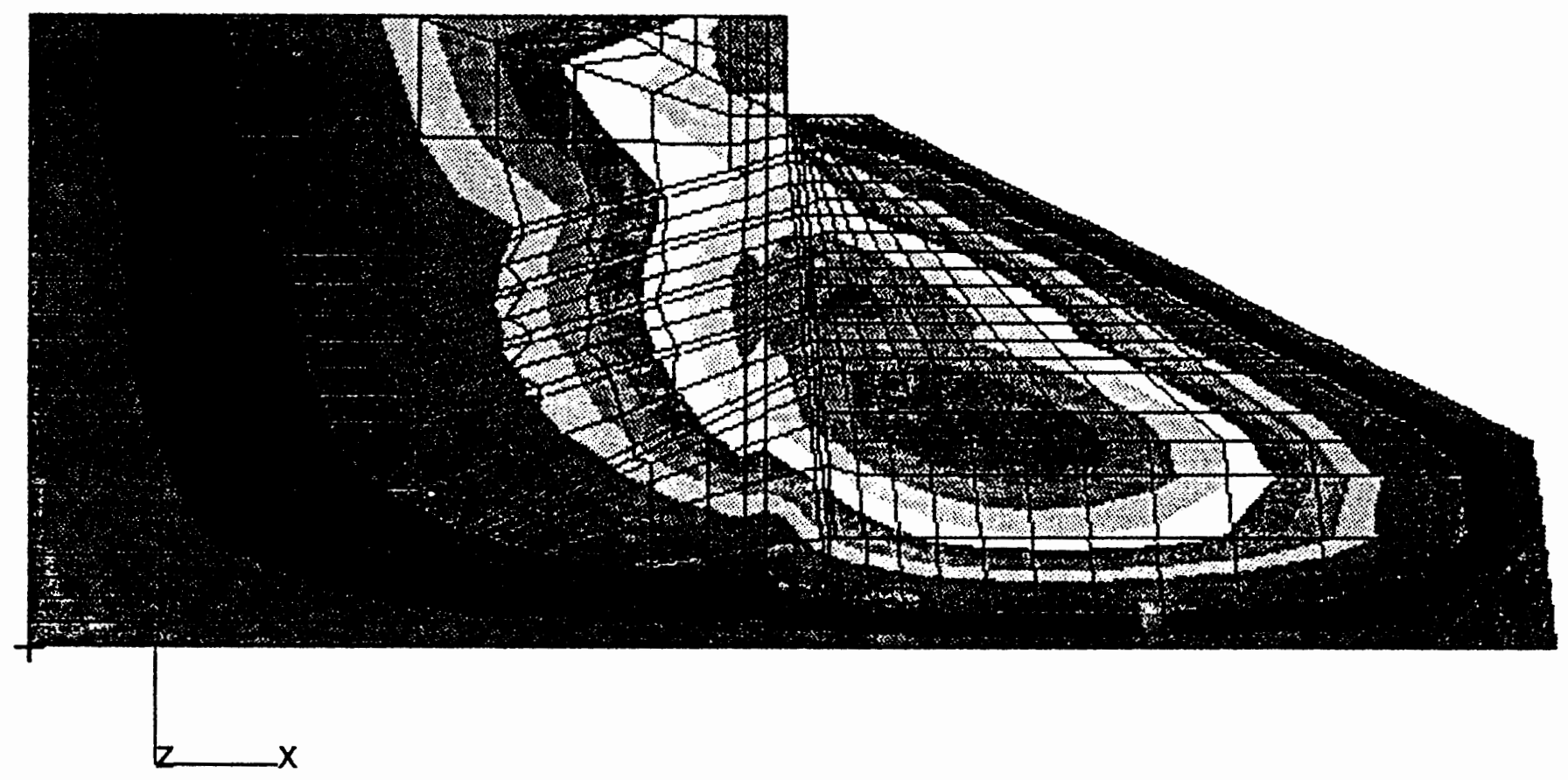

.006612

.005959

.005306

.004653

.004000

.003347

.002694

.002041

.001388

.0007344

.00008136

$-.0005717$

nolintp3.fil

$-.001225$ 
Fringe: $L C=3.7-R E S=2.1-P 3 / P A T R A N$ R.1-(Major)-ABAQUS-17-Sep-94 14:52:41 Major Strain

SWIFT DELTA SOIL NAIL WALL FEM RESULTS

.007492 MODEL NOLIN1P STATIC STEP 8

.006993

.006493

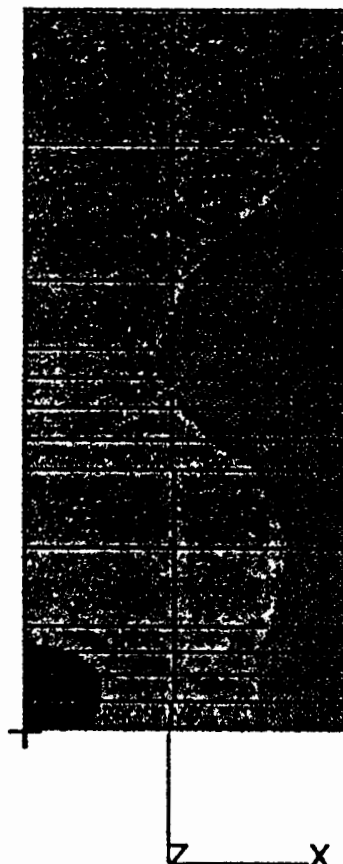

.005994

.005494

.004995

.004495

.003996

.003496

.002997

.002497

.001998

.001498

.0009990

.0004995

nolin1p3.fil

$-.000000001000$ 
Fringe: LC=2.1-RES=1.1-P3/PATRAN R.1-(Tensor-XX)-ABAQUS-31-Aug-94 09:22:06 SWIFT DELTA SOIL NAIL FEM RESULTS

Horiz Stress (psf)

MODEL NOLIN1N GEOSTATIC STEP 2

$-233.3$

$-466.7$

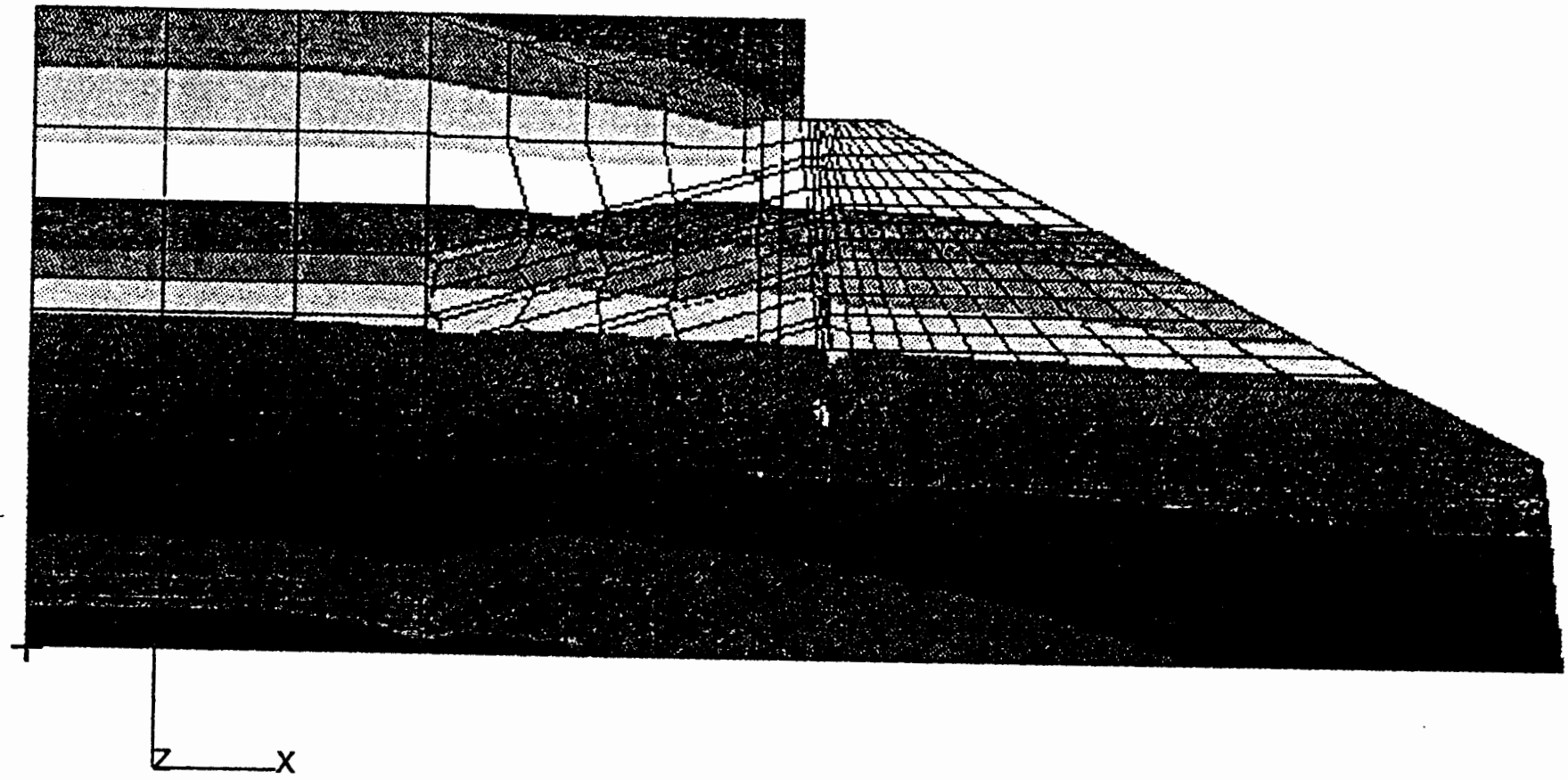

$-700.0$

$-933.3$

$-1167$.

$-1400$

$-1633$.

$-1867$

-2100 .

$-2333$.

$-2567$.

-2800 .

-3033 .

nolin1n3.fil

$-3267$.

-3500 . 
Fringe: $L C=2.17-$ RES $=1.1$-P3/PATRAN R.1-(Tensor-YY)=ABAQUS-23-Jul-94 16:41:55

SWIFT DELTA SOIL NAIL WALL FEM RESULTS

0.

MODEL NOLIN2N STATIC STEP 8

$-233.3$

$-466.7$

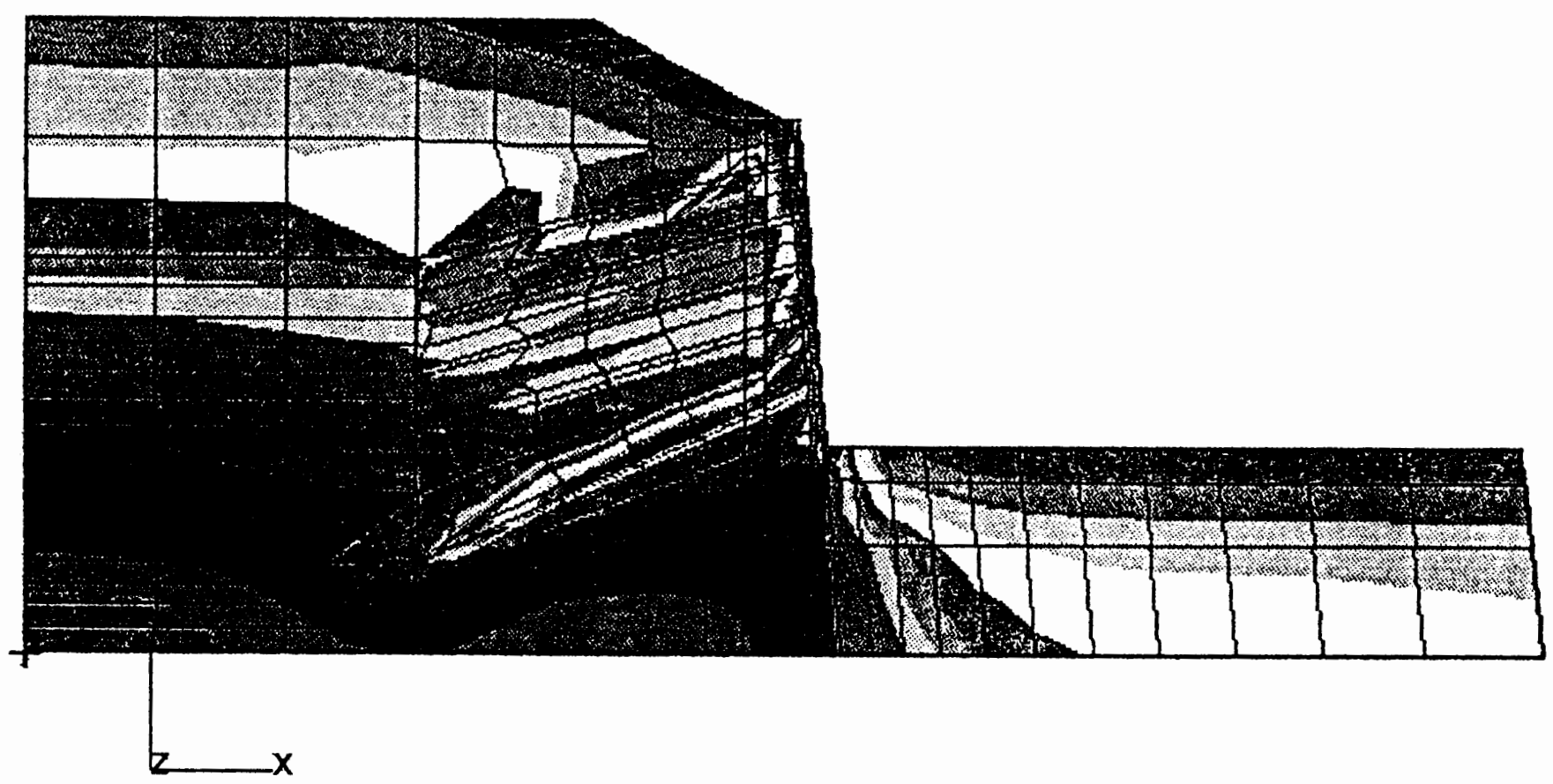

$-700.0$

$-933.3$

$-1167$.

-1400 .

$-1633$.

$-1867$.

$-2100$.

$-2333$.

$-2567$.

$-2800$.

$-3033$.

$-3267$.

nolin2n1.fil

-3500 . 


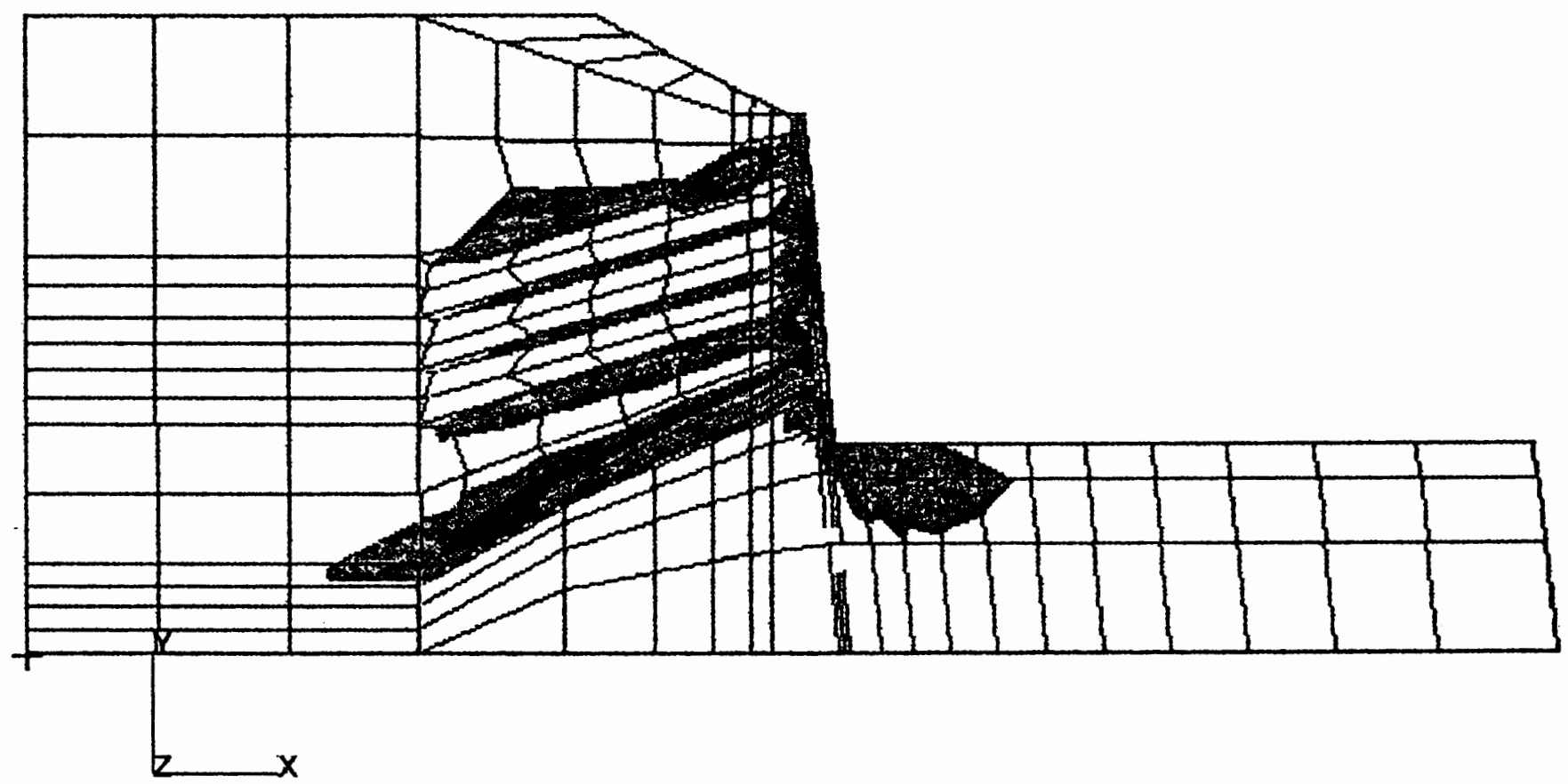

25785.

24066.

22347.

20628.

18909.

17190.

15471.

13752.

12033.

10314.

8595.

6876.

5157.

3438.

1719.

nolin2n1.fil

$-.002197$ 
Fringe: LC=2.17-RES=2.1-P3/PATRAN R.1-(Major)-ABAQUS-23-Jul-94 16:57:47

\section{SWIFT DELTA SOIL NAIL WALL FEM RESULTS} MODEL NOLIN2N STATC STEP 8

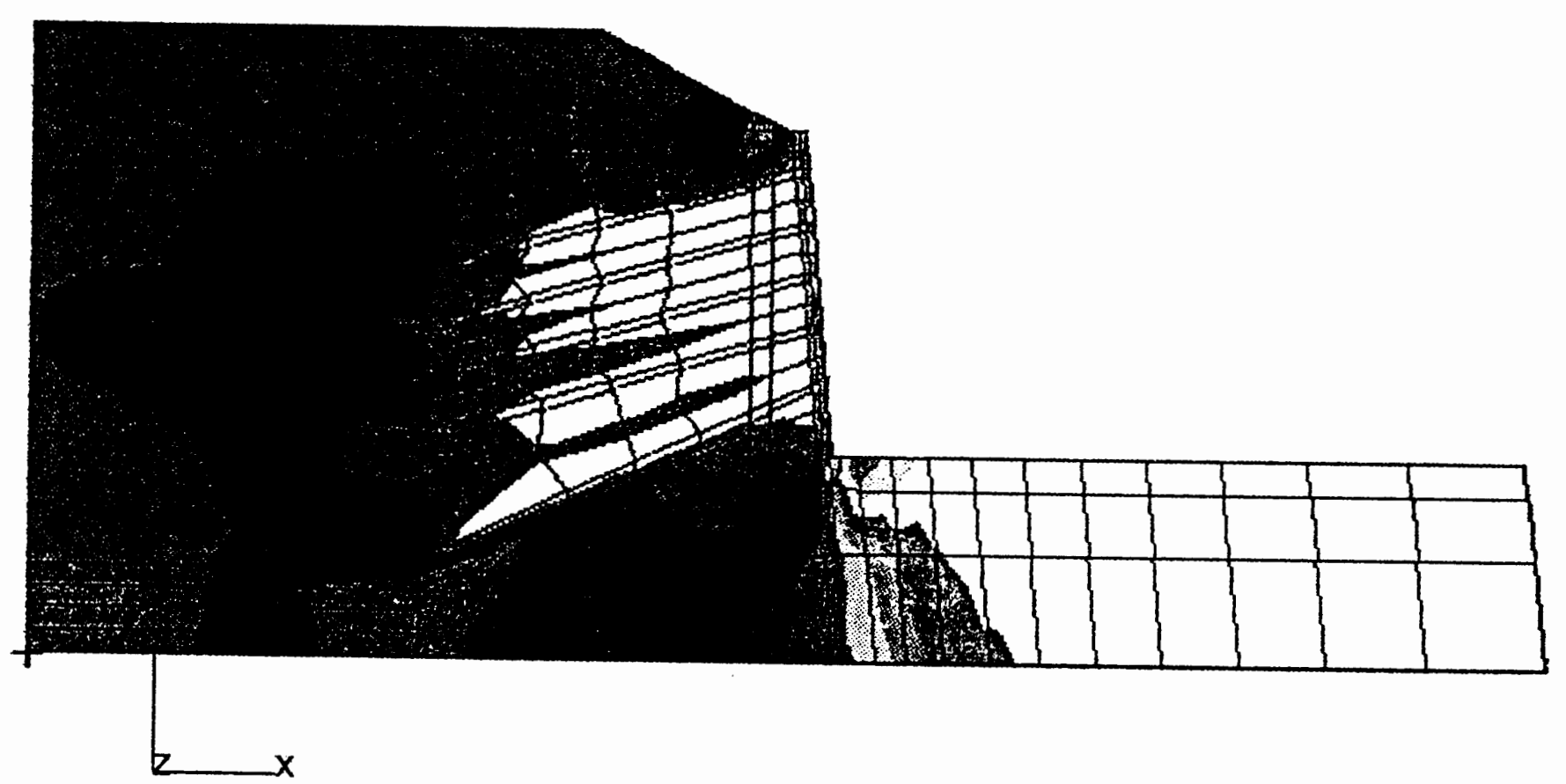

.005174

.004830

.004485

.004140

.003795

.003450

.003105

.002760

.002415

.002070

.001725

.001380

.001035

.0006899

.0003450

nolin2n1.fil 